\title{
Synthesis and Characterization of electrodes for III-Nitride Resonant Cavity Light Emitting Diode Applications
}

\author{
Vamsi Krishna Kumbham \\ West Virginia University
}

Follow this and additional works at: https://researchrepository.wvu.edu/etd

\section{Recommended Citation}

Kumbham, Vamsi Krishna, "Synthesis and Characterization of electrodes for III-Nitride Resonant Cavity Light Emitting Diode Applications" (2012). Graduate Theses, Dissertations, and Problem Reports. 4882. https://researchrepository.wvu.edu/etd/4882

This Thesis is protected by copyright and/or related rights. It has been brought to you by the The Research Repository @ WVU with permission from the rights-holder(s). You are free to use this Thesis in any way that is permitted by the copyright and related rights legislation that applies to your use. For other uses you must obtain permission from the rights-holder(s) directly, unless additional rights are indicated by a Creative Commons license in the record and/ or on the work itself. This Thesis has been accepted for inclusion in WVU Graduate Theses, Dissertations, and Problem Reports collection by an authorized administrator of The Research Repository @ WVU. For more information, please contact researchrepository@mail.wvu.edu. 


\title{
Synthesis and Characterization of electrodes for III-Nitride Resonant Cavity Light Emitting Diode Applications
}

\author{
By \\ Vamsi Krishna Kumbham
}

Thesis submitted to the

Benjamin M. Statler College of Engineering and Mineral Resources at

West Virginia University

in partial fulfillment of the requirements for the degree of

Master of Science

in

Electrical Engineering

Committee members:

Dr. Lawrence.A.Hornak (Committee Chairperson)

Dr. Dimitris Korakakis

Dr. Jeremy Dawson

Lane Department of Computer science and Electrical Engineering Morgantown, West Virginia

2012

Keywords: GaN, Ion beam assisted e-beam evaporation, Zinc oxide. 


\section{Abstract \\ Synthesis and Characterization of electrodes for III-Nitride Resonant Cavity Light Emitting Diode Applications}

\section{Vamsi Krishna Kumbham}

In recent years Light Emitting Diodes (LEDs) of high efficiency and long lifetime have been produced. Gallium Nitride in particular is used in the manufacture of Blue LEDs because it is a direct band gap semiconductor which can be alloyed with AlN and InN allowing band gap energies to range from $1.9 \mathrm{eV}$ to $6.2 \mathrm{eV}$, which allows the emission of short wavelengths including blue light. The interest in replacing conventional lighting by solid-state lighting has led to focus on the development of high brightness Gallium Nitride (GaN) LEDs. Efficient LED structures such as flip chip configurations and Resonant Cavity LEDs (RCLEDs) typically need a highly reflective ohmic contact on p-GaN. RCLEDs are of great interest due their features such as, high spectral purity, and high emission intensity when compared to conventional GaN based LEDs [1]. Au based contacts are not appropriate for the RCLEDs due to low reflectance in the blue region. Ag films have much higher reflectivity in the visible region when compared to Au films.

The first part of the thesis presents the detailed fabrication process and characterization of $\mathrm{Ag}$ based electrodes for III-Nitride Resonant Cavity LEDs. A GaN/AlGaN Distributed Bragg reflector (DBR) of very high reflectance is employed on the sapphire substrate below the LED, which acts as the bottom mirror. For the top mirror, low resistance and highly reflective ohmic contacts on p-type GaN were achieved using an Ag-based metallization scheme. The second part of the thesis presents, development of a transparent, conductive zinc oxide contact to a GaN/InGaN MQW LED. A process and post-deposition annealing have been optimized to obtain $\mathrm{ZnO}$ films with high electrical conductivity and transparency, and $\mathrm{ZnO}-$ based contacts with a low contact resistance. This work represents a step toward the fabrication of high-efficiency GaN-based blue and green LEDs with transparent $\mathrm{ZnO}$ electrodes. 


\section{Acknowledgements}

I would like to thank Dr. Hornak, my advisor, who has been a source of inspiration in my pursuit of master's degree. I would like to thank him for his patience, support and encouragement throughout the research. Dr. Hornak helped me develop a wide range of skills in semiconductor processing area for which I am very thankful to him.

I would like to thank Dr. Korakakis, for his time, expertise and evaluation. I would also like to thank Dr. Dawson for his valuable inputs during the LED project meetings. The assistance from members of my group and Dr. Korakakis's group is greatly appreciated.

I sincerely acknowledge Dr. Kolin Brown for his support in the cleanroom. Special thanks to Sridhar Kuchibhatla for his support and constant motivation. I would like to thank Lee. E. Rodak and $\mathrm{K}$. Lee for the GaN sample growths, Ronak Rahimi for her input on ZnO for OLEDs, Vishal Narang for his help on LED's characterization, and other lab members, Anand Kadiyala, Nitya Musunuru, Rohit Goswami, Joshua Justice and all my friends for their valuable advice and friendly support.

Most importantly, I express my deepest gratitude to my father, Mr. K. Veera Venkata Chalam, mother Mrs. K. Jayasree, whose love and sacrifice for me is beyond anything I will ever understand and my brother K. Kranthi Kumar for loving and supporting me unconditionally. I wouldn't have made it this far without them. To them I dedicate my thesis. 


\section{Table of Contents}

Abstract..................................................................................

Acknowledgements...............................................................................ii

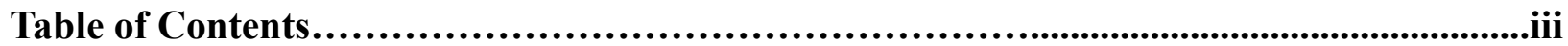

List of Figures................................................................................................v

List of Tables...........................................................................ix

References.........................................................................85

Chapter 1: Introduction..................................................................1

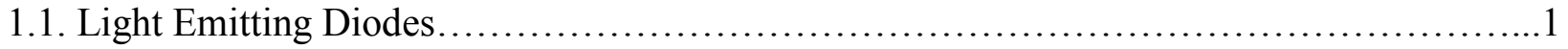

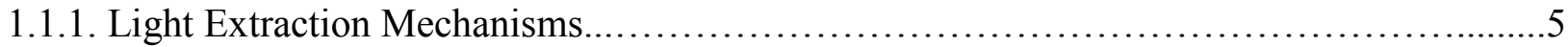

1.1.2. Resonant Cavity Light Emitting Diodes........................................6

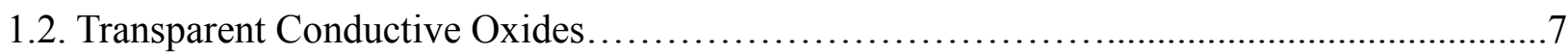

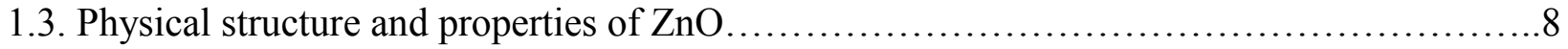

1.4. Objective and layout of Thesis.............................................. 10

Chapter 2: Background of Thin Film Processing.........................................12

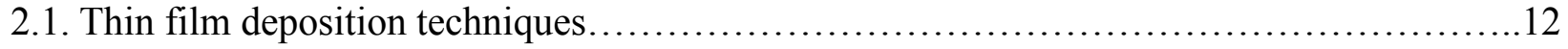

2.1.1. E-beam evaporation system...............................................

2.1.2. Ion beam assisted evaporation system ...................................... 16

2.2. Metal Contacts to Semiconductors.............................................. 17

2.2.1. Schottky Contacts.............................................................. 18

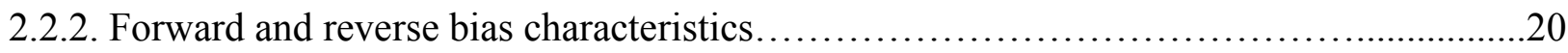

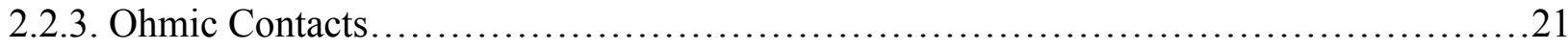

2.2.4. Transmission Line method \& Contact resistance calculation...........................25

Chapter 3: GaN/InGaN MQW Light emitting Diodes.....................................29

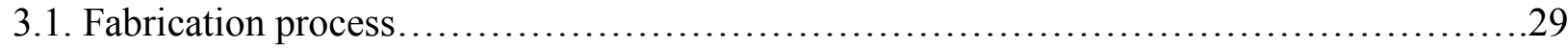

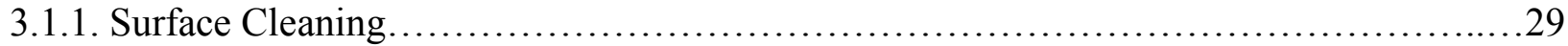

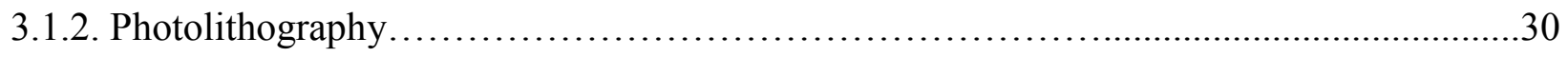

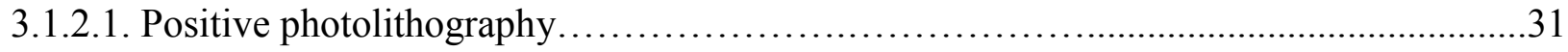

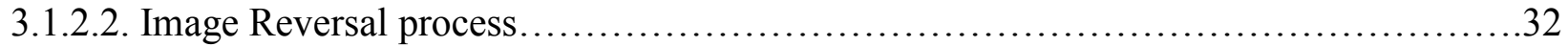

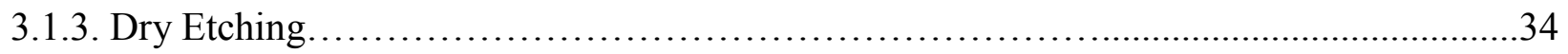




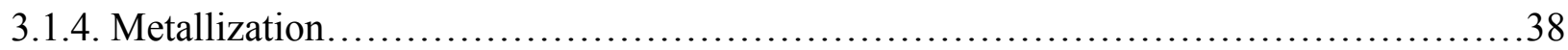

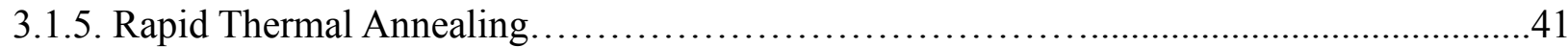

Chapter 4: Electrical and Optical properties of Ag based metallization scheme..............43

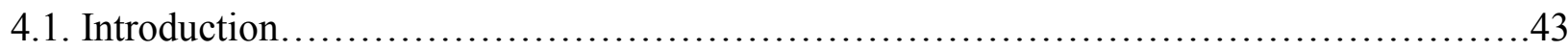

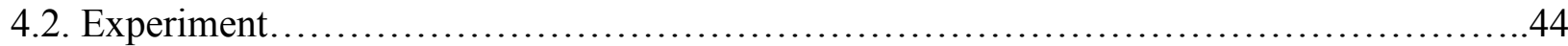

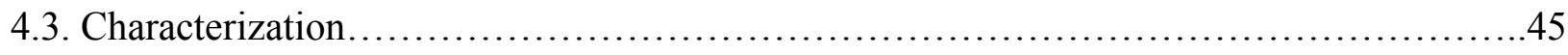

4.3.1. Atomic Force Microscopy (AFM) .............................................. 45

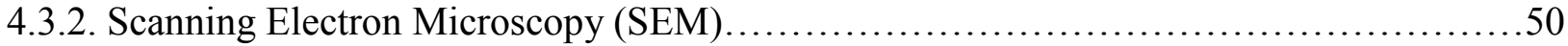

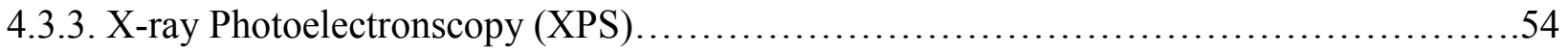

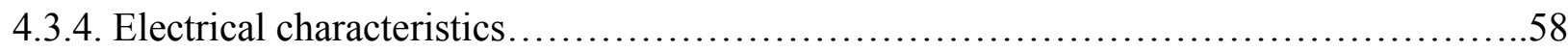

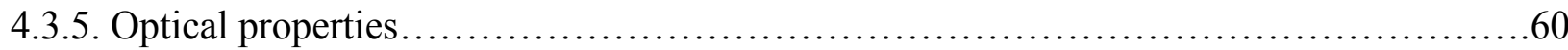

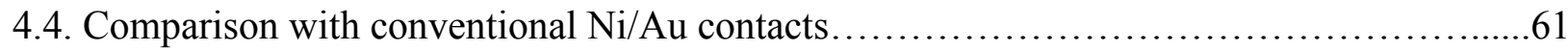

Chapter 5: Electrical and Optical properties of ZnO Thin films.............................64

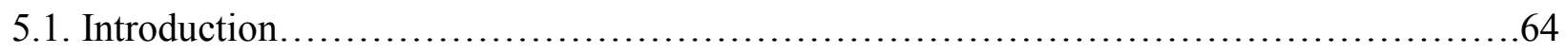

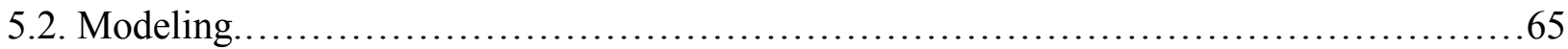

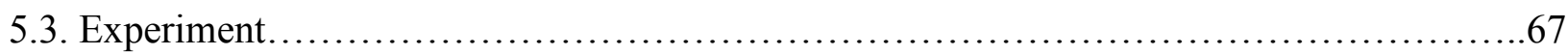

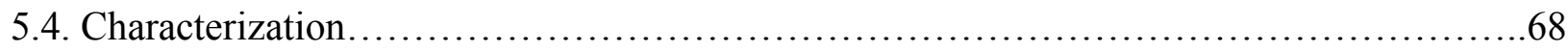

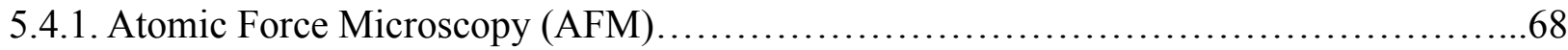

5.4.2. Scanning Electron Microscopy (SEM) .................................................69

5.4.3. X-ray Photoelectronscopy (XPS) ….................................................

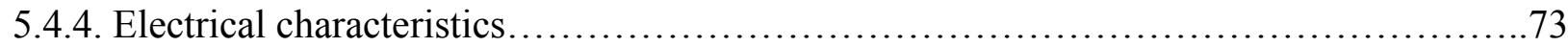

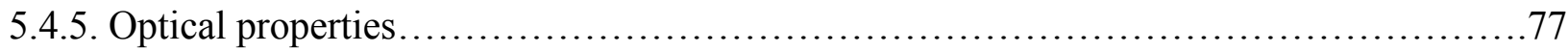

5.5. ZnO integration to GaN/InGaN MQW Light emitting diodes............................79

Chapter 6: Conclusions and Future works................................................84

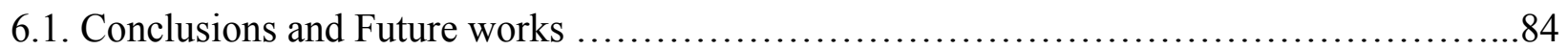

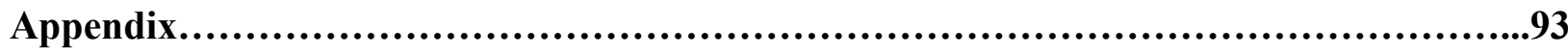

A1. Fabrication parameters for GaN/InGaN MQW LED processing ........................93

A2. Matlab code for $\mathrm{ZnO}$ Modeling ...................................................... 95

A3. Matlab code for TLM and C-TLM calculations.......................................96 


\section{List of Figures}

Figure 1.1: The inner working mechanism of a LED ...................................

Figure 1.2: Light output per LED as a function of production year......................... 3

Figure 1.3: One dimensionally confined Quantum well structure $\ldots \ldots \ldots \ldots \ldots \ldots \ldots \ldots \ldots \ldots \ldots$

Figure 1.4: Resonant cavity Light Emitting diode structure..............................6

Figure 1.5: Crystal structures of ZnO, (a) Rocksalt, (b) Zinc blende, (c) Wurtzite, shaded grey

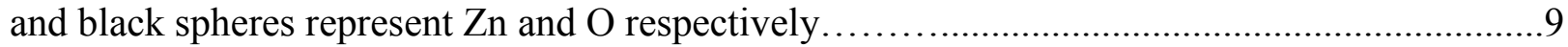

Figure 2.1: A schematic diagram of a typical system for e-beam evaporation..................13

Figure 2.2: E-beam evaporator system used for this experiment......................... 14

Figure 2.3: A schematic diagram of a typical system for ion beam assisted e-beam evaporation

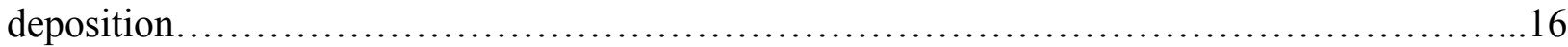

Figure 2.4: Energy band diagram of metal adjacent to n-type and p-type semiconductor, left, under thermal non equilibrium, right, thermal equilibrium conditions $\ldots \ldots \ldots \ldots \ldots \ldots \ldots \ldots \ldots 18$ Figure 2.5: Energy band diagram of metal-semiconductor junction under, (a) forward bias and (b) reverse bias. 21

Figure 2.6: Energy band diagram of metal-semiconductor junction forming an ohmic contact, left, junction under non thermal equilibrium, right, under thermal equilibrium................22 Figure 2.7: Conduction mechanism of metal-semiconductor contacts as a function of barrier width and doping, (a) Thermionic emission, (b) Thermionic field emission, (c) Field emission..24 Figure 2.8: Rectangular pattern where $\mathrm{W}$ is the width of the pads, 1 is the length of the pads and $\mathrm{d}$ is the contact pad separation. .25

Figure 2.9: Circular pattern used to find the specific contact resistance, with different radii and

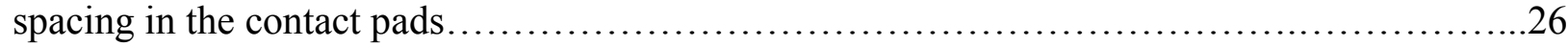

Figure 2.10: Experimental setup for derivation of specific contact resistance..................27

Figure 2.11: Graph of $\mathrm{R}_{\mathrm{T}}$ versus $(1 / 2 \pi)^{*} \ln \left(\mathrm{r}_{\mathrm{i}} /\left(\mathrm{r}_{\mathrm{i}}-\mathrm{d}\right)\right)$ can be used to deduce specific contact

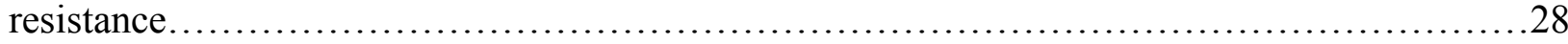

Figure 3.1: Fabricated structure of the GaN/InGaN MQW LED used in this work...............29

Figure 3.2: Illustration of Positive Photo-lithography process............................. 31

Figure 3.3: SEM Images of, left, Positive photo-lithography, right, image reversal PR pattern...32 Figure 3.4: Illustration of Image reversal photo-lithography process........................33 
Figure 3.5: Cross sections of different etch profiles by different etch mechanisms..............34

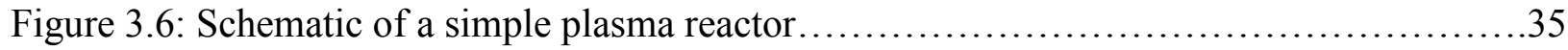

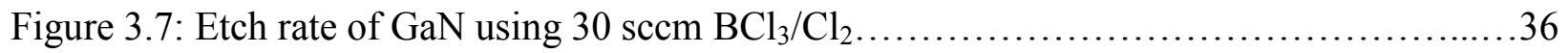

Figure 3.8: SEM Images of side wall angle and etch profiles of GaN, top, ICP/RIE powers 300W/100W, bottom, ICP/RIE powers 400W/150W .................................. 37

Figure 3.9: I-Vs between different $\mathrm{Ni} / \mathrm{Au}$ contact pad spacing............................. 39

Figure 3.10: Resistance Vs contact pad spacing of rectangular TLM for p-GaN................39

Figure 3.11: I-Vs between different $\mathrm{Ti} / \mathrm{Al} / \mathrm{Ti} / \mathrm{Au}$ contact pad spacing with $\mathrm{n}-\mathrm{GaN} \ldots \ldots . . . \ldots . . .40$

Figure 3.12: Resistance Vs contact pad spacing of rectangular TLM for $n-G a N \ldots \ldots \ldots \ldots \ldots . . .40$

Figure 3.13: The Rapid Thermal Anneal system used in this experiment....................41

Figure 3.14: The Recipe in a RTA system.......................................... 42

Figure 4.1: C-TLM Pattern that was used to find the specific contact resistivity between p-GaN

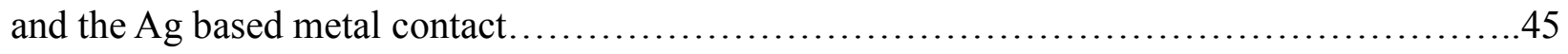

Figure 4.2: The schematic of Atomic Force Microscopy (AFM) setup used in this

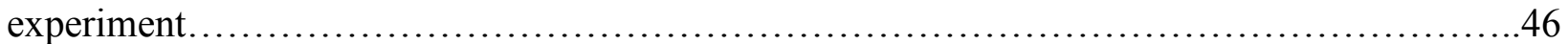

Figure 4.3: Surface morphology of (a) Ni/Ag contact, (b) Ni/Ag/Pt contact annealed at 380

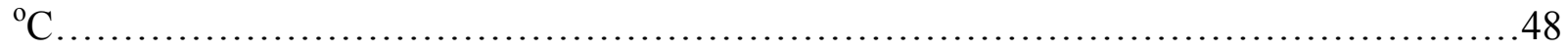

Figure 4.4: Surface morphology of (a) Ni/Ag contact, (b) Ni/Ag/Pt contact annealed at 430 ${ }^{\circ} \mathrm{C}$. . .48

Figure 4.5: Surface morphology of (a) Ni/Ag contact, (b) Ni/Ag/Pt contact annealed at 480 ${ }^{\circ} \mathrm{C}$. .49

Figure 4.6: RMS roughness of the contacts with different annealing temperatures.... 49

Figure 4.7: The schematic of Scanning Electron Microscopy (SEM) setup used in this

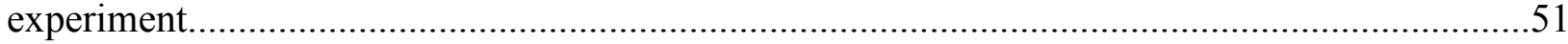

Figure 4.8: Illustration of interaction volumes for various electron-sample interactions..........52

Figure 4.9: Surface morphology of (a) Ni/Ag contact, (b) Ni/Ag/Pt contact annealed at 380 ${ }^{\mathrm{o}} \mathrm{C}$. .52

Figure 4.10: Surface morphology of (a) Ni/Ag contact, (b) Ni/Ag/Pt contact annealed at 430 ${ }^{\circ} \mathrm{C}$. .53

Figure 4.11: Surface morphology of (a) Ni/Ag contact, (b) Ni/Ag/Pt contact un-annealed.......54

Figure 4.12: Working of an X-ray Photoelectron Spectroscopy system. .55 
Figure 4.13: Schematic of the system used for this work................................56

Figure 4.14: Sputter XPS (Depth profiling) analysis on Ni (2nm)/ Ag (150nm)/ Pt (50nm)/ Ni

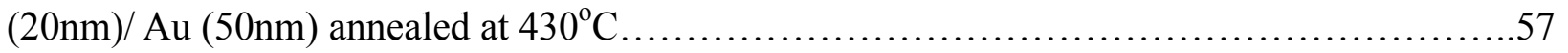

Figure 4.15: I-Vs of Ni/Ag/Pt/Ni/Au contact pads with different annealing conditions...........58

Figure 4.16: Specific Contact resistivity of the contact annealed at different temperatures......59

Figure 4.17: Reflectivity measurement of as deposited, $\mathrm{Ni} / \mathrm{Ag}$ and $\mathrm{Ni} / \mathrm{Ag} / \mathrm{Pt}$ contacts...........60

Figure 4.18: Reflectivity measurement of, (a) $\mathrm{Ni} / \mathrm{Ag}$ and $\mathrm{Ni} / \mathrm{Ag} / \mathrm{Pt}$ contacts annealed at $380^{\circ} \mathrm{C}$,

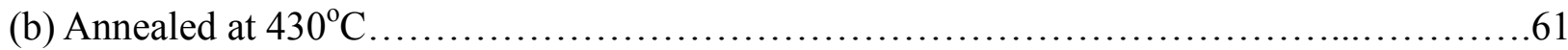

Figure 4.19: Resonant Cavity LED structure used in this work.............................62

Figure 4.20: EL spectrum of GaN/InGaN MQW LED with and without at 6V bias voltage, (a), 6

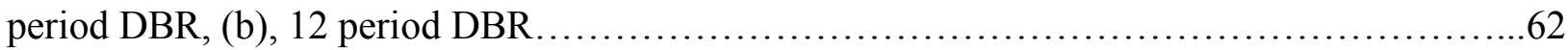

Figure 4.21: Comparison of electrical characteristics between $\mathrm{Ni} / \mathrm{Au}$ and $\mathrm{Ni} / \mathrm{Ag} / \mathrm{Pt} / \mathrm{Ni} / \mathrm{Au}$ contacts, (a), I-V characteristics, (b), Series resistance and turn-on voltages..................66

Figure 5.1: Transmission line model, (a), Schematic, (b), with $\mathrm{ZnO}$ and $\mathrm{p}-\mathrm{GaN}$ substrate.........65 Figure 5.2: The plot showing Reflection coefficient Vs Thickness of $\mathrm{ZnO}$ for $460 \mathrm{~nm}$ blue

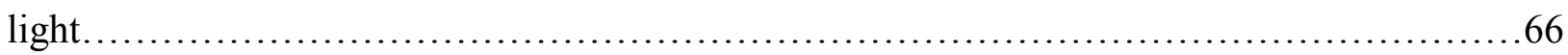

Figure 5.3: (a) TLM Pattern that was used to find the specific contact resistivity between p-GaN and the $\mathrm{ZnO}$ contact. (b) Schematic of Ion beam assisted e-beam evaporation system...........67 Figure 5.4: Surface morphology of (a) As deposited contact, (b) $\mathrm{ZnO}$ contact annealed at

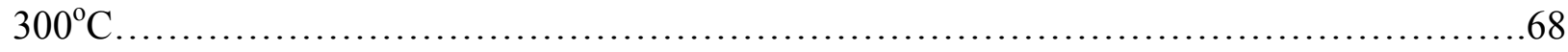

Figure 5.5: Surface morphology of (a) $\mathrm{ZnO}$ contact annealed at $500^{\circ} \mathrm{C}$, (b) $\mathrm{ZnO}$ contact annealed at $700^{\circ} \mathrm{C}$

Figure 5.6: Surface morphology of (a) As deposited contact, (b) $\mathrm{ZnO}$ contact annealed at $300^{\circ} \mathrm{C}$. .70

Figure 5.7: Surface morphology of (a) $\mathrm{ZnO}$ contact annealed at $500^{\circ} \mathrm{C}$, (b) $\mathrm{ZnO}$ contact annealed at $700^{\circ} \mathrm{C}$ .70

Figure 5.8: Surface scan of $\mathrm{Al}$ alloyed (5\%wt) $\mathrm{ZnO}(150 \mathrm{~nm})$ contact deposited on the glass substrate .71

Figure 5.9: Depth profiling scan of (a) $\mathrm{Zn} 2 \mathrm{p} 3$ peak, (b) O 1s peak in $\mathrm{Al}$ alloyed $\mathrm{ZnO}$ films.....72 Figure 5.10: Depth profiling scan of (a) $\mathrm{Al} 2 \mathrm{p}$ peak in $\mathrm{Al}(5 \% \mathrm{wt})$ alloyed $\mathrm{ZnO}$ films.............72 Figure 5.11: The basic schematic of the hall measurement system............................74 
Figure 5.12: I-Vs of, (a) Ni (2nm)/ZnO (100nm), (b) Ni (25nm)/ZnO (100nm) contact pads....76 Figure 5.13: (a) Plot showing pad spacing Vs Total resistance, (b) Specific contact resistivity of

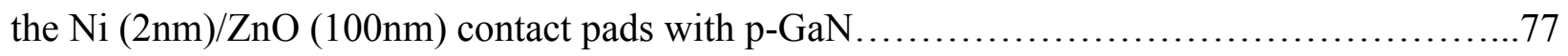
Figure 5.14: Transmission measurement of $\mathrm{Ni}(2 \mathrm{~nm}) / \mathrm{ZnO}(100 \mathrm{~nm})$ with varying oxygen flow

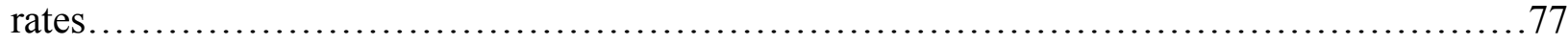

Figure 5.15: The basic schematic of the Ellipsometry setup used in this experiment............78 Figure 5.16: (a) Ellipsometry data is fitted using Cauchy model, (b) Refractive Indices Vs wave

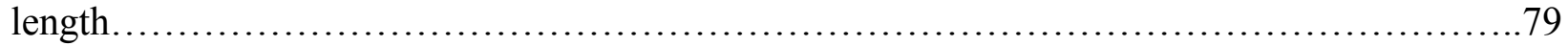

Figure 5.17: InGaN LED structure with $\mathrm{ZnO}$ contacts used in this work....................79 Figure 5.18: $\mathrm{I}-\mathrm{V}$ between $\mathrm{Ti} / \mathrm{Al} / \mathrm{Ti} / \mathrm{Au}$ and $\mathrm{Ni} / \mathrm{ZnO}$ (a) unannealed contacts, (b) annealed at $350^{\circ} \mathrm{C}$ . .80

Figure 5.19: (a) I-V comparison with conventional $\mathrm{Ni} / \mathrm{Au}$ contacts (b) EL spectrum of GaN/InGaN MQW LED @ 455nm emission........................................... 81

Figure 5.20: (a) Ni/Au contact on a Planar GaN/InGaN LED (b) Ni/Au contact on a 12 period DBR GaN/InGaN LED (c) Ni/ZnO contact on a Planar GaN/InGaN LED (d) Ni/ZnO contact on

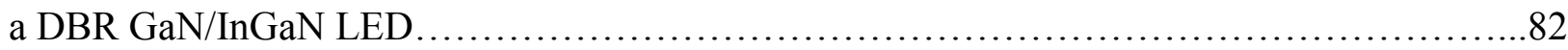




\section{List of Tables}

Table 1.1: Typical electrical and optical properties of $\mathrm{ZnO}$ films deposited by various techniques.................................................................

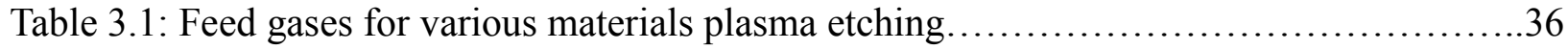

Table 5.1: Hall measurements with varying oxygen flow rates during deposition...............75

Table 5.2: Hall measurements with varying substrate temperatures........................75

Table 5.3: Specific Contact resistance for unannealed contact scheme.......................80

Table 5.4: Specific Contact resistance for contact scheme annealed at $350^{\circ} \mathrm{C} \ldots \ldots \ldots \ldots \ldots \ldots 1$ 


\section{Chapter 1}

\section{Introduction}

\subsection{Light Emitting Diodes}

Solid State lighting is of interest in today's economy because of the potential for large energy savings. A Light Emitting Diode (LED) is a semiconductor light source. It was introduced as a practical electronic component in the year 1962 [2]. The LEDs that were developed in the early years emitted low-intensity red light, but later on, due to the research and development in recent years, they are available across the visible, ultraviolet and infrared wavelengths, with very high brightness. In a LED, by applying forward bias, the electrons in the conduction band will recombine with holes in the valence band within the device, releasing energy in the form of photons. This effect is called electroluminescence. The energy gap of the semiconductor that was used in making the device, determines the color of the light emitted. There are many advantages of light emitting diodes over the conventional incandescent light sources, such as, lower power consumption, extended lifetimes, improved robustness, smaller size, faster switching, and greater durability and reliability. The disadvantages are, for a comparable output, the compact fluorescent lamp sources require less precision in current and heat management and are presently less expensive. The compact size of LEDs has allowed new text and video displays and sensors to be developed, while their high switching rates are useful in advanced communications technology.

In a LED, a p-n junction is created by doping the semiconductor material with impurities. It is observed that the current flows readily from the $\mathrm{p}$-side to the $\mathrm{n}$-side (from anode to cathode) as in other diodes, but not in the reverse direction. The charge-carriers in a p-n junction diode are electrons and holes. These charge carriers will flow into the junction from electrodes with different voltages. When an electron meets a hole, it falls into a lower energy level, and releases energy in the form of a photon. The wave length emitted depends upon the band gap energy of the semiconductor materials used for forming the $\mathrm{p}-\mathrm{n}$ junction. The light emission is observed only in the diodes made of direct band gap materials. For example, in the diodes made up of indirect band gap materials like silicon or germanium, the electrons and holes 
recombine by a non-radiative transition that produces no optical emission. The materials that were used for LED applications have a direct band gap with energies corresponding to nearinfrared, visible or near-ultraviolet light. LED development began with infrared and red devices made with gallium arsenide. The first blue LED was made in 1971 [3], but it proved difficult in extending the wavelength to the range below $550 \mathrm{~nm}$. In the next decade, blue LEDs were of little practical use because of low efficiencies. Due to the lack of blue spectrum devices, the applications of LEDs were limited mostly to electronic indicators. Advances in materials science have enabled making devices with ever-shorter wavelengths, emitting light in a variety of colors. In general, LEDs are usually built on an n-type substrate, with an electrode attached to the p-type layer deposited on its surface. P-type substrates, while less common, are used as well. Many commercial LEDs, especially $\mathrm{GaN} / \mathrm{InGaN}$, also use a sapphire substrate upon which the semiconductor is grown.

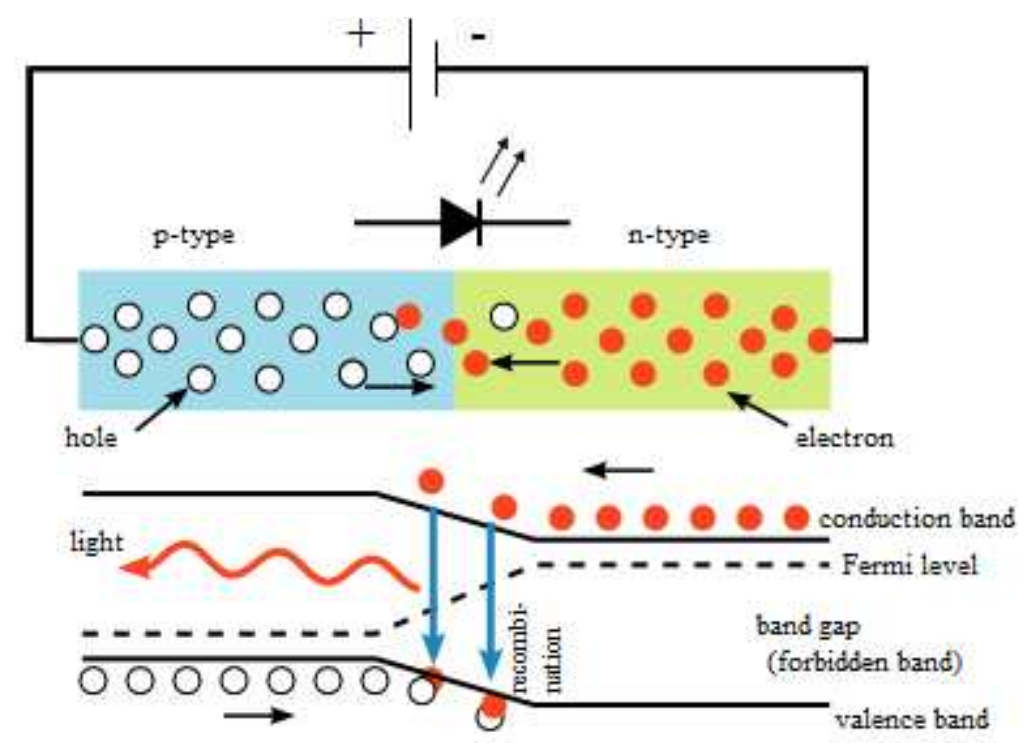

Figure 1.1: The inner working mechanism of a LED [4]

Gallium Nitride $(\mathrm{GaN})$ is a suitable material for the manufacture of Blue LED's because it is a direct band gap semiconductor. This is an advantage over Silicon Carbide that used to be used as a material for blue LED's. The Blue LED's produced however, had a low efficiency because of its indirect band gap. Along with this GaN may be alloyed with $\mathrm{InN}$ and $\mathrm{AlN}$ to allow band gap energies ranging from $1.9 \mathrm{eV}$ to $6.2 \mathrm{eV}$ [Kim, 1999]. This gives 
one the ability to tailor the device to emit visible light over the entire spectrum. Shuji Nakamura of Nichia Corporation demonstrated the first high-brightness blue LED based on InGaN [5] and Isamu Akasaki and $\mathrm{H}$. Amano in Nagoya developed, borrowing from critical developments in GaN nucleation on sapphire substrates and the demonstration of p-type doping of GaN. A high brightness and reliable LED with a transparent contact made of indium tin oxide (ITO) on (AlGaInP/GaAs) LED was demonstrated by Alberto Barbieri at Cardiff University Laboratory in 1995. The existence of blue LEDs and high efficiency LEDs quickly led to the development of The first white LED with high efficiency were developed from the blue LEDs using, Y3A15O12:Ce, or "YAG", phosphor coating to mix yellow (down-converted) light with blue to produce light that appears white [6]. Similar to Moore's law, it was observed that the development of LED technology has caused their efficiency and light output to rise exponentially, with a doubling occurring about every 36 months. The advances are generally attributed to the parallel development of other semiconductor technologies and advances in optics and material science. This trend is normally called Haitz's Law after Dr. Roland Haitz [7].

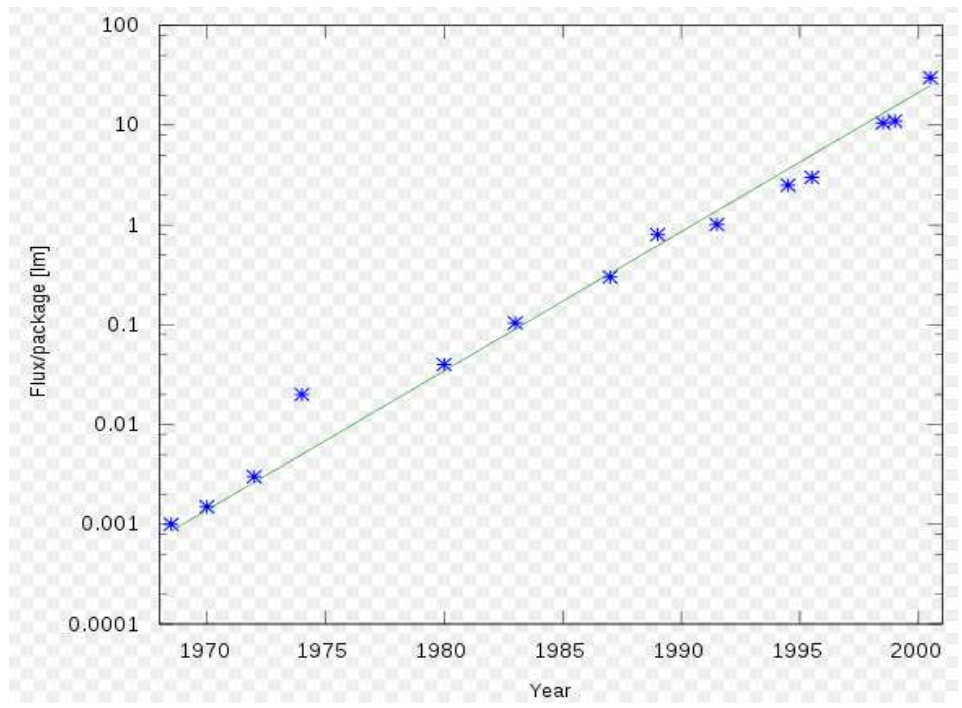

Figure 1.2: Light output per LED as a function of production year [8]

The wide band gap semiconductors $\mathrm{GaN}$ (gallium nitride) and $\mathrm{InGaN}$ (indium gallium nitride) are used in the current high brightness blue LEDs. They can be added to existing red and green LEDs to produce the impression of white light. The first blue LEDs using gallium nitride were made in 1971 by Jacques Pankove at RCA Laboratories made the first blue LEDs using gallium nitride [9]. The devices that were developed in early 70 's had too little light 
output to be of practical use and research into gallium nitride devices slowed. In late 80's using an indirect band gap semiconductor material $\mathrm{SiC}$, commercially available blue LEDs were developed by Cree Inc [10]. These SiC LEDs that were in market had very low efficiency, at about $0.03 \%$, but they did emit in the blue portion of the visible light spectrum. Then in late 1980s, there were some key breakthroughs in GaN epitaxial growth and p-type doping [11] that lead to the modern GaN-based optoelectronic devices. In early 90's high brightness blue LEDs were demonstrated with efficiency (light energy produced vs. electrical energy used) at around $10 \%$ [12]. These high-brightness blue LEDs that were invented by Shuji Nakamura of Nichia Corporation using gallium nitride revolutionized LED lighting.

By the late 1990s, blue LEDs had become widely available. The blue LEDs have an active region, where, the entire lighting phenomenon (electroluminescence) is observed. The active region consists of one or more InGaN quantum wells sandwiched between thicker layers of $\mathrm{GaN}$. The wavelength of light that is emitted is altered by varying the relative InN-GaN fraction in the InGaN quantum wells. A quantum well can be defined as a potential well with discrete energy levels. The quantization can be explained as the ability to confine particles which were free to move in three dimensions, to two dimensions, forcing them to occupy a planar region. The quantum confinement effect can be observed if the quantum well thickness becomes comparable to the de Broglie wavelength of the carriers, there-by leading to energy levels called energy sub-bands [13].

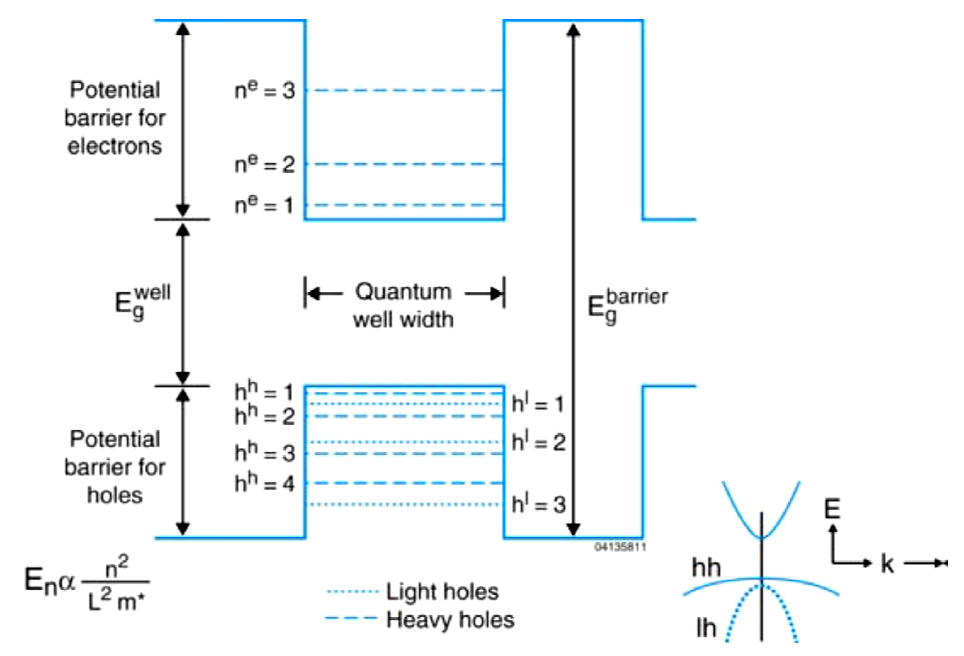

Figure 1.3: One dimensionally confined Quantum well structure [13] 
A single quantum well is formed by a thin small band gap semiconductor layer sandwiched between two larger band gap semiconductor layers, where, the center layer forms the quantum well and the two layers sandwiching the QW creates the potential barriers. In a quantum well structure, two different potential wells were formed, one is for the conduction band electrons and the other one is for valence band holes. The difference between the conduction-band edges of the well and barrier semiconductors gives us the well depth of the electrons and the valence-band offset will give us the well depth for holes. In the InGaN based LEDs, a layer of Indium Gallium Nitride $(\mathrm{InGaN})$ is sandwiched between two layers of Gallium Nitride $(\mathrm{GaN})$.

\subsubsection{Light Extraction Mechanisms}

As a result of the high refractive index of semiconductors, light incident on a planar semiconductor - air interface is totally internally reflected, if the angle of incidence is sufficiently large. Snell's law gives the critical angle of total internal reflection. The light can be trapped inside of the semiconductor due to the total internal reflection. The light that is trapped inside can be reabsorbed, by substrate, active region, or by metallic contact. This re-absorption event can reduce the efficiency of the LED. If the light is absorbed by the substrate, the electronhole pair will most likely recombine non-radiatively due to the inherently low efficiency of substrates. If the light is absorbed by the active region, the electron-hole pair may re-emit a photon or recombine non-radiatively. The external quantum efficiency of an LED is the product of the internal quantum efficiency, $\eta_{\text {int }}$, and the extraction efficiency, $\eta_{\text {extraction, }}$ [14] i.e.

$$
\eta_{\text {ext }}=\eta_{\text {int }}{ }^{*} \eta_{\text {extraction }}
$$

As a result, the extraction efficiency plays an important role in increasing the power efficiency of the LEDs. There are different mechanisms employed for the improvement of light extraction from the LEDs, such as, shaping of LED dies [15], textured semiconductor surfaces [16-20], cross-shaped contacts and other contact geometries, transparent contact technology, anti-reflection optical coatings, and flip-chip packaging. Of all these mechanisms, this work focuses on the use of transparent contact technology for improvement of light extraction in the LEDs. 


\subsubsection{Resonant Cavity Light Emitting Diodes}

Resonant-cavity light-emitting diodes were first realized in 1992 in the GaAs material system [21]. About a year later, RCLEDs were demonstrated in organic materials [22]. The resonant-cavity light-emitting diode (RCLED) is a light-emitting diode that has a lightemitting region inside an optical cavity. The optical cavity has a thickness equal to an integral number of half wavelengths in the medium, typically one-half or one times the wavelength of the light emitted by the LED. The resonance wavelength of the cavity coincides or is in resonance with the emission wavelength of the light-emitting active region of the LED. Thus the cavity is a resonant cavity.

The placement of an active region inside a resonant cavity results in multiple improvements of the device characteristics. Firstly, the light intensity emitted from the RCLED along the axis of the cavity, i.e. normal to the semiconductor surface, is higher compared with conventional LEDs. Secondly, the emission spectrum of the RCLED has a higher spectral purity compared with conventional LEDs. Thirdly, the emission far-field pattern of the RCLED is more directed compared with conventional LEDs. In conventional LEDs, the emission pattern is lambertian (i.e. cosine-function). In an RCLED, the emission pattern is directed more along the optical axis of the cavity. Compared with lasers, LEDs are less expensive, more reliable, and less temperature sensitive. The RCLED has improved characteristics compared with conventional LEDs while maintaining the inherent advantages of LEDs. The enhanced spontaneous emission occurring in resonant-cavity structures can be beneficially employed in semiconductor and polymer LEDs.

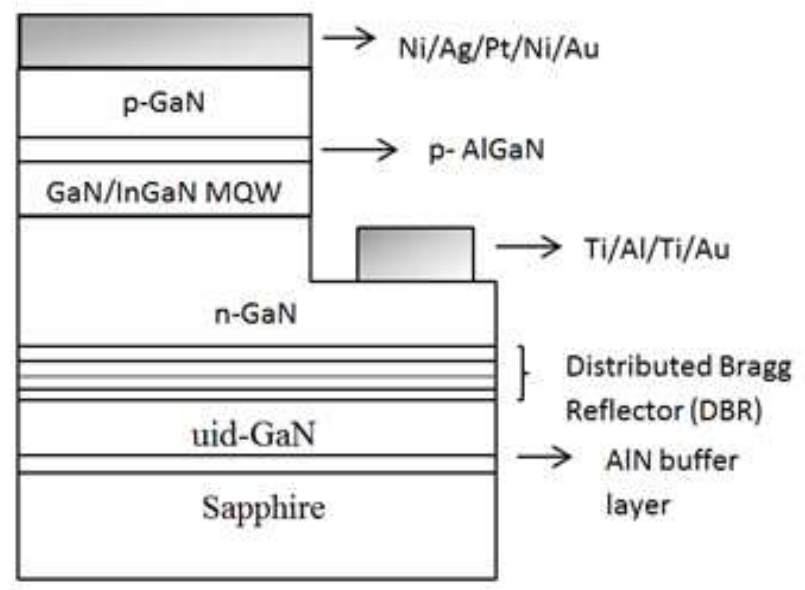

Figure 1.4: Resonant cavity Light Emitting diode structure [23] 


\subsection{Transparent Conductive oxides}

In nature, we can find numerous materials that are either conductive or transparent. Of all those materials, the transparent conductors have a part of both these properties partially, which make them useful for many applications. Both the high conductivity and optical transparency properties are opposite in nature. The reason behind that is, when there are large numbers of charge carries available to increase the electrical conduction; the incoming electromagnetic radiation is dissipated due to skin effect of the free charge carries [24]. Hence an optimum point between electrical conduction and optical transparency should be found while depositing these kinds of transparent oxide films.

The electrical and optical properties of a solid are dependent mainly on its electronic band structure. The three major forms of solids are, conductors, insulators and semiconductors. In the first case, we know that, in metals there is a high density of free electrons in the uppermost partially filled energy band [25]. These abundant free charge carriers cause reflection or absorption of the low energy photons from the transmission of visible and IR radiation. Hence it can be concluded that the metals can be good electrical conductors but poor light transmitters in the visible region. Secondly, in an insulator, the valence band is completely filled, the conduction band is empty and both were separated by energy equal to the band gap energy [26]. In these insulating materials, transmittance is possible for all wavelengths having energy below this energy band gap. Hence it can be concluded that insulators can be good transmitters but poor conductors because of the absence of free carriers. In some semiconducting oxide films such as Zinc Oxide $(\mathrm{ZnO})$, good transparency and electrical conductivity can be obtained simultaneously by adding dopants that enter substitutionally into the lattice or by adjusting the preparation condition. Normally we dope $\mathrm{ZnO}$ with low concentrations of aluminum to make it more conductive. It is transparent and colorless in thin layers. The other kind of conductive oxide, Indium Tin Oxide (ITO) is extensively used in industry for transparent conductive oxide electrode applications. But, because of the high price of Indium, ZnO-based materials are favored as a potential alternative to ITO [27]. The charge carriers in the semiconductor oxides arise from three fundamental sources: interstitial metal ion impurities, oxygen vacancies, and doping ions [28]. The first two sources act as electron donors. When an oxygen vacancy is present in the lattice it acts as a charged electron donor. The third source of 
charge carriers is doping ions, where, dopant ionization within the oxide occurs in the same way as in other semiconductor crystals. All these charge carriers from the electron donors are responsible for the improved electrical conduction in these semiconductor oxides. One important challenge in these semiconductor oxides is carrier scattering. The carrier scattering in these oxides arises primarily from ionized impurity scattering. Charged impurity ions and point defects have scattering cross-sections that are much greater than the neutral ions. Increasing the scattering decreases the mean-free path of the carriers in the oxide, which leads to poor device performance and a high resistivity. Hence, these conductive oxide materials can be modeled reasonably well by the free electron gas theory assuming a parabolic conduction band and doping levels above the Mott Criterion [29]. This criterion states that an insulator such as an oxide can experience a composition-induced transition to a metallic state given a minimum doping concentration $\mathrm{N}_{\mathrm{c}}$ [28], determined by:

$$
N_{C}^{1 / 3} * a_{H}=0.26 \pm 0.05
$$

Where, $a_{H}$ is the mean ground state Bohr radius. For $\mathrm{ZnO}$, this value requires a minimum doping concentration of roughly $10^{19} \mathrm{~cm}^{-3}$. Above this level, the typically electrically insulating material becomes metallic and is capable of allowing carrier flow.

\subsection{Physical structure and properties of $\mathrm{ZnO}$}

The group II-VI binary compound semiconductors crystallize in either cubic zinc blende or hexagonal wurtzite (Wz) structure [30], where each anion is surrounded by four cations at the corners of a tetrahedron, and vice versa. $\mathrm{ZnO}$ is an II-VI compound semiconductor, whose ionicity resides at the borderline between the covalent and ionic semiconductors [31]. The crystal structures that were shared by $\mathrm{ZnO}$ are Wurtzite (B4), Zinc blende (B3), and rocksalt (or Rochelle) (B1) as schematically shown in Figure 1.5. Under ambient conditions, the most common and thermodynamically stable phase of $\mathrm{ZnO}$ is that of wurtzite symmetry. $\mathrm{ZnO}$ is $\mathrm{n}$-type by nature, in the absence of intentional doping. Controllable n-type doping is easily achieved by substituting $\mathrm{Zn}$ with group-III elements such as $\mathrm{Al}, \mathrm{Ga}$, In or by substituting oxygen with group-VII elements chlorine or iodine [32]. The lattice constants are $a=$ $3.25 \AA$ and $c=5.2 \AA$; their ratio $c / a \sim 1.60$ is close to the ideal value for hexagonal cell $c / a=1.633$ [33]. 


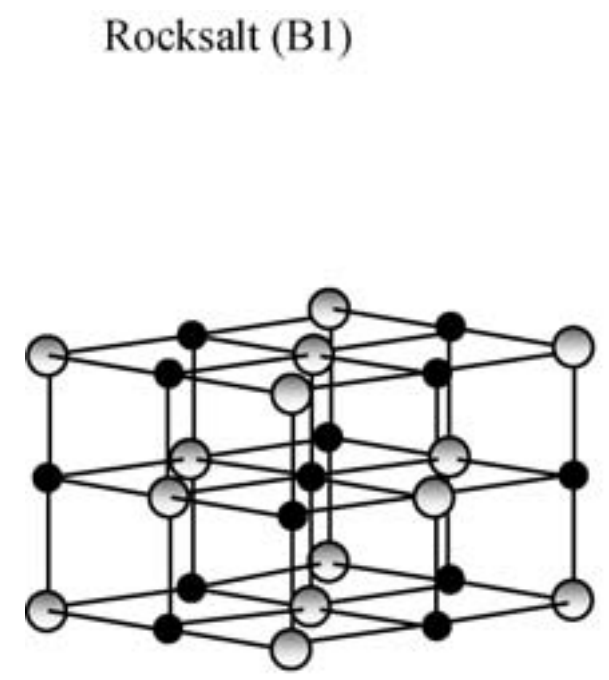

(a)

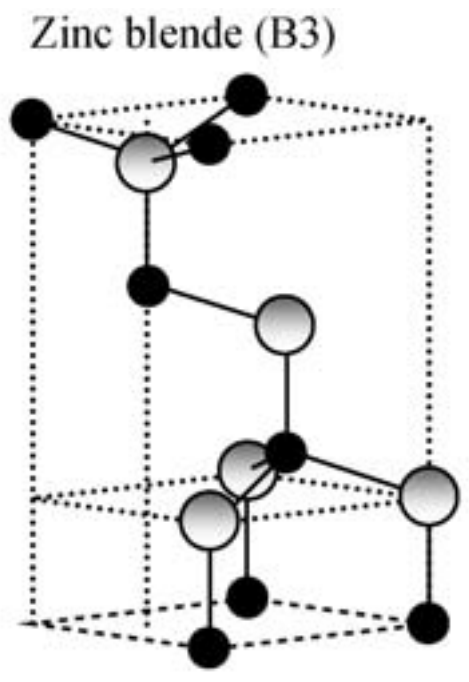

(b)
Wurtzite (B4)

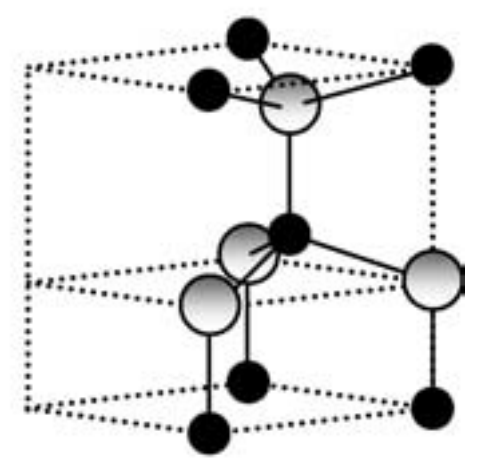

(c)

Figure 1.5. Crystal structures of $\mathrm{ZnO}$, (a) Rocksalt, (b) Zinc blende, (c) Wurtzite, shaded grey and black spheres represent $\mathrm{Zn}$ and $\mathrm{O}$ respectively [31].

$\mathrm{ZnO}$ has a density of $5.606 \mathrm{~g} / \mathrm{cm} 3$ and a melting point of $1975^{\circ} \mathrm{C}$. The optical and electronic properties of $\mathrm{ZnO}$ films are dependent on factors such as deposition parameters and starting materials. Solid $\mathrm{ZnO}$ is typically yellowish to grey depending on its degree of oxidation. A summary of electrical and optical properties of typical $\mathrm{ZnO}$ films deposited using various techniques is shown in Table 1.1.

Table 1.1: Typical electrical and optical properties of $\mathrm{ZnO}$ films deposited by various techniques [34-35].

\begin{tabular}{|c|c|c|c|c|c|}
\hline $\begin{array}{l}\text { Deposition } \\
\text { Techniques }\end{array}$ & $\begin{array}{l}\text { Thickness } \\
\left(\mathrm{A}^{0}\right)\end{array}$ & $\begin{array}{c}\text { Hall } \\
\text { Mobility } \\
\left(\mathrm{cm}^{2} / \mathrm{V} . \mathrm{s}\right)\end{array}$ & $\begin{array}{l}\text { Carriers } \\
\left(\mathrm{cm}^{-3}\right)\end{array}$ & $\begin{array}{l}\text { Resistivity } \\
\text { (ohm.cm) }\end{array}$ & $\begin{array}{c}\text { Transmittance } \\
(\%)\end{array}$ \\
\hline ALD & 2500 & 14 & $3.7 \mathrm{E} 19$ & $1.2 \mathrm{E}-3$ & 87 \\
\hline $\begin{array}{c}\text { R.F. } \\
\text { sputtering }\end{array}$ & 2500 & 3.3 & 4E19 & $9.4 \mathrm{E}-3$ & 94 \\
\hline $\begin{array}{c}\text { Reactive } \\
\text { evaporation }\end{array}$ & 1500 & 27 & 1.7E19 & $3.3 \mathrm{E}-3$ & 89 \\
\hline
\end{tabular}


It was observed that the $\mathrm{ZnO}$ thin films deposited using the above mentioned mechanisms were basically n-type (degenerately doped) in nature. The high conductivity of $\mathrm{ZnO}$ films is said to be due to high carrier concentration, $\mathrm{N}$, rather than high Hall mobility $\mu_{\mathrm{H}}[36]$, bearing in mind that resistivity, $\mathrm{r}=1 /\left(\mathrm{q} * \mathrm{~N}^{*} \mu_{\mathrm{H}}\right)$ according to Ohm's law. The scattering mechanisms due to ionized impurities or grain boundaries were the primary reasons for low mobility of $\mathrm{Al}: \mathrm{ZnO}$ compared to bulk $\mathrm{ZnO}$. Mobility is said to increase due to enhanced crystallinity of films deposited at higher substrate temperatures [37]. It is observed that $\mathrm{ZnO}$ films grown at room temperature have large stacking faults and represent an amorphous structure, increasing this temperature to $200{ }^{\circ} \mathrm{C}$ will lead to a polycrystalline structure [38]. ZnO has a relatively large direct band gap of $\sim 3.3 \mathrm{eV}$ at room temperature. Advantages associated with a large band gap include higher breakdown voltages, ability to sustain large electric fields, lower electronic noise, and high-temperature and high-power operation. The bandgap of $\mathrm{ZnO}$ can further be tuned to $\sim 3-4 \mathrm{eV}$ by its alloying with magnesium oxide or cadmium oxide [39].

The reported value for the refractive index of $\mathrm{ZnO}$ is $2.10 @ 450 \mathrm{~nm}$ wavelength [40]. The transmittance of $\mathrm{ZnO}$ films is also influenced by a number of minor effects that include surface roughness and optical inhomogeneity in the direction normal to the film surface. This opaqueness has been attributed to un-oxidized $\mathrm{Zn}$ metal grains on the $\mathrm{ZnO}$ surface as a result of instability due to absence of sufficient oxygen during deposition [33].

\subsection{Thesis Objective and Organization}

The two objectives of the thesis are 1) Developing a fabrication process for IIINitride Resonant Cavity LEDs with silver (Ag) based ohmic contacts and 2) Development of Al doped $\mathrm{ZnO}$ transparent and conductive electrodes using the Ion beam assisted E-beam evaporation deposition (IBAD) technique.

1) Ag Contacts for RCLEDs: The objective is to develop a fabrication process for III-Nitride resonant cavity LEDs, in which a Ag based metallization scheme is introduced to achieve highly reflective and ohmic contacts to $\mathrm{p}-\mathrm{GaN}$. Work is carried out to understand the effects of post annealing treatments on reflectivity and conductivity of the Ag based contact 
scheme. An X-ray Photoelectron spectroscopic (XPS) study is conducted to understand the formation of the ohmic contact between the Ag based metallization scheme and the p-GaN.

2) Al doped ZnO Electrodes: Extensive work is carried out to understand the particular effects of various deposition conditions and post-deposition annealing on the electrical and optical properties of $\mathrm{ZnO}$ films deposited on $\mathrm{GaN}$ and glass substrates. Once the optimal condition for $\mathrm{ZnO}$ deposition is established, the work is extended to the study of $\mathrm{ZnO}$ contacts to $p$-type GaN. Direct deposition of $\mathrm{ZnO}$ on $p$-GaN generally produces Schottky contacts. The effects of substrate doping, pre-metal plasma treatment and post-metal annealing on the ohmic behavior are studied. A low-resistance, highly transparency and thermally stable $\mathrm{ZnO}$ ohmic contact to $\mathrm{p}-\mathrm{GaN}$ is obtained by introducing a thin $\mathrm{Ni}$ intermediate layer.

One of the primary objectives of this work is to apply transparent $\mathrm{ZnO}$ contacts to blue and green LEDs. This requires the development of high-quality $\mathrm{ZnO}$ Ohmic contacts to $p$-type GaN. We have compared the electrical characteristics of $\mathrm{ZnO}, \mathrm{Ni} / \mathrm{ZnO}$ and $\mathrm{Al}$ doped $\mathrm{ZnO}$ contacts formed by IBAD technique. It is found that $\mathrm{Al}$ doped $\mathrm{ZnO}$ forms thermallystable ohmic contacts to $p$-GaN after annealing at $800{ }^{\circ} \mathrm{C}$ in $\mathrm{N}_{2}$ ambient, with a contact resistance comparable with industrially used ITO contacts.

This thesis is organized as follows. Chapter 2 addresses basic principles of several processing techniques use in the work, including electron beam evaporating and RF magnetic sputtering. An overview of metal contacts to semiconductors is then given followed by a discussion of the various methods that are used to find the electrical characteristics between the contacts and the semiconductors. Chapter 3 focuses on the detailed fabrication process of the GaN/InGaN MQW III-Nitride Resonant cavity LED devices. Chapter 4 discusses the development of the Ag based metallization scheme for high reflectivity and conductivity. Chapter 5 discusses the modeling, fabrication, characterization and integration to $\mathrm{GaN} / \mathrm{InGaN}$ MQW Light emitting diodes. The conclusion and a list of suggestions for further work are presented in Chapter 6. Appendix includes the coding used for the modeling and specific contact resistance calculations. 


\section{Chapter 2}

\section{Background of Thin Film Processing}

\subsection{Thin Film deposition techniques}

Various methods can be used for $\mathrm{ZnO}$ film deposition, such as electron beam evaporation, sputtering, spray pyrolysis technique, pulsed laser deposition, atomic layer deposition [41] and thermal evaporation [42]. However, different processing techniques with many kinds of doping conditions usually produce $\mathrm{ZnO}$ films with significantly different properties. In this study, $\mathrm{ZnO}$ films were produced by ion beam assisted e-beam evaporation deposition and RF sputtering deposition techniques.

The most common method used for the deposition of $\mathrm{ZnO}$ thin films other metals by various groups was RF Sputtering deposition [43]. Here in this work, Ion beam assisted e-beam evaporation mechanism and RF sputtering mechanisms was used primarily for deposition of $\mathrm{Al}$ alloyed $\mathrm{ZnO}$ films, e-beam evaporation for deposition of metals. The advantages of e-beam evaporator were, the deposition rate can be varied from few nanometers to few microns per minute, material utilization efficiency is high relative to other methods, structural and morphological control of films and the disadvantage of this evaporation method was, filament degradation results in non-uniform evaporation rate. The disadvantages of conventionally used RF sputtering over e-beam evaporation deposition mechanisms is, there will be surface damage due to collision of high energy ions and there will be less control over film thickness and surface morphology.

\subsubsection{E-beam evaporation system}

Electron Beam Physical Vapor Deposition or EBPVD is a form of physical vapor deposition in which a target anode is bombarded with an electron beam given off by a charged tungsten filament under high vacuum. The electron beam causes atoms from the target to transform into the gaseous phase. These atoms then precipitate into solid form, coating everything in the vacuum chamber (within line of sight) with a thin layer of the anode material. 
The electron beam method of evaporation is of interest to both dielectric and metal depositions. A wide variety of materials including refractory metals (such as tungsten), low vapor pressure metals (such as platinum), and alloys can be evaporated. Since the electron beam method concentrates large amounts of heat on a very small area, high deposition rates are possible.

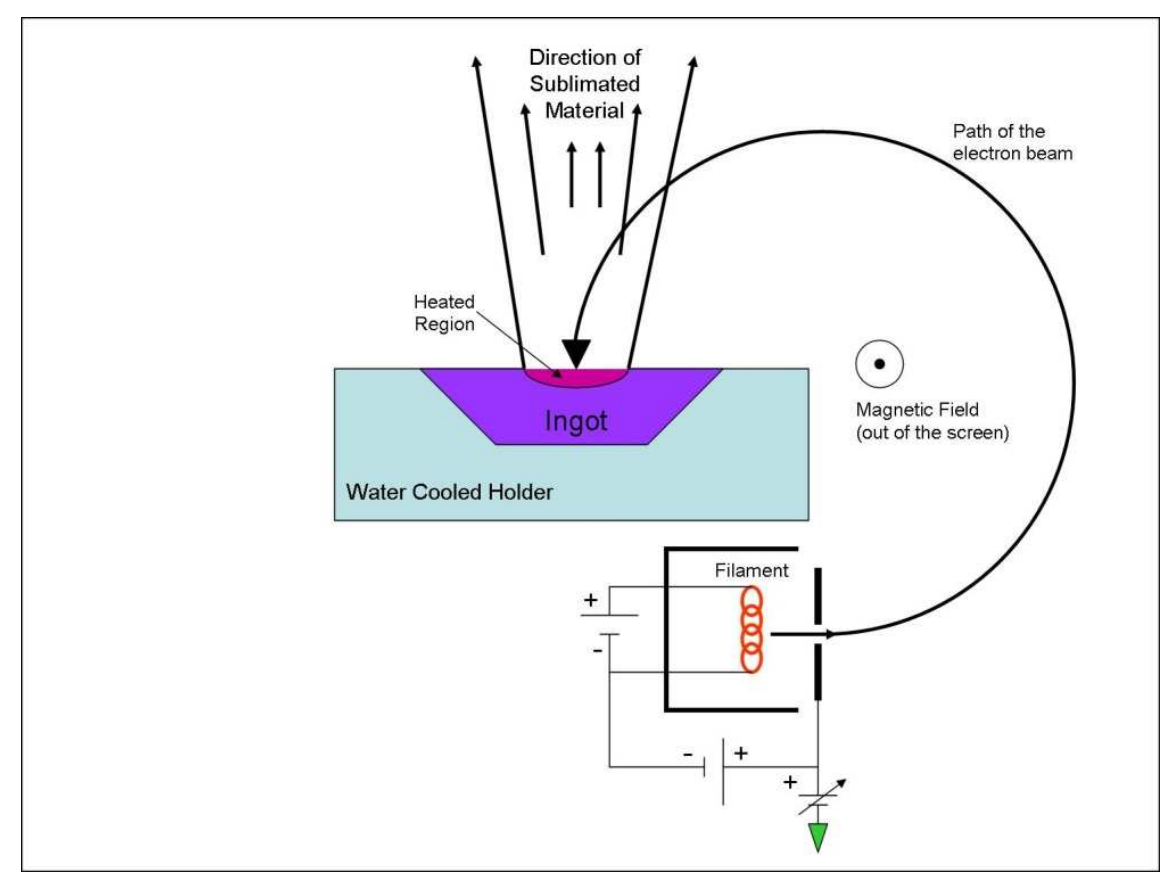

Figure 2.1: A schematic diagram of a typical system for e-beam evaporation [44]

In an EBPVD system, the deposition chamber is evacuated to a pressure of $10^{-5}$ Torr, because high vacuum is required to maintain a large mean free path of ejected material. The source material must be pressed into a dense pellet free of voids so that the temperature gradients produced by an electron beam do not explode the pellet ingots. An electron gun (tungsten filament) is used to emit the e-beam as shown in the Figure 2.1. The generated electron beam is accelerated to a high kinetic energy and focused towards the crucible. When the accelerating voltage is at $10 \mathrm{kV}$ and the beam current is a few amperes, $85 \%$ of the kinetic energy of the electrons is converted into thermal energy as the beam bombards the surface of the material in the crucible [45]. In evaporation, the substrate is placed inside a vacuum chamber, in which a block (source) of the material to be deposited is also located. The source material is then heated to the point where it starts to boil and evaporate. The vacuum is required to minimize 
contamination and allow the molecules to evaporate freely in the chamber without reaction or collision, and they subsequently condense on all surfaces.

The system used for e-beam evaporation for this experiment is shown in Figure 2.2. In the evaporator that is used in our work, the gun assembly is located outside the evaporation zone to avoid becoming contaminated by evaporants. When the filament becomes hot enough, it begins to emit electrons. These electrons form a beam which is deflected and accelerated toward and focused on the material to be evaporated by means of a magnetic or electric fields. When the electron beam strikes the target surface, the kinetic energy of motion is transformed by the impact into thermal energy (heat). The energy given off by a single electron is quite small and that the heating is accomplished simply by virtue of the vast number of electrons hitting the evaporant surface. This is the energy which vaporizes the target material. Effectively the material locally becomes very hot from the focused electron beam. Due to the intensity of the heat generated by the electron beam, the evaporant holder, usually a crucible made of graphite or platinum which has a high-melting temperature, must be water cooled to prevent it from melting.

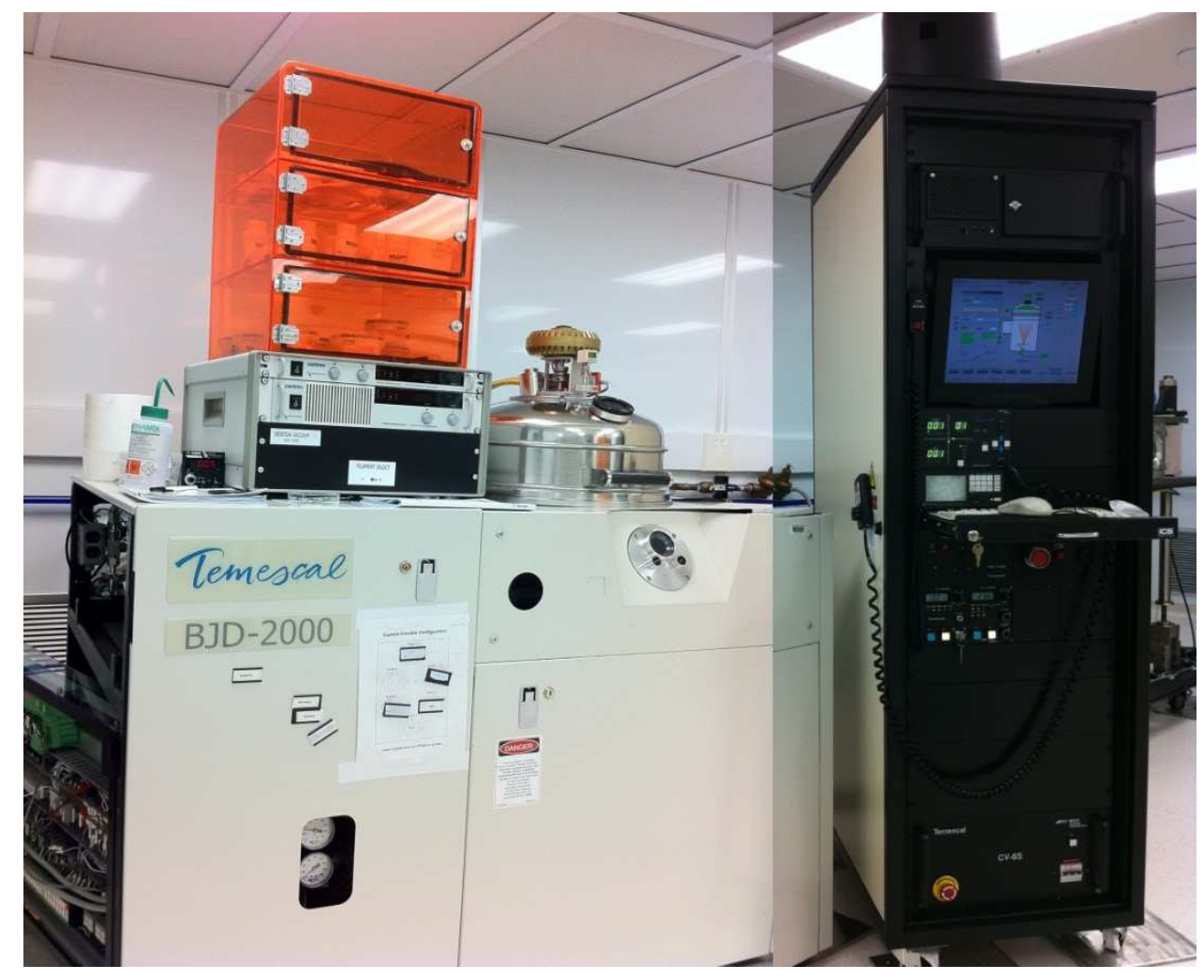

Figure 2.2: E-beam evaporator system used for this experiment. 
The deflection/focusing apparatus is designed using either permanent magnets or electromagnets to create a field that can shape and direct the path of the electrons. This is necessary because the electrons are emitted in a random manner and must all be directed to the very small area where the evaporation will occur. A magnetic field is used since it can directly attract or repel the negatively charged electrons. The material would uniformly cover the surfaces of the chamber of evaporation station including a region containing the sample.

Typically, the sample can be protected by a shutter so that once a stable deposition rate is established the amount of time the sample is within the flux of atoms can be timed and therefore the amount of deposited material can be accurately estimated. A quartz crystal is used to measure the deposition rate. The quartz crystal oscillates at a resonance frequency that is dependent on the thickness and mass of the film deposited onto it. When a voltage is applied across the faces of a properly shaped piezoelectric crystal, the crystal is distorted and changes shape in proportion to the applied voltage. The quartz crystal sensor will be provided with a water cooling system, because, as the temperature is increased inside the chamber, the resonance frequency will be altered, there by the thickness and deposition rate readings. There is a leaf shaped structure that will protect the thermo-couple from coating, will obstruct the sample from deposition. The substrate holder is attached to the manipulator shaft. The manipulator shaft moves translationally to adjust the distance between the ingot source and the substrate. The shaft also rotates the substrate at a particular speed so that the film is uniformly deposited on the substrate.

The advantage of EBPVD is that the deposition rate in this process can be as low as $1 \mathrm{~nm}$ per minute to as high as few micrometers per minute. The material utilization efficiency is high relative to other methods and the process offers structural and morphological control of films. The disadvantages are, EBPVD is a line-of-sight of deposition process. The translational and rotational motion of the shaft helps for coating the outer surface of complex geometries, but this process cannot be used to coat the inner surface of complex geometries. Another potential problem is that filament degradation in the electron gun can result in a nonuniform evaporation rate for extended depositions. 


\subsubsection{Ion beam assisted e-beam evaporation system}

The E-beam evaporation system used is equipped with an ion source. The different applications of the ion source are, substrate etching and cleaning, sputtering the target, controlling the microstructure of the substrate and thin film (di-electric and conductive) depositions. The ion beams bombard with the surface and alters the quality of the film deposited. Ion bombardment also increases the density of the film, changes the grain size and modifies amorphous films to polycrystalline films. Low energy ions are used for the surfaces of semiconductor films. Ion Beam Assisted Deposition (IBAD) is a thin film deposition process that combines evaporation with concurrent ion beam bombardment in a high-vacuum environment. The evaporant (or coating) material is produced using a high power electron beam. Components are placed in the vapor, and individual coating atoms or molecules condense and stick on the surface of the component to form the coating. Simultaneously, highly energetic ions (100-2000 $\mathrm{eV}$ ) are produced and directed at the component surface.

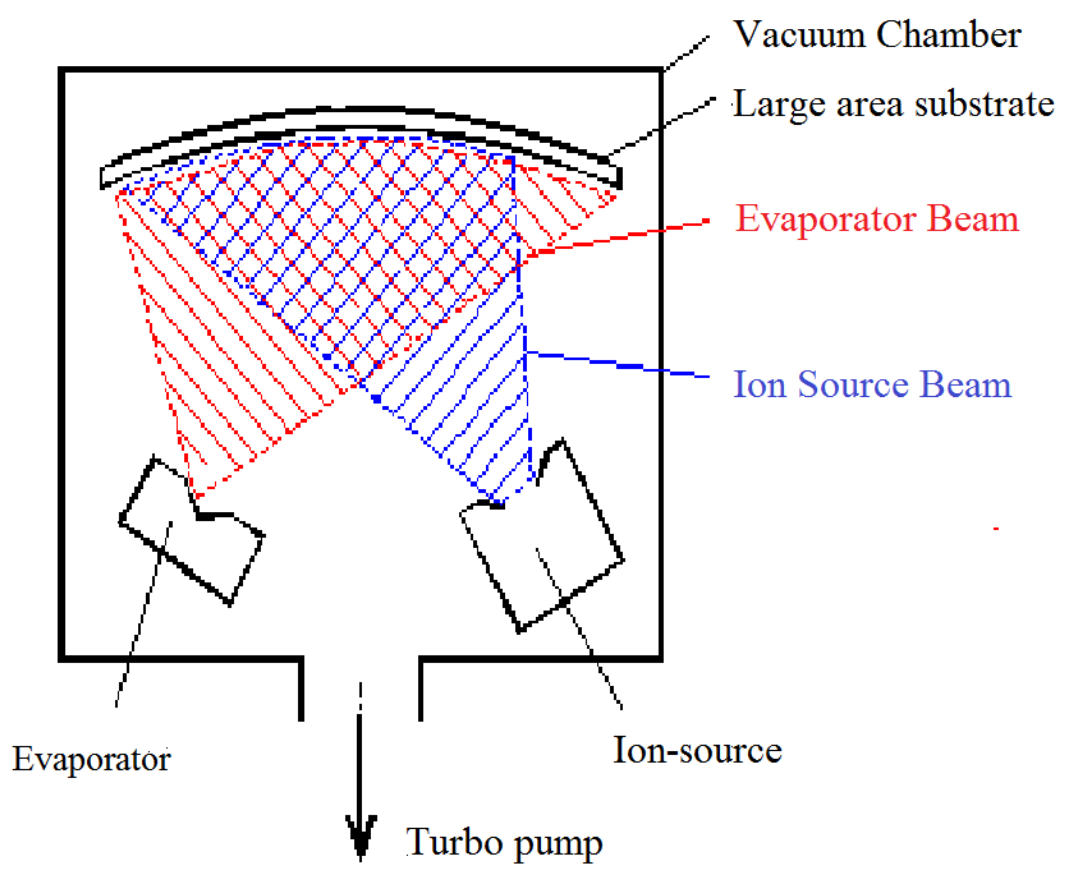

Figure 2.3: A schematic diagram of a typical system for ion beam assisted e-beam evaporation deposition [46]

The component is situated at the intersection of the evaporant and ion beam. The concurrent ion bombardment differentiates IBAD from other thin film deposition 
techniques. It significantly improves adhesion, and permits control over film properties such as morphology, density, stress level, crystallinity, and chemical composition. Ion bombardments inter mixes coating and substrate atoms and eliminates the columnar microstructure often observed in conventional, low temperature physical vapor deposition to create very dense, adherent film structures [47]. IBD processing yields excellent control and repeatability of film thickness and properties. Process pressures in IBD systems are $\sim 10^{-4}$ Torr. As a result, there is very little scattering of either ions delivered by the ion sources or material evaporated from the target of the surface. In combination with a substrate fixture that rotates and changes angle, IBD systems deliver a broad range of control over sidewall coatings, trench filling and liftoff profiles. In this work, IBAD is primarily used for the deposition of di-electrics like $\mathrm{SiO}_{2}, \mathrm{TiO}_{2}$ and transparent conductive $\mathrm{Al}$ doped $\mathrm{ZnO}$ thin films. Here, $\mathrm{Al}: \mathrm{ZnO}$ is evaporated, and the $\mathrm{O}_{2}$ deficiency caused during the evaporation deposition is compensated by the $\mathrm{O}_{2}$ ion source.

\subsection{Metal Contacts to Semiconductors}

In general, in a semiconductor device, the metal contacts will play a vital role in the device performance. The resistance between the metal and a semiconductor can be reduced to some extent by using suitable combination of materials depending on their properties, but not as low as a metal and metal contact resistance. The primary component that should be considered while forming good contacts between the metal and the semiconductor was, there should be low mismatch between the Fermi energy of the metal and the semiconductor [48]. Metals should be chosen based on their work functions for forming good contacts with different semiconductor materials. Sometimes we cannot find any suitable metals for some semiconductor materials, then alternate approaches like, heavy doping of semiconductors, deposition of thin interfacial layers, have to be implemented in order to form a good contact. Through this kind of approach, a thin barrier layer will be formed for tunneling of carriers. It was observed that, in most of the cases, after forming a metal semiconductor contact, post annealing treatments will be performed in order to reduce the interfacial surface defects and form an alloy, thereby reducing the contact resistivity. In this section, different contact mechanisms that are used for various semiconductor applications and also the mechanisms used by us in our work are explained in detail. 


\subsubsection{Schottky Contacts}

In general, in the ohmic contacts, we find negligible contact resistance between the metal and semiconductor when compared to the series resistance of the material. But it is hard to form a good ohmic contact with all the semiconductor materials due to limited availability of metals that have work functions suitable for them. Hence the second type of contacts that are formed between metal-semiconductor interfaces was Schottky contacts. The Schottky contacts are formed between metal and semiconductor materials if there is a large barrier height (the potential difference between Fermi energy of the metal and the band edge in a semiconductor where majority carriers will reside) and also very low doping concentration in the semiconductor material that is less than the density of states in the conduction band or the valence band [49].
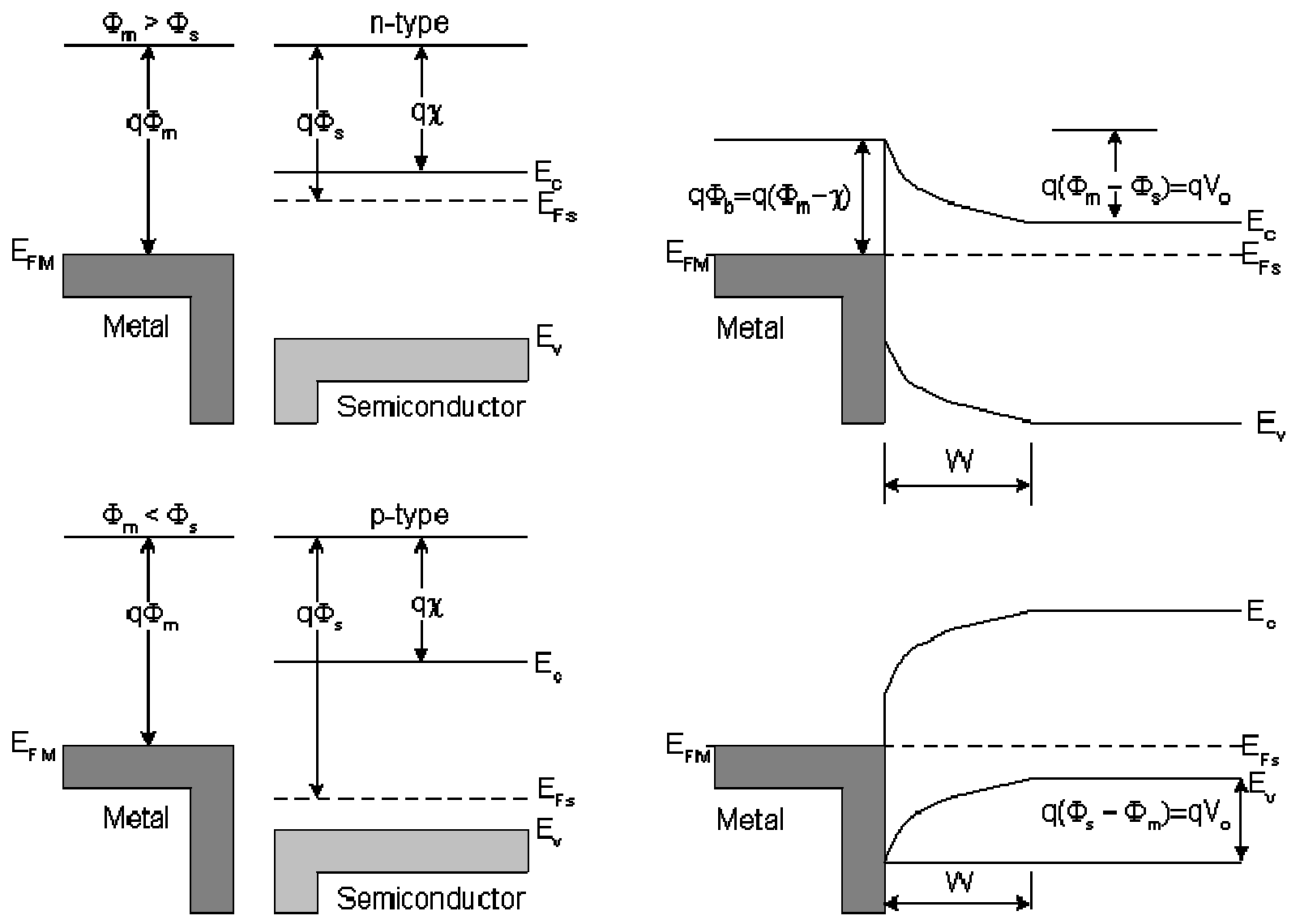

Figure 2.4: Energy band diagram of metal adjacent to n-type and p-type semiconductor, left, under thermal non equilibrium, right, thermal equilibrium conditions [50]. 
In a Schottky contact, there will be a potential barrier that prevents carriers (electrons or holes) from passing one side to the other side. In order to study the potential barrier between the metal and semiconductor, we need to construct an energy band diagram. When a metal is brought near a semiconductor, under thermal equilibrium, as shown in Figure 2.4, the Fermi energies of both the materials should be equal. The barrier height (Schottky barrier) between a p-type (equation 2.1) and n-type (equation 2.2) and semiconductor material [49] and metal can be found using,

$$
\begin{gathered}
\emptyset_{B_{p}}=\frac{E_{g}}{q}+\chi-\emptyset_{m} \\
\emptyset_{B_{n}}=\emptyset_{m}-\chi
\end{gathered}
$$

Where,

$E_{g}$ is the band gap of the semiconductor material,

$\chi$ is the electron affinity,

$\emptyset_{m}$ is the work function of the metal.

The energy $q \emptyset_{m}$ required to remove an electron from the Fermi level to the vacuum outside the metal is called work function of metal [51]. The amount of energy released when an electron is added to a neutral atom is the electron affinity $(\chi)$ [52]. The energy gap between the valence band and the conduction band in a semiconductor is defined as the band gap $\left(E_{g}\right)$. As shown in Figure 2.4, it can be observed that, when the metal is brought in contact with the semiconductor, there will be charge transfer until both the Fermi levels align at equilibrium. For a $n$ type material and metal interface, $\emptyset_{m}>\emptyset_{s}$, in order to align both the Fermi levels of metal and n-type semiconductor, electrons from semiconductor had to transfer to metal and hence a depletion region will be formed in the n-type semiconductor with width $\mathrm{W}$, consisting of ionized impurities creating a built in potential. Hence, a depletion region can be defined as, in thermal equilibrium, with no external voltage applied; as a region in the semiconductor close to the junction which is depleted of mobile carriers. The depletion width can be calculated using the following equations [53],

$$
W=\sqrt{\frac{2 \varepsilon_{S} V_{O}}{q N_{D}}}
$$

Where, 


$$
\begin{gathered}
V_{0}=\frac{\emptyset_{m}-\emptyset_{s}}{q} \\
\text { And } \quad \emptyset_{m}-\emptyset_{s}=k T \ln \left(\frac{N_{c}}{N_{D}}\right)
\end{gathered}
$$

The depletion width is given by the equation 2.3 , where, $\varepsilon_{s}$ gives the permittivity of the material, $\mathrm{k}$ is the Boltzmann constant, $\mathrm{T}$ is the temperature, $N_{c}$ gives the carrier concentration, $N_{D}$ gives the dopant concentration. It can be concluded that the depletion width is mainly dependent of the doping concentration and the temperature. The equilibrium is reached when there are two equal and opposite electron flows over the barrier and $\mathrm{J}=0$ at $\mathrm{V}=0$.

\subsubsection{Forward and reverse bias characteristics}

A metal-semiconductor junction under forward and reverse bias conditions is discussed in the following section. Whenever a positive bias is applied to the metal, the Fermi energy of the metal is lowered with respect to that of the semiconductor [54], as shown in Figure 2.5 (a), as a result, a smaller potential drop is observed across the semiconductor. This causes a disturbance in the balance between drift and diffusion in electrons, i.e.; more number of electrons will try to diffuse towards the metal than the number of electrons drifting into the semiconductor. As a result a positive current is observed through the junction comparable to that of built in potential. The depletion region will be narrowed and the potential barrier in the semiconductor is reduced and the electrons spill from semiconductor into metal. A large amount of current will be flowing through the device, relative to the bias V applied.

Vice versa, when a negative voltage (reverse bias) is applied, it is observed that the Fermi energy of the metal is raised with respect to that of the semiconductor, as shown in the Figure 2.5 (b). There will be an increase in the potential across the semiconductor, which will yield a larger depletion width. Independent of the applied voltage, the barrier which restricts the flow of electrons to the metal remains unchanged. Therefore a rectifying behavior will be observed across the metal-semiconductor junction due to the presence of a positive barrier height. As there is no flow of carriers, almost no current exists under reverse bias condition, opposite to what we see under the forward bias condition. 


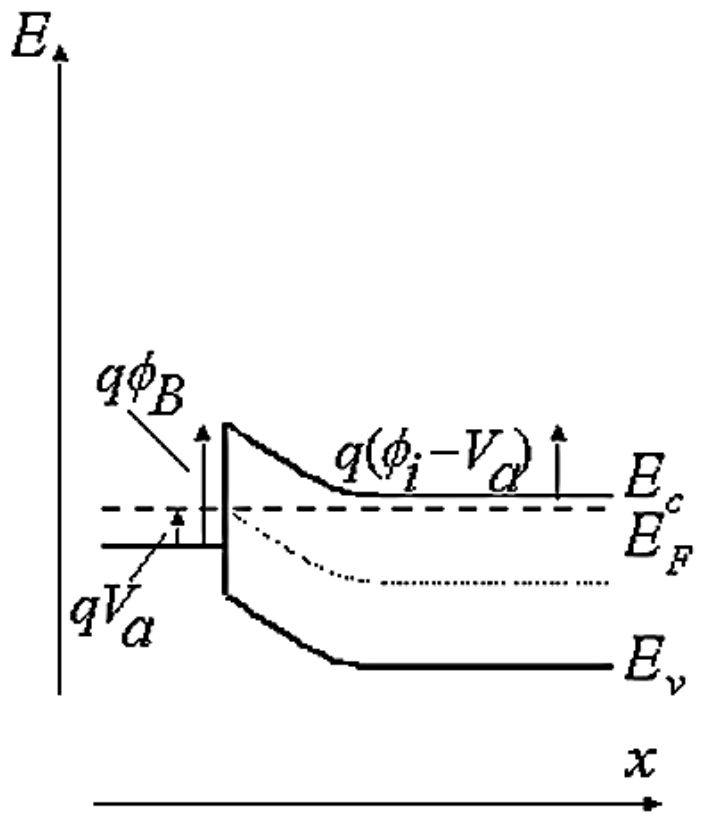

(a)

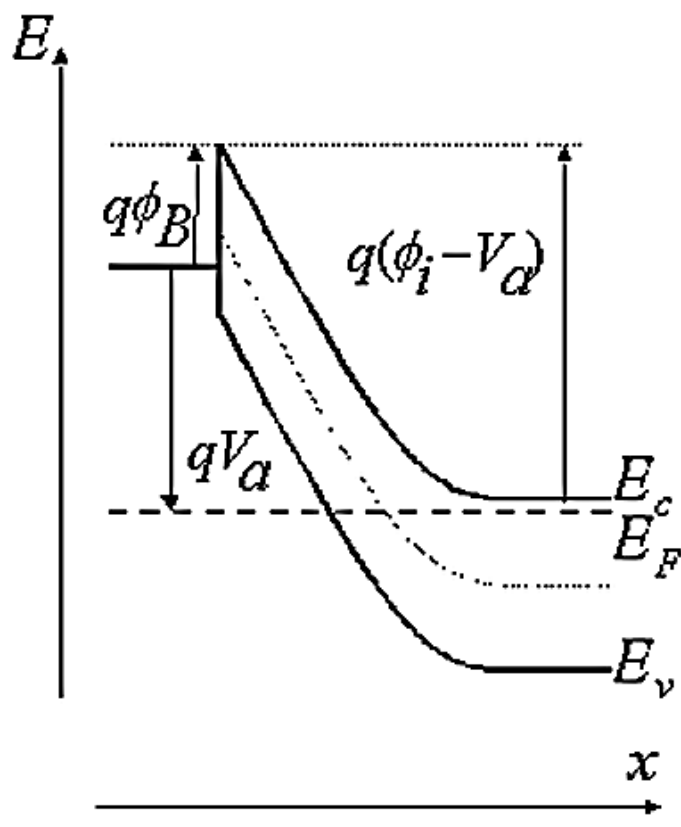

(b)

Figure 2.5: Energy band diagram of metal-semiconductor junction under, (a) forward bias and (b) reverse bias [54]

\subsubsection{Ohmic Contacts}

An ohmic contact can be formed between a metal and a semiconductor if the Schottky barrier height can be reduced to zero or negative [48]. As there is no barrier, there will be a free flow of carriers from the metal to semiconductor and vice versa. Hence, from Figure 2.4, it can be said that, in order to form an ohmic contact with an $n$-type semiconductor, the work function of the metal must be close to or smaller than the electron affinity of the semiconductor. Similarly, in case of a p-type semiconductor, it is required that the work function of the metal must be close to or larger than the sum of the electron affinity and the band gap energy. So, it is not an easy task to form an ohmic contact with the p-type semiconductors with large band gap like GaN, as most of the metals that were available, had a work function less than that of $6 \mathrm{eV}$ [55] and typical electron affinity is less than $4 \mathrm{eV}$ [56]. A contact between a metal and a semiconductor is typically a Schottky barrier contact, so different mechanisms have been developed to make them ohmic in nature. It is observed that, if the semiconductor is heavily doped, the Schottky barrier depletion region becomes very thin [48]. At very high doping levels, 
a thin depletion layer becomes quite transparent for electron tunneling. Therefore, to obtain a reliable ohmic contact, the semiconductor under the metal should be heavily doped by diffusion, implantation, or alloying [57].

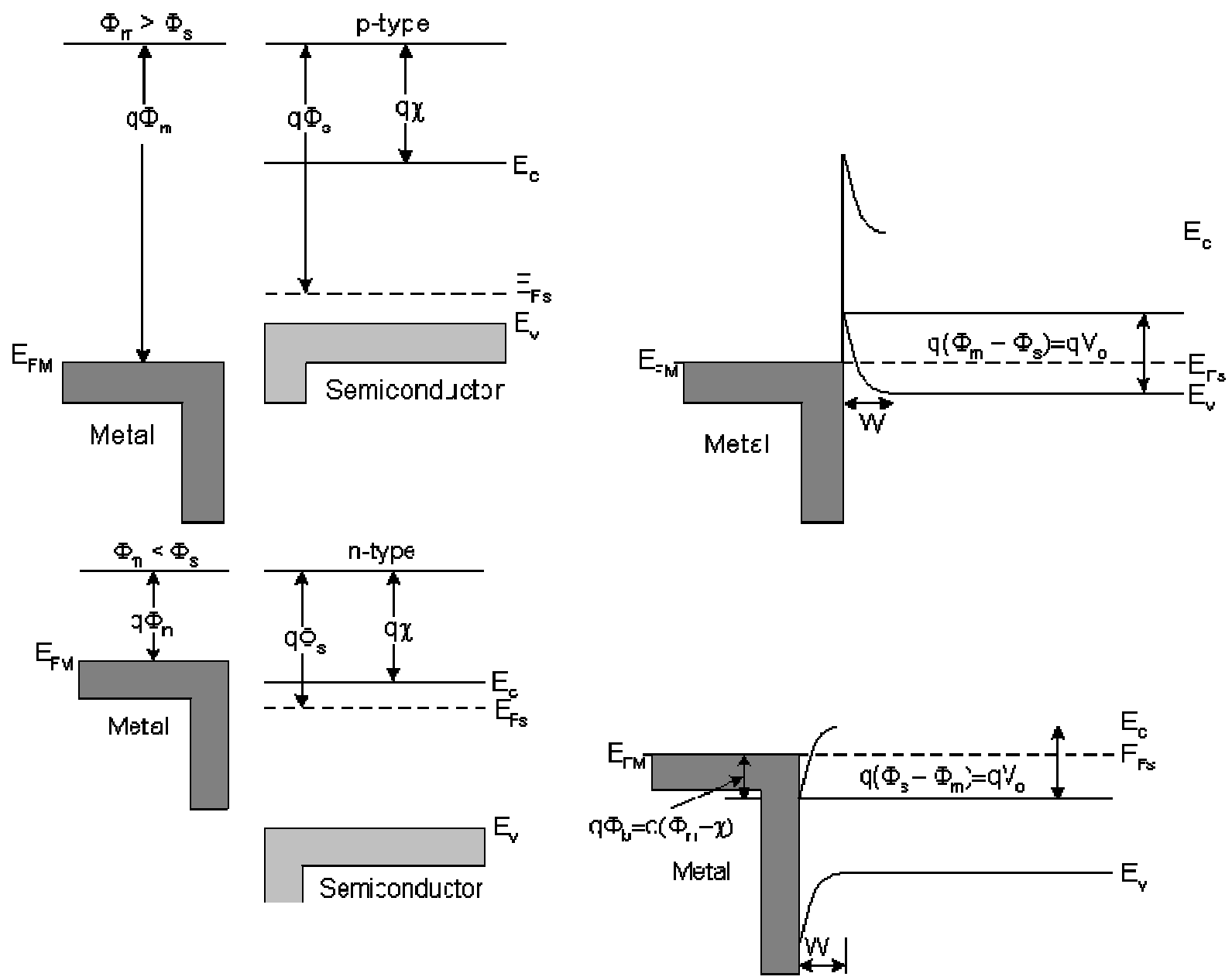

Figure 2.6: Energy band diagram of metal-semiconductor junction forming an ohmic contact, left, junction under non thermal equilibrium, right, under thermal equilibrium. [58]

From Figure 2.6, left, when a metal and semiconductor before they are brought into contact, from, Figure 2.6, right, after metal and semiconductor are contacted, it can be observed that, electrons flow from metal into semiconductor. An ohmic contact can be explained by, in a metal, the electron current forms a positive surface charge layer and an electric field will be created in the opposite direction, an electric potential and hence bending of bands is observed. The bands of the semiconductor will bend downward and no barrier exists for the flow 
of electrons in either direction. The current increases linearly with increasing voltage and is symmetric about the origin.

As explained in the previous section, it is hard to find suitable metals to form good contacts with the semiconductors. The selection of metals alone cannot control the barrier height; hence other mechanisms have to be implemented to form good conduction mechanism (Ohmic contact). The other mechanism that can be used to form good ohmic contacts was, high doping of the semiconductor materials [59]. The Schottky barrier is dependent on the doping concentration [60], which in turn is a function of depletion width $\mathrm{W}$, from equation 2.3. As we know, from equation 2.3 , depletion width $\mathrm{W}$ is proportional to $1 / \sqrt{N_{D}}$, if the doping is increased, the depletion width will get narrower and hence the probability of the carriers that can tunnel through the barrier increases. Therefore, by increasing the doping concentration, narrowing of barrier width and hence an ohmic contact can be achieved through tunneling mechanism.

The various conduction mechanisms based on the doping of the semiconductor, Thermionic emission, Thermionic-field emission and Field emission [59] were shown in the Figure 2.7. From Figure 2.7 (a), when the doping concentration $\left(\mathrm{N}_{\mathrm{D}}\right)$ is less than $10^{17} \mathrm{~cm}^{-3}$, the conduction mechanism is called as Thermionic emission, the barrier width is too wide and the carriers will not be able to tunnel through it and were thermally excited over the barrier [59]. If the doping concentration was in between $10^{18}$ and $10^{17} \mathrm{~cm}^{-3}$, then electrons use thermal energy to tunnel through the thin barrier, this is called Thermionic-field emission. In the extreme case, if the doping concentration is higher than $10^{19} \mathrm{~cm}^{-3}$ then the barrier will be sufficiently narrow enough for the electrons to tunnel directly, this is called Field emission [59]. FE is the main reason behind the formation of ohmic contacts with the semiconductor materials. The conduction mechanism can be explained in a more quantitative manner, the current density $\mathrm{J}$ across the barrier can be given by the expression [59],

$$
J=J_{S}\left(e^{\frac{q V}{k T}}-1\right)
$$

And,

$$
J_{S}=A^{*} T^{2} \exp \left(\frac{-q \emptyset_{B n}}{k T}\right)
$$


Where, $\mathrm{J}_{\mathrm{s}}$ is the saturation current density, $\mathrm{T}$ is the temperature and $\mathrm{A}^{*}$ is effective Richardson's constant. For the ohmic contact based on FE, the current density can be given by [62],

$$
J=\exp \left(\frac{-q \emptyset_{B}}{\left(q h / 4 \pi \sqrt{\frac{N}{\varepsilon m^{*}}}\right.}\right)
$$

Where, $\mathrm{N}$ is the doping concentration, $\mathrm{h}$ is the plank's constant, $\varepsilon$ is the permittivity and $\mathrm{m}^{*}$ is the mass of the electron. From the above expression, it can be concluded that, by degenerately doping the semiconductor the tunneling current can be increased drastically.

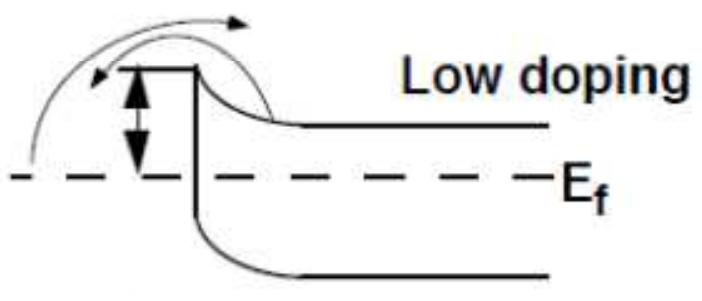

(a) Thermionic emission
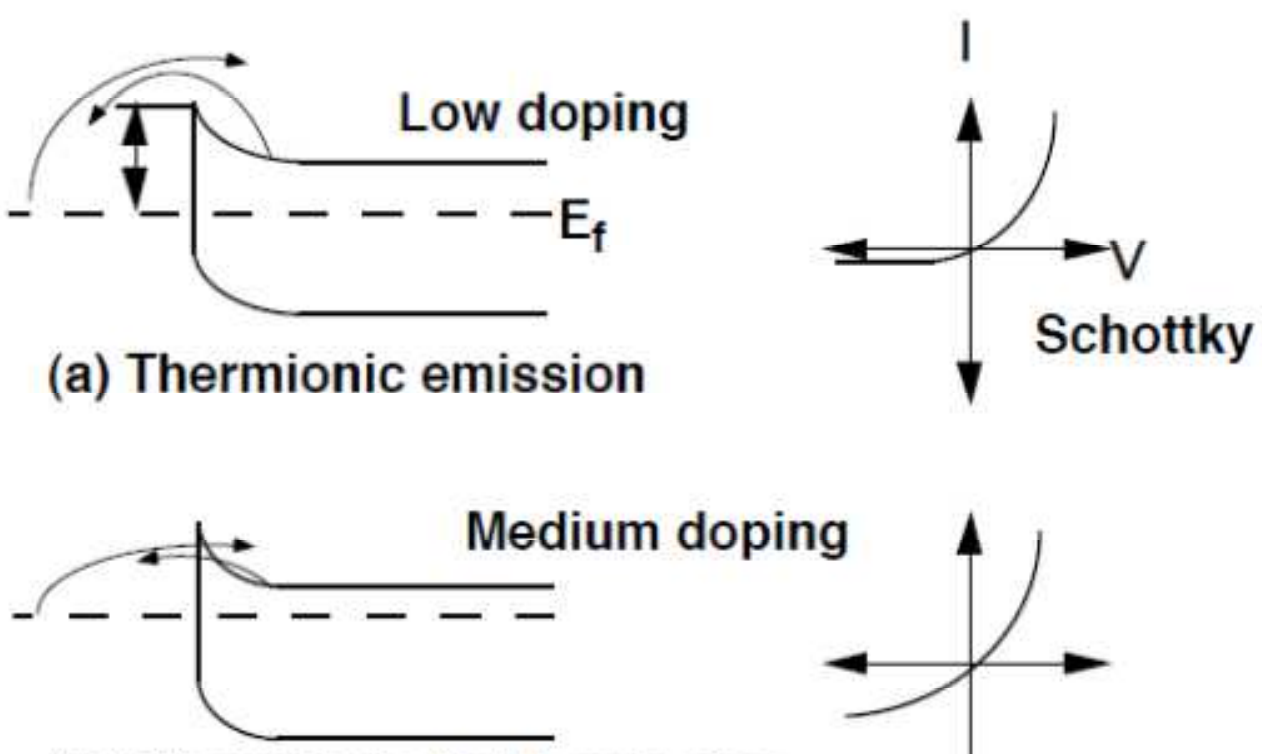

(b) Thermionic-field emission
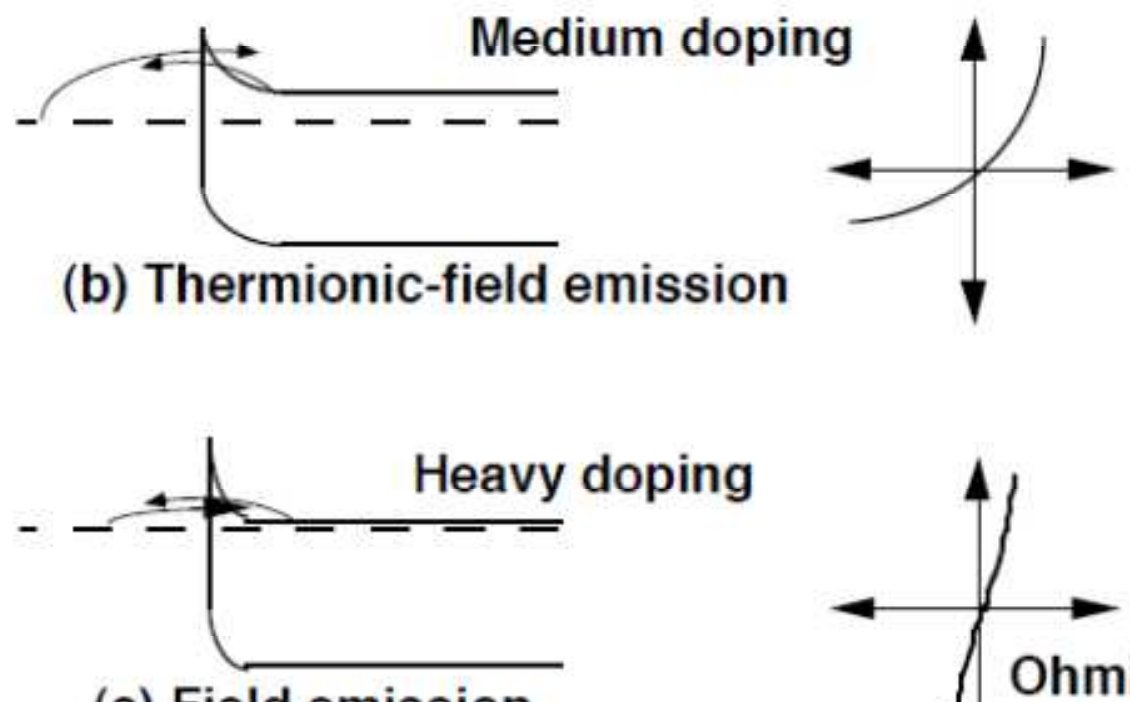

(c) Field emission.

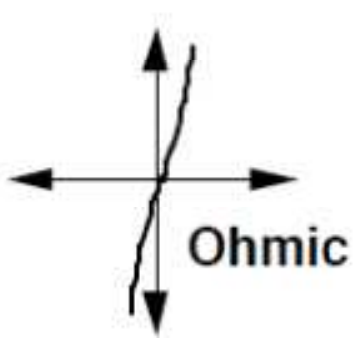

Figure 2.7: Conduction mechanism of metal-semiconductor contacts as a function of barrier width and doping, (a) Thermionic emission, (b) Thermionic field emission, (c) Field emission 
In this work, we dealt with two different kinds of contact schemes, one was an annealed and alloyed contact and the other one was a tunnel contact. The first kind of contact was annealed at high temperatures in order to form an alloy with the semiconductor or to reduce any kind of un-intentional surface states at the interface [63]. The second kind of contact was the tunneling contact, which was formed by two mechanisms, one is introduction of a thin metal layer between the contact and the semiconductor to enhance the tunneling mechanism and the second one is by increasing the doping concentration in the semiconductor. It was observed through simulation that, if the width of the depletion region at the metal-semiconductor interface is very thin, on the order of $3 \mathrm{~nm}$ or less [63], carriers can readily tunnel across such barrier. The required doping density for such a contact is $10^{19} \mathrm{~cm}^{-3}$ or higher.

\subsubsection{Transmission Line Method \& Contact Resistance Calculation}

In order to find the specific contact resistance of ohmic contact systems in the semiconductor devices, two different methods were employed, one is a rectangular geometry, transmission line method [64], and the other one is a circular transmission line method [65]. In order to confine the current flow between two contacts in the rectangular geometry method, a mesa structure should be used, however, in a circular pattern method we don't face such complications, and hence a Circular Transmission Line Method (c-TLM) has been used in our work. Figure 2.8 gives us the basic idea of the rectangular geometry pattern used to calculate the specific contact resistance.

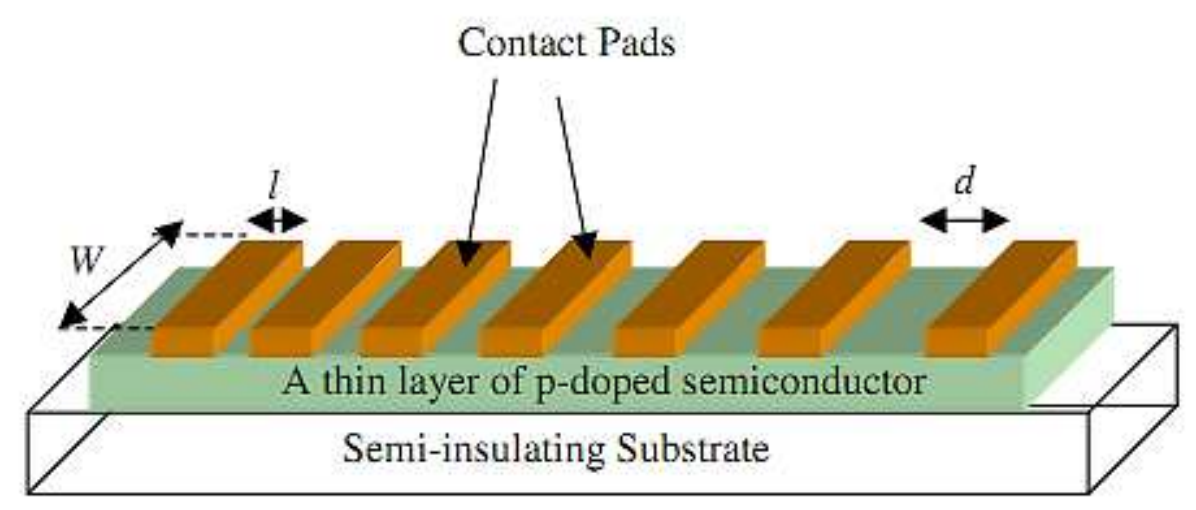

Figure 2.8: Rectangular pattern where $\mathrm{W}$ is the width of the pads, 1 is the length of the pads and $\mathrm{d}$ is the contact pad separation [66]. 
Similarly, Figure 2.9, shown below, gives us the circular pattern geometry that was used in this work. The inner radii of the contact pads changes from $10 \mu \mathrm{m}$ to $100 \mu \mathrm{m}$ with spacing of $40 \mu \mathrm{m}$.
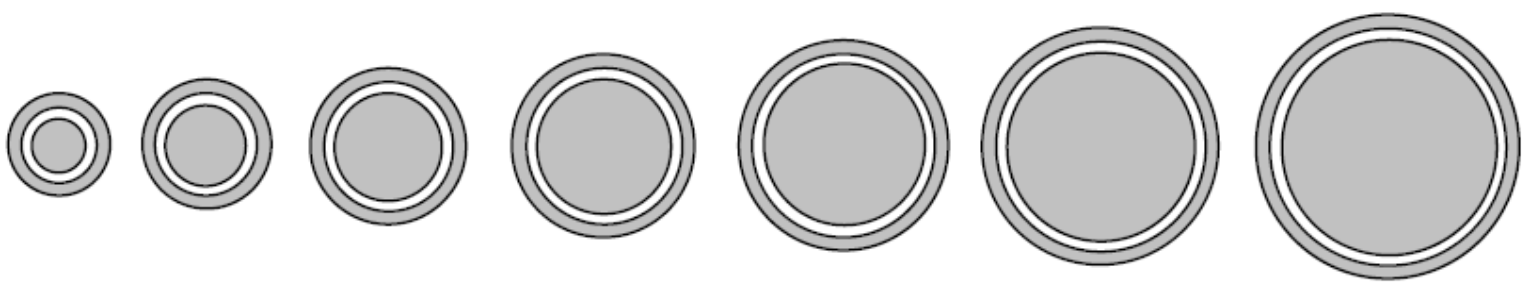

Figure 2.9: Circular pattern used to find the specific contact resistance, with different radii and spacing in the contact pads

In general, the total resistance in a metal-semiconductor junction includes, contact resistance and the bulk resistance [64]. If the total resistance is $R_{c}$ and the area of the contact is $\mathrm{A}$, then the specific contact resistance can be given by the expression [67],

$$
\rho_{c}=R_{c} * A
$$

The above given equation will be valid only if the current flows uniformly through the contact [64], hence a different mechanism, TLM method, has been developed to calculate the specific contact resistance. The specific contact resistance is also independent of the measurement and the geometry of the contact used. The derivation of specific contact resistivity in a c-TLM method is explained briefly in the following section. A two point contact method, as shown in the Figure 2.10 was implemented for this work. Using a semiconductor parameter analyzer, when a current is given between the inner and outer circular contact pads, there will be a voltage drop $\mathrm{V}$ across the separation, $d$, between the pads is given by [68-69],

$$
V=\frac{i R_{S}}{2 \pi}\left[\ln \left(\frac{r_{o}}{r_{i}}\right)+\frac{L_{T} I_{o}}{r_{o} I_{1}}+\frac{L_{T} K_{o}}{r_{o} K_{1}}\right]
$$

Where, $\mathrm{i}$ is the current across the separation, $R_{S}$ is the semiconductor sheet resistance, $L_{T}$ is the transfer length, $I_{o}, I_{1}, K_{o}, K_{1}$ were the Bessel functions and $r_{o}, r_{i}$ were the radii of the inner and other circular contact pads. 


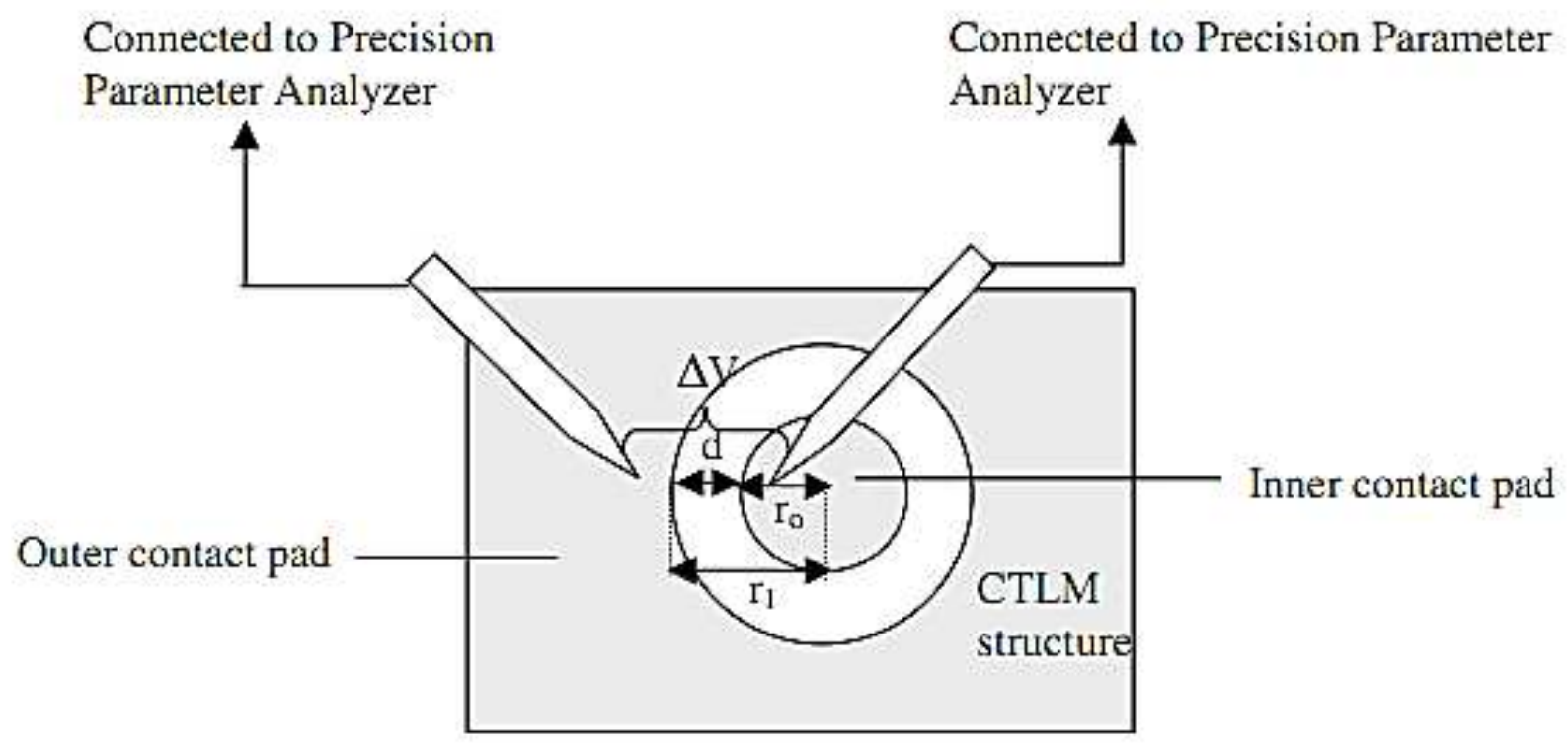

Figure 2.10: Experimental setup for derivation of specific contact resistance [66]

In the equation 2.11, the term transfer length, $\mathrm{L}_{\mathrm{T}}$, is defined as, the distance over which most of the current transfers from the semiconductor to the metal or vice versa. It is related to the specific contact resistance, $\rho_{\mathrm{c}}$ of the metal/semiconductor contact and the sheet resistance, $\mathrm{R}_{\mathrm{s}}$, by the expression [70],

$$
L_{T}=\sqrt{\frac{\rho_{c}}{R_{s}}}
$$

From the Figure 2.10, it can be calculated as, $d=r_{i}-r_{0}$,

$$
r_{0}=r_{i}-d
$$

If the values of the radii $r_{o}, r_{i}$, were much greater (at least 4 times) than the transfer length $L_{T}$ then Bessel function ratios will be approximated to unity [71].These approximations were taken to simplify the equations, substituting all these values in the equation 2.10 , we will get the equation as,

$$
V=\frac{i R_{S}}{2 \pi}\left[\ln \left(\frac{r_{i}-d}{r_{i}}\right)+L_{T}\left(\frac{1}{r_{i}-d}+\frac{1}{r_{i}}\right)\right]
$$

From Ohms law, the total resistance $\left(\mathrm{R}_{\mathrm{T}}\right)$, will be equal to the ratio of Voltage drop V and current i. Hence, the total resistance is calculated using the equation 2.13 as, 


$$
R_{T}=\frac{R_{S}}{2 \pi}\left[\ln \left(\frac{r_{i}-d}{r_{i}}\right)+L_{T}\left(\frac{1}{r_{i}-d}+\frac{1}{r_{i}}\right)\right]
$$

Now using the semiconductor parameter analyzer, a set of $R_{T}$ values was obtained for different $r_{i}$ values. An $\mathrm{X}-\mathrm{Y}$ plot is drawn with, $(1 / 2 \pi)^{*} \ln \left(\mathrm{r}_{\mathrm{i}} /\left(\mathrm{r}_{\mathrm{i}}-\mathrm{d}\right)\right)$ as $\mathrm{X}$ - coordinates and $\mathrm{R}_{\mathrm{T}}$ as the $\mathrm{Y}$ coordinates. We get a plot, as shown in Figure 2.11, with a straight line having slope equal to $\mathrm{R}_{\mathrm{s}}$. The transfer length can be extracted from the intercept on the Y-axis.

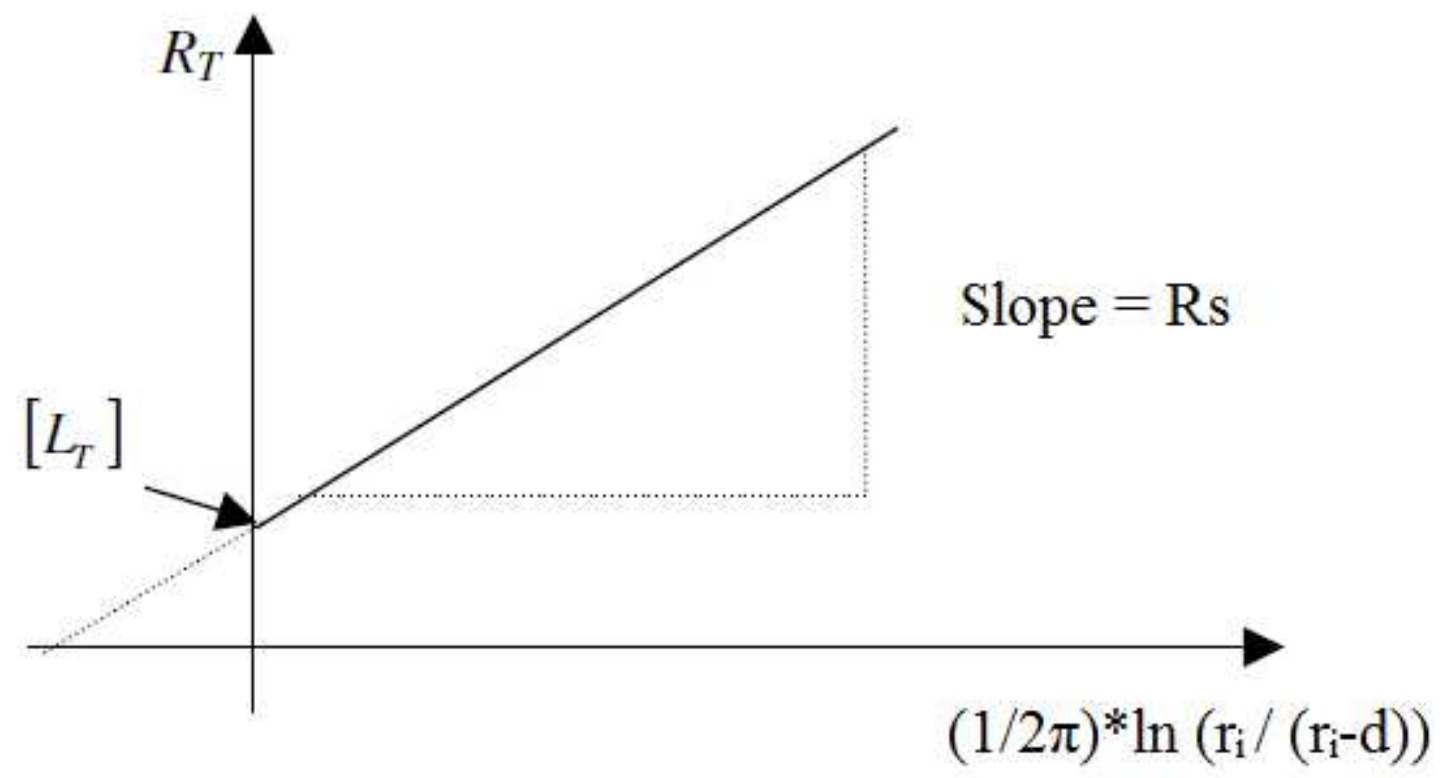

Figure 2.11: Graph of $\mathrm{R}_{\mathrm{T}}$ versus $(1 / 2 \pi) * \ln \left(\mathrm{r}_{\mathrm{i}} /\left(\mathrm{r}_{\mathrm{i}}-\mathrm{d}\right)\right)$ can be used to deduce specific contact resistance $\rho_{\mathrm{c}}$

Hence, from the Figure 2.11 shown above, the values of transfer length $L_{T}$ and $R_{s}$ were extracted and substituted in the equation 2.11 to calculate the specific constant resistivity $\rho_{\mathrm{c}}$ as shown below,

$$
\rho_{c}=\left(L_{T}\right)^{2} * R_{S}
$$




\section{Chapter 3}

\section{GaN/InGaN MQW Light Emitting Diodes}

\subsection{Fabrication Process}

This chapter explains the detailed fabrication process of GaN/InGaN MultiQuantum well (MQW) Light emitting diodes. The fabrication process explained here, includes, surface treatments, photo-lithography, dry etching, metallization, pre and post annealing treatments. The motivation for this study is to optimize the fabrication process, so as to improve the optical and electrical efficiency of the LEDs. For this purpose, various factors affecting LED properties, including pre and post annealing temperatures, ambient conditions suitable for $\mathrm{p}$ $\mathrm{GaN}$, electrode film thickness, annealing conditions (annealing temperature, ambient and time) and dry etching conditions have been studied.

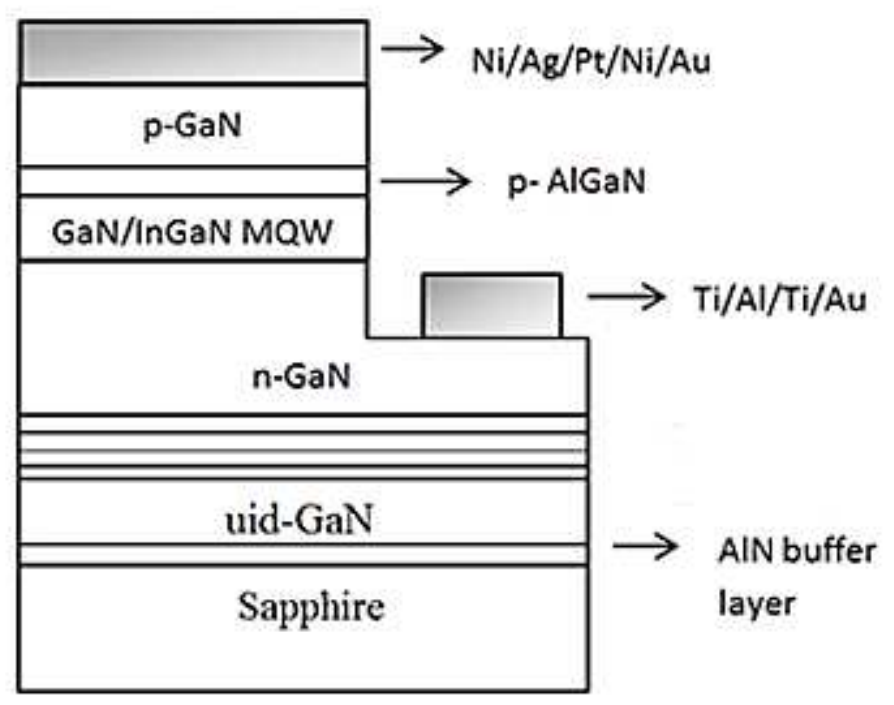

Figure 3.1: Fabricated structure of the GaN/InGaN MQW LED used in this work.

\subsubsection{Surface cleaning}

For the GaN/InGaN MQW Light emitting diodes, the p-GaN surface will be oxidized due to exposure to normal atmosphere. This oxidation of the top layer leads to 
formation of rectifying metal contacts which can degrade the performance of the device. Hence, in a solid state architecture, the fundamental components that can play a key role in the device performance are the surfaces and the interfaces between various layers of semiconductor device structures [72]. As the technology develops, it leads to reduction in the feature sizes [73], for cost effectiveness; hence the quality of the interfaces has become an increasingly important concern. Based on these studies, it was observed that, losses at the interfaces constitute a major fraction of the total losses in a device due the presence of parasitic resistances and capacitances present at contact interfaces [72]. This section will deal with various surface treatments employed prior to metallization for the removal of oxygen $(\mathrm{O})$ and carbon $(\mathrm{C})$, degreasing and removal of gross contamination.

Firstly, the surface is degreased [74] by treating it with Acetone and Methanol for 10 minutes at room temperature in an ultra-sonication chamber. This process will remove any organic contaminants present on the surface. The surface is then treated with HCL: DI water (1:1) for 2 minutes, this solution will result in minimum levels of residual $\mathrm{O}$ and $\mathrm{C}$. HF based solutions (Buffered Oxide Etch) treatment for 3 minutes, resulted in more effective thermal desorption of $\mathrm{C}$ from the surfaces [72].

\subsubsection{Photolithography}

Photolithography is defined as, a process in which, patterning is done, to selectively remove parts of a thin film or the bulk of a substrate. In this process, a light sensitive material called, photo resist is spun over the substrate and a pattern is transferred from a photo mask on to the film using UV light exposure. Depending upon the wavelength of the deep UV light and mask used, we can create extremely small patterns up to a few tens of nanometers in size, with exact control over the shape and size [75]. Its main disadvantages are that it requires a flat substrate to start with, it is not very effective at creating shapes that are not flat, and it can require extremely clean operating conditions and high maintenance tools. The photo-resist does not stick well to the substrate if moisture or contaminants are present on the surface. So after degrease, the wafer is initially baked to a temperature sufficient to drive off any moisture that may be present on the wafer surface. After heating the substrate, for better adhesion of photo resist to the substrate, Bis (trimethylsilyl) amine ("hexamethyldisilazane", HMDS), is applied [76]. 


\subsubsection{Positive photolithography}

The substrate is spin coated with HMDS at 7500rpm for 20 to 40 seconds, and produces a layer between 0.5 to 1 microns thick. A viscous, liquid solution of AZ 4400 photoresist is dispensed onto the coated HMDS, and the substrate is spun rapidly to produce a uniformly thick layer. The spin coating typically runs at $4000 \mathrm{rpm}$ for 30 seconds, and produces a layer of $\sim 4.6$ microns thick. The spin coating process results in a uniform thin layer, usually with uniformity of within 5 to 10 nano-meters. This uniformity can be explained by detailed fluid-mechanical modeling, which shows that the resist moves much faster at the top of the layer than at the bottom, where viscous forces bind the resist to the wafer surface. Thus, the top layer of resist is quickly ejected from the wafer's edge while the bottom layer still creeps slowly radially along the wafer. In this way, any bump or ridge of resist is removed, leaving a very flat layer. The photo resist-coated wafer is then prebaked to drive off excess photoresist solvent, typically at 90 to $100{ }^{\circ} \mathrm{C}$ for 100 to 120 seconds on a hotplate.

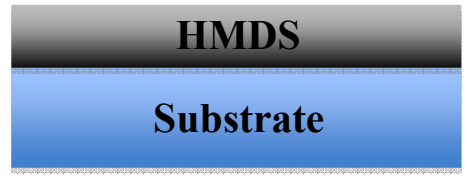

(a) HMDS coated on substrate

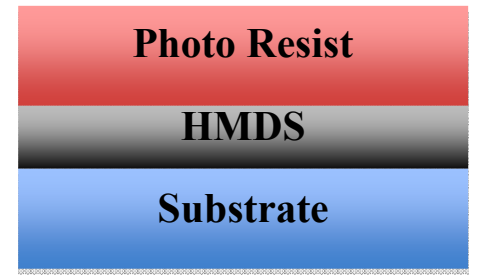

(b) PR coated on HMDS

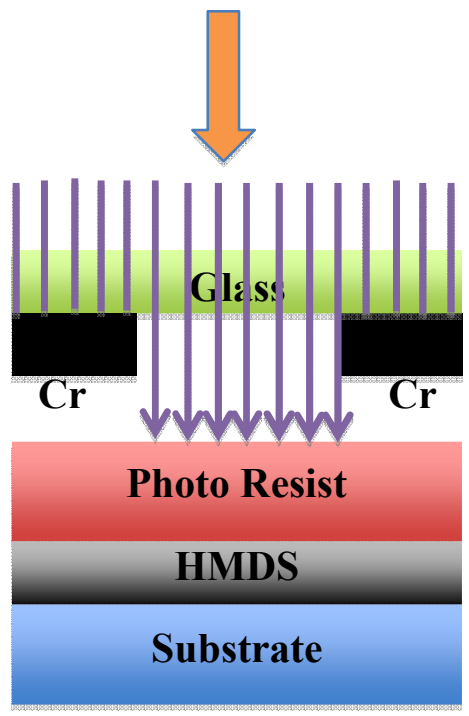

(c) Expose to UV light

(d) Develop and remove PR exposed to UV light

Figure 3.2: Illustration of Positive Photo-lithography process 
The prebaked photo resist coated substrate is placed on a mask aligner and exposed with $320 \mathrm{~nm}$ UV light of Intensity $250 \mathrm{~mJ} / \mathrm{cm}^{2}$. The mask has a chrome pattern on glass. After exposure, the positive photo resist is treated in the basic developer AZ $400 \mathrm{~K}$ for approximately 150 seconds to get the developed pattern. For a positive photolithography process, the $\mathrm{Cr}$ metal pattern on the mask will be transferred on to the substrate. The detailed process flow is shown in the Figure 3.2 above.
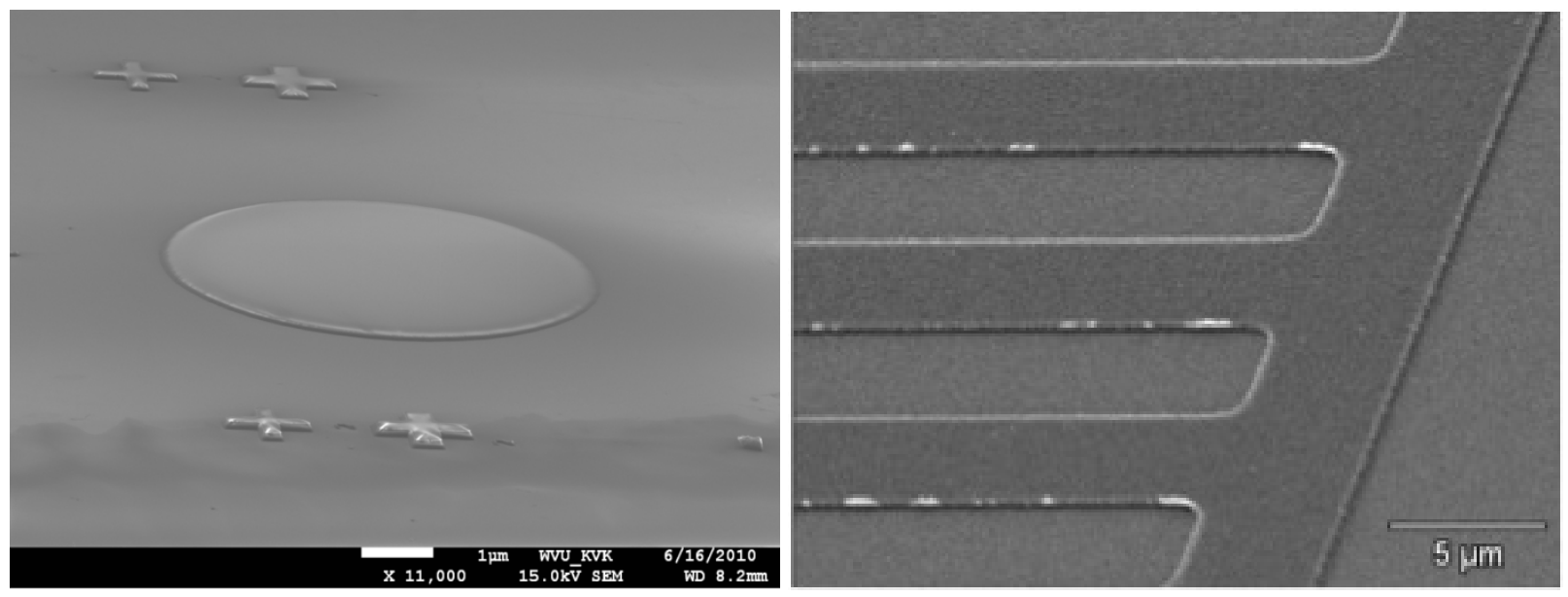

Figure 3.3: SEM Images of, left, Positive photo-lithography, right, image reversal PR pattern

\subsubsection{Image reversal photolithography}

The Figure 3.3 shows the Scanning Electron Microscopy (SEM) images of both the kinds of photo lithography used in this work. In image reversal photo lithography, the substrate is spin coated with HMDS at 7500rpm for 20 to 40 seconds, and produces a layer between 0.5 to 1 microns thick. A viscous, liquid solution of AZ 5214 EIR photoresist is dispensed onto the coated HMDS, and the substrate is spun rapidly to produce a uniformly thick layer. The spin coating typically runs at $4000 \mathrm{rpm}$ for 30 seconds, and produces a layer of $\sim 1.46$ microns thick. The photo resist-coated wafer is then prebaked to drive off excess photoresist solvent, typically at 90 to $100{ }^{\circ} \mathrm{C}$ for 45 to 60 seconds on a hotplate. The prebaked photo resist coated substrate is placed on a mask aligner and exposed with $320 \mathrm{~nm}$ UV light of intensity $50 \mathrm{~mJ} / \mathrm{cm}^{2}$. The mask has a chrome pattern on glass. After exposure, the photo resist is image reversal baked at temperatures 115 to $125{ }^{\circ} \mathrm{C}$ for 120 seconds. The image reversal bake 
will make the PR (polymer) cross linking at temperatures above $110{ }^{\circ} \mathrm{C}$. After image reversal bake, the PR is treated with UV Flood Exposure system, with $365 \mathrm{~nm}$ UV light of $2000 \mathrm{~mJ}$ intensity. It is treated in the basic developer AZ 300MIF for approximately 45 seconds to get the developed pattern. For an image reversal photo-lithography process, the area other than $\mathrm{Cr}$ metal on the mask will be transferred on to the substrate. The detailed process flow is explained in the Figure 3.4.

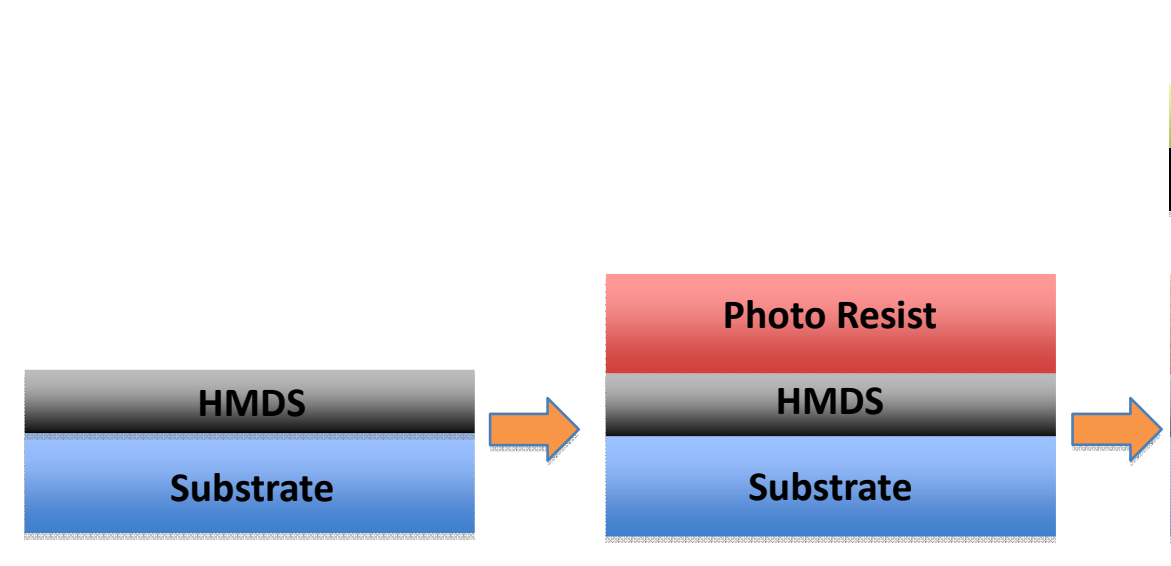

(a) HMDS coated on substrate

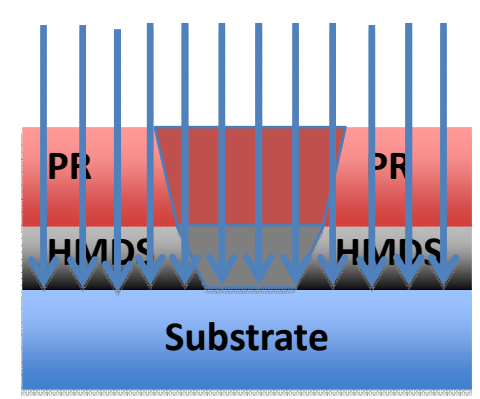

(f) Flood exposure (no mask) (b) PR coated on HMDS

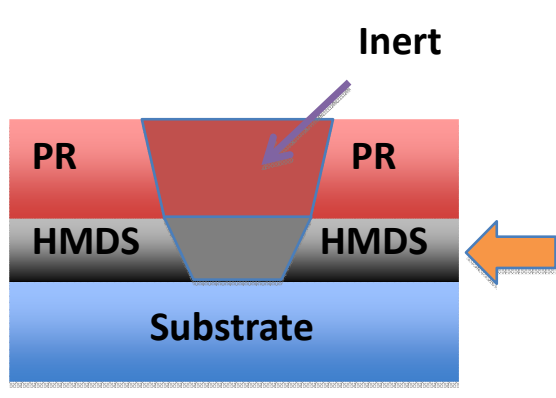

(e) The reversal bake crosslinks the exposed area

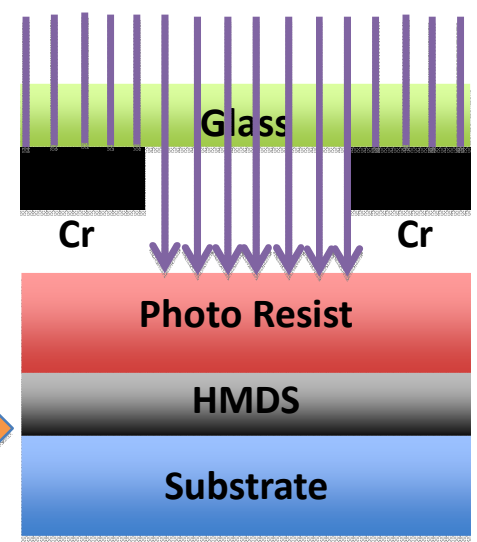

(c) Expose to UV light

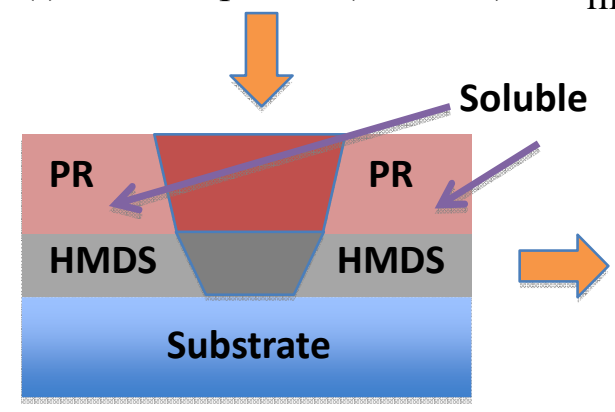

(g) PR not exposed in the fourth step is soluble in developer

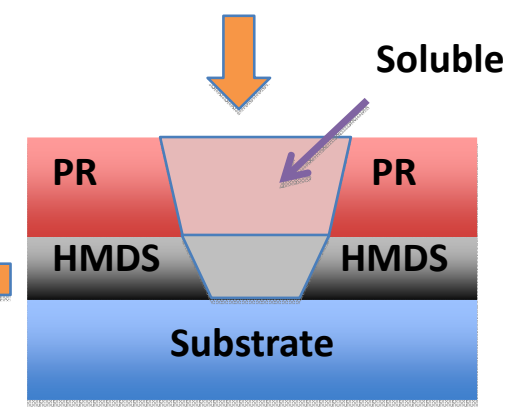

(d) The resist would behave like a positive resist

Figure 3.4: Illustration of Image reversal photo-lithography process 


\subsubsection{Dry Etching}

Wet etching used to be the key technology to integrated circuit manufacturing until the late 1960's, with low cost and good selectivity. As feature sizes reduced due to the developments in the technology, for micron and sub-micron sized patterns, this was not effective. The main disadvantage of this technology is, isotropic etching leads to under cutting of the mask material, limiting the minimum size of the feature size [77]. An alternate method, plasma etching (dry etching) was developed in order to meet the growing semiconductor industry requirements. Plasma etching is chosen because; it performs an-isotropic etching to create high aspect ratio features with high yield [78].

In a dry etching technique, plasma is used to employ high energy ion beams to chemically and mechanically remove material from the substrate. A simple plasma reactor chamber is shown in the Figure 3.6. In this chamber, wafers that need to be etched are placed on the lower electrode. Now, gases are introduced in to the chamber through inlets. Using the RF power source, plasma is struck, breaking the gas molecules into ions. These ions are accelerated towards the wafer using a power source, reacting with the surface of the wafers. The material etched will form a gaseous mixture and will be removed using the gas outlets. A RF source is used instead of DC power sources to prevent any charge accumulation over the insulators. The basic etch profile in dry and wet etching is shown in the Figure 3.5. Plasma etch leads to a largely anisotropic etch profile.

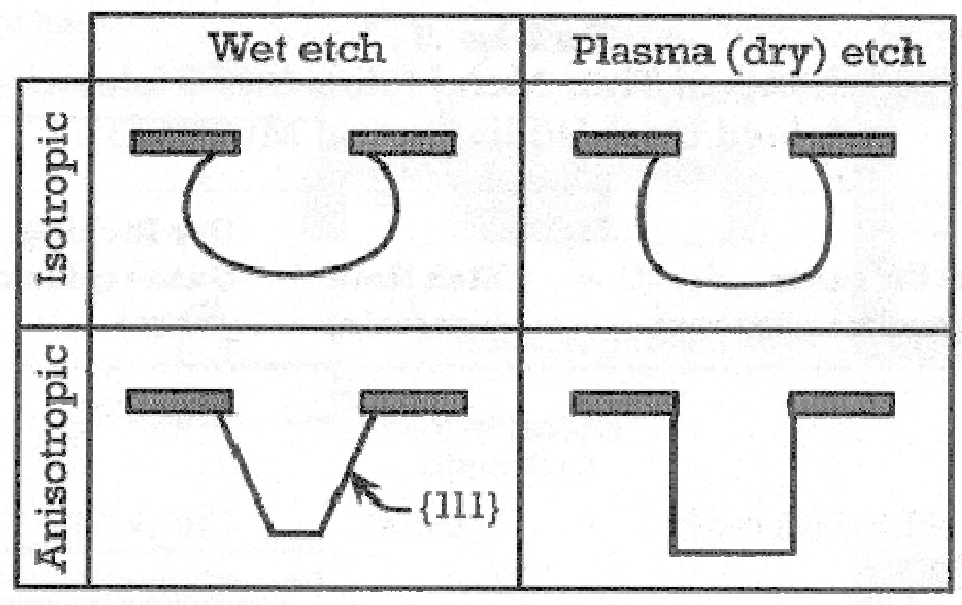

Figure 3.5: Cross sections of different etch profiles by different etch mechanisms [80] 
In a dry etch mechanism, there will be many parameters that need to be optimized for each different material like, gases used, gas flow rates, chamber pressure, RF power to generate plasma, and the RIE power to accelerate ions towards the substrate. Each parameter affects the etch profile differently. For example, if the RIE power is higher than optimum, there will be more ions colliding rapidly, causing etch damage and higher etch rates etc. So each parameter plays a vital role is obtaining the desired etch profile.

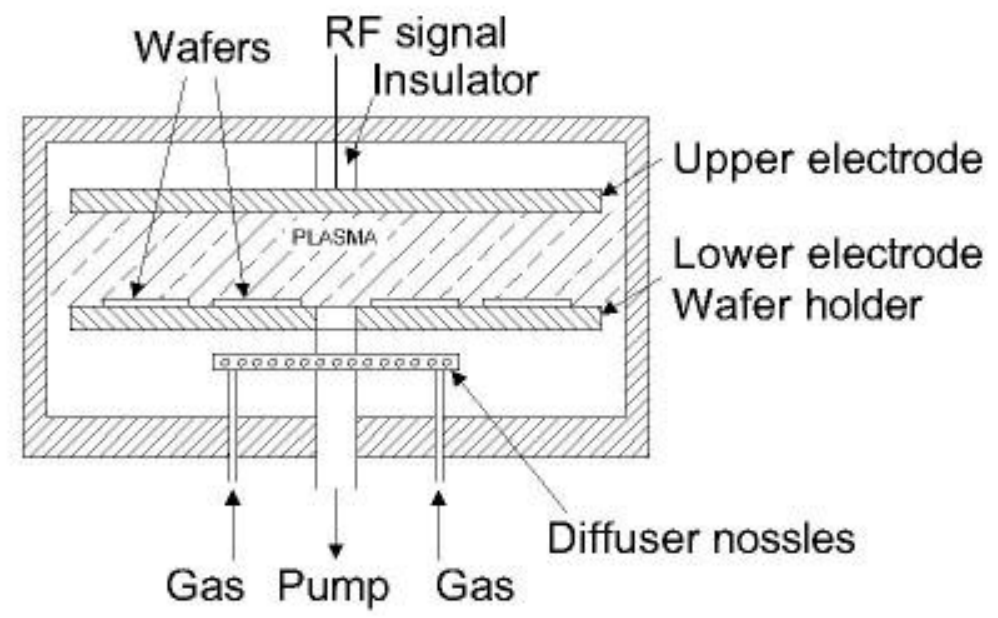

Figure 3.6: Schematic of a simple plasma reactor [79]

The etch metrics that were considered primarily were, etch rate, selectivity, etch profile, plasma damage [81]. Etch rate is the measure of how fast the material being etched is removed from the wafer surface. It will be the difference between the rates of generation and loss of the reactive species. Selectivity is the relative etch rate of film to be etched to the rate of another material under similar conditions [81]. Etch profile is the evaluated based on the lateral and vertical etch depths. If the lateral and vertical etch depths are equal, then it is called isotropic etching [82]. If the lateral etch depth is lower than that of the vertical etch depth, then it is called anisotropic etching and the degree of anisotropy is given by equation 3.1[83].

$$
A=1-\frac{l}{h}
$$

Where, 1 is the lateral etch rate and $\mathrm{h}$ is the vertical etch rate. If the value of degree of anisotropy is close to one, then it is anisotropic, or if it is 1 , then it is called perfect anisotropy and if it is zero, then it is perfect isotropy profile. 
Table 3.1: Feed gases for various materials plasma etching [84]

\begin{tabular}{|c|c|c|c|}
\hline Source gas & Additive & Materials etched & Selective Over \\
\hline $\mathbf{C l}_{2}$ & $\mathrm{C}_{2} \mathrm{~F}_{6}, \mathrm{SiCl}_{4}$ & n-doped $\mathrm{Si}$ & $\mathrm{SiO}_{2}$ \\
\hline $\mathbf{C l}_{2}, \mathbf{C C l}_{4}, \mathbf{S i C l}_{\mathbf{4}}$ & $\mathrm{O}_{2}$ & $\mathrm{Si}$ & $\mathrm{SiO}_{2}$ \\
\hline $\mathbf{C l}_{\mathbf{2}}$ & $\mathrm{SiCl}_{4}, \mathrm{CCl}_{4}, \mathrm{BCl}_{3}$ & $\mathrm{Al}$ & $\mathrm{SiO}_{2}$, Resists \\
\hline $\mathbf{C l}_{\mathbf{2}}$ & $\mathrm{BCl}_{3}, \mathrm{CCl}_{4}, \mathrm{O}_{2}$ & III-V Semiconductors & $\mathrm{SiO}_{2}, \mathrm{Resists}$ \\
\hline $\mathbf{C l}_{\mathbf{2}}$ & $\mathrm{O}_{2}, \mathrm{H}_{2} \mathrm{O}$ & III-V Alloys & $\mathrm{SiO}_{2}, \mathrm{Si}_{3} \mathrm{~N}_{4}$ \\
\hline
\end{tabular}

In this work, we mainly dealt with etching of III-Nitride semiconductor materials like, $\mathrm{GaN}$ and $\mathrm{InGaN}$. The source gas is $\mathrm{Cl}_{2}$ and the additive is $\mathrm{BCl}_{3}$ as shown in the Table 3.1. Photo resist, $\mathrm{SiO}_{2}$ and $\mathrm{Ni}$ are the primary masking materials used [85]. These sections deal with the determined selectivity and etch rates and the resulting etches profiles of $\mathrm{GaN}$ with $\mathrm{PR}$ and $\mathrm{SiO}_{2}$.

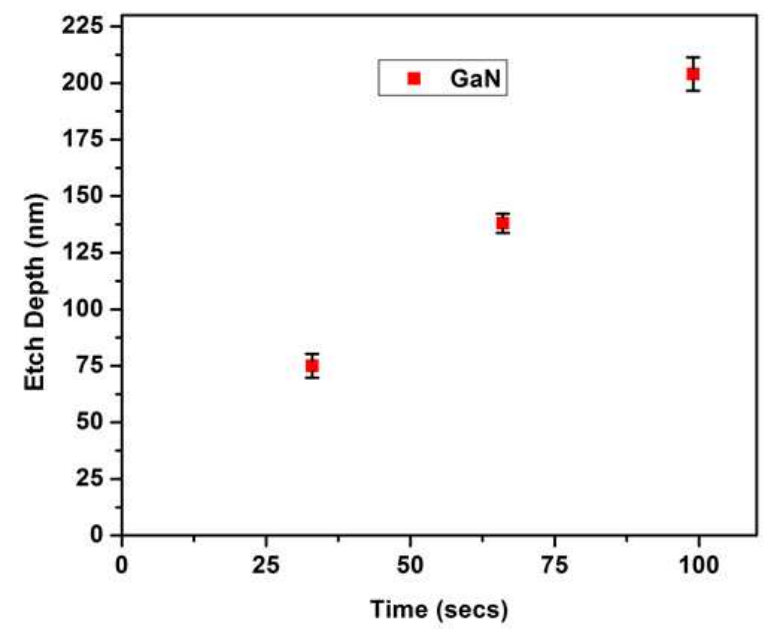

Figure 3.7: Etch rate of $\mathrm{GaN}$ using $30 \mathrm{sccm} \mathrm{BCl}_{3} / \mathrm{Cl}_{2}$

The GaN samples were grown in a MOVPE (Metal Organic Vapour Phase Epitaxy) chamber by Dr. Korakakis's group. The sample is p-GaN, grown on a sapphire substrate with thickness around $1 \mu \mathrm{m}$. All the samples were degreased with acetone, methanol 
and DI water using ultra sonication for 10 minutes. The samples were dipped in Buffered Oxide Etch (BOE) for 3 minutes and Dilute $\mathrm{HCl}(1: 1)$ for 1 minute to remove the native oxides from the surface of $\mathrm{GaN}$ and then dried using $\mathrm{N}_{2}$ gun. A positive photo resist AZ 4400 is patterned on top of GaN samples and hard baked for 20 minutes. Etching is done using Trion's ICP-RIE system. The etch parameters that were used in this work are a chamber pressure of $10 \mathrm{mT}$, ICP power of $300 \mathrm{~W}$, RIE power of $100 \mathrm{~W}$, and total mixture of $\mathrm{BCl}_{3} / \mathrm{Cl}_{2}$ gases of $30 \mathrm{sccm}$. The chamber pressure and total gas mixture is kept constant and other parameters such as ICP and RIE powers are altered to find optimum powers that can be used to get the desired etch profiles and etch rates. The ratio of the gas flow $\mathrm{BCl}_{3} / \mathrm{Cl}_{2}$ that was used in this experiment was $10 \mathrm{sccm} /$ $20 \mathrm{sccm}$ respectively. The etch rate obtained with the parameters mentioned above, is shown in the Figure 3.7.

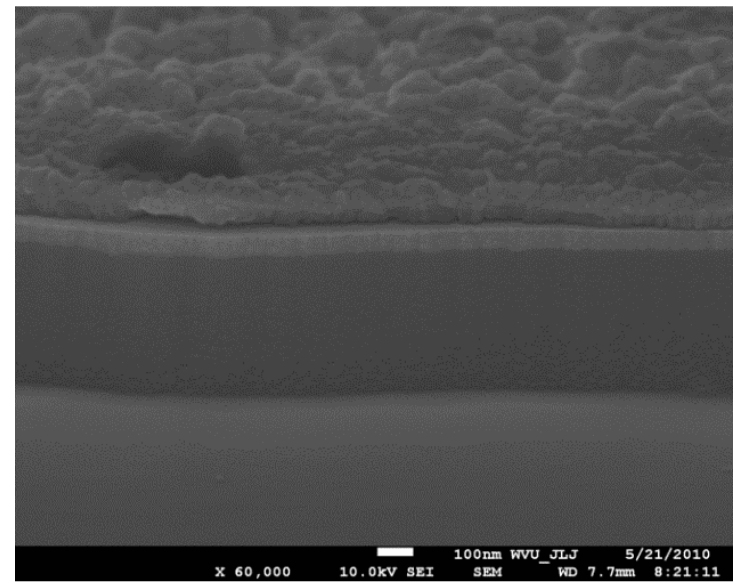

(a)

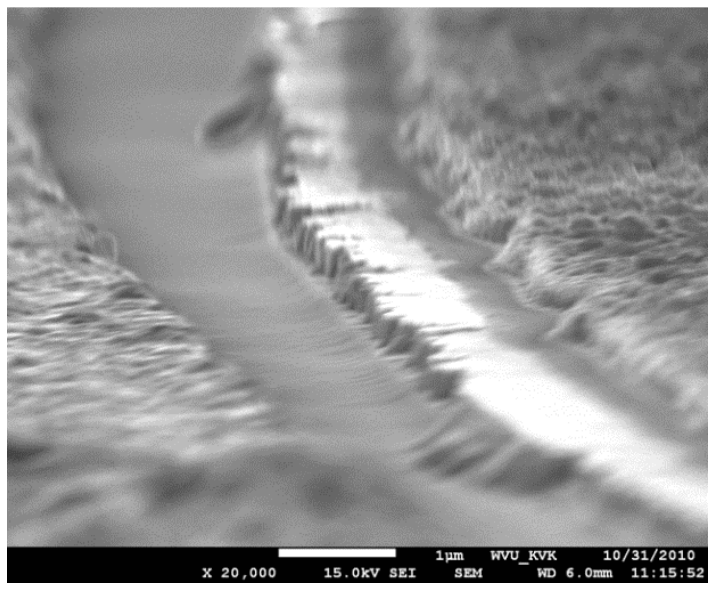

(c)

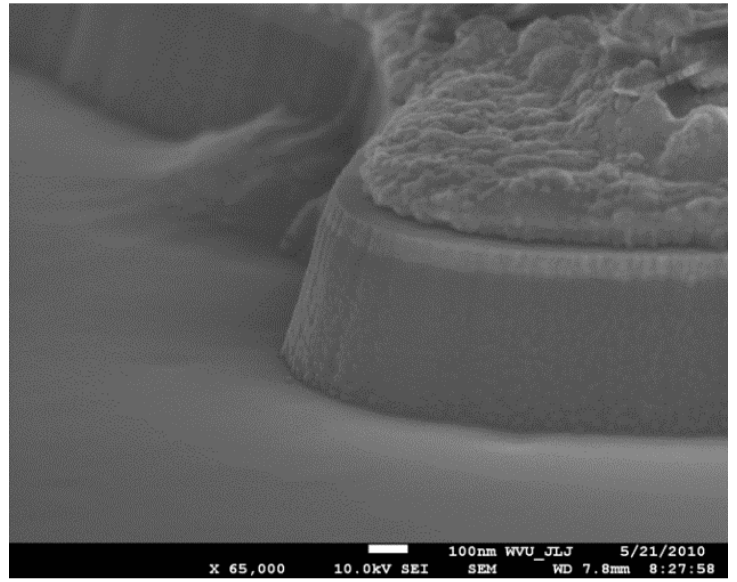

(b)

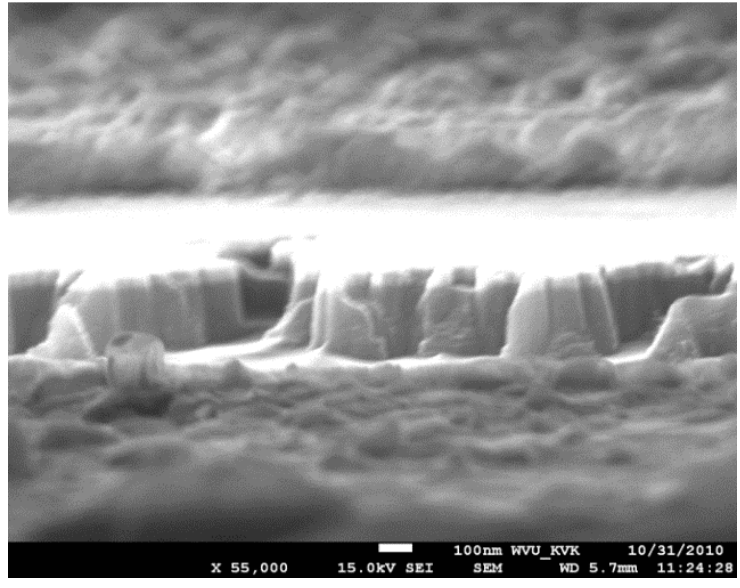

(d)

Figure 3.8: SEM Images of side wall angle and etch profiles of GaN, top, ICP/RIE powers $300 \mathrm{~W} / 100 \mathrm{~W}$, bottom, ICP/RIE powers $400 \mathrm{~W} / 150 \mathrm{~W}$. 
In the Figure 3.8, Scanning Electron Microscopy (SEM) images of the side wall angle and etch profile of etched GaN samples; under different ICP/RIE power conditions were shown. It can be observed that, etch damage was very less, as in Figure 3.8 ((a), (b)) when compared to Figure 3.8 ((c), (d)). The RIE power $150 \mathrm{~W}$ in the second case, increases the etch rate and side wall etch damage drastically, hence $100 \mathrm{~W}$ was found to be the optimum RIE power for better side wall and less etch damage. The etch selectivity values of GaN/PR, $\mathrm{GaN} / \mathrm{SiO}_{2}$ and $\mathrm{GaN} / \mathrm{Ni}$, were 2, 5 and 26 respectively, from the Profilometry calculations. It is better to use $\mathrm{SiO}_{2}$ or $\mathrm{Ni}$ as hard mask when compared to that of Photo resist based on selectivity measurements, but, it is hard to remove $\mathrm{Ni}$ and $\mathrm{SiO}_{2}$ after etching was done. Hence all the experiments in this work were done using PR as a hard mask to reduce complications in device fabrication process.

\subsubsection{Metallization}

The evaporation deposition mechanism is a common method of thin film deposition. The two different deposition methods that were used in this work were E-beam evaporation and sputtering deposition. In e-beam evaporation, a source material is placed in a crucible and high energy electron beam is concentrated on the target in order to melt the material. This process is done under high vacuum condition. The vacuum allows vapor particles to travel directly towards the substrate, where they condense back to form a solid thin film [86]. In a sputtering evaporation deposition, the material from the target (source) is ejected and deposited on to the substrate.

The different metal configurations that are used in this work are $\mathrm{Ni} / \mathrm{Au}, \mathrm{Ni} / \mathrm{Ag} / \mathrm{Pt} / \mathrm{Ni} / \mathrm{Au}$ and $\mathrm{Ni} / \mathrm{ZnO}$ contacts as the electrode on the $\mathrm{p}-\mathrm{GaN}$ substrate and $\mathrm{Ti} / \mathrm{Al} / \mathrm{Ti} / \mathrm{Au}$ contacts as electrodes on $\mathrm{n}-\mathrm{GaN}$ substrate. The $\mathrm{Ni} / \mathrm{Ag} / \mathrm{Pt} / \mathrm{Ni} / \mathrm{Au}$ and $\mathrm{Ni} / \mathrm{ZnO}$ contact schemes were discussed in detail in Chapters 4 and 5. So, we will deal with the commonly used $\mathrm{Ni} / \mathrm{Au}$ and $\mathrm{Ti} / \mathrm{Al} / \mathrm{Ti} / \mathrm{Au}$ contacts in this chapter. The $\mathrm{p}-\mathrm{GaN}$ (70nm thick) and $\mathrm{n}-\mathrm{GaN}$ (1.5 microns thick) samples were grown in a MOVPE chamber. The p-GaN samples were annealed at $800^{\circ} \mathrm{C}$ in $\mathrm{N}_{2}$ ambient for 5 minutes to activate the $\mathrm{Mg}$ dopants. These samples were degreased and treated with acids like $\mathrm{HCl}$ and $\mathrm{BOE}$ to remove any native oxides present on the surface. The TLM and c-TLM patterns were transferred using AZ5214 EIR Image reversal PR. Using e-beam 
evaporation deposition, $\mathrm{Ni}(30 \mathrm{~nm}) / \mathrm{Au}(200 \mathrm{~nm})$ is deposited on the surface treated $\mathrm{p}-\mathrm{GaN}$ substrate. The deposited contacts were annealed at $600^{\circ} \mathrm{C}$ in $\mathrm{O}_{2}$ ambient for 3 minutes. Figure 3.9 gives the I-V between different contact pad spacing.

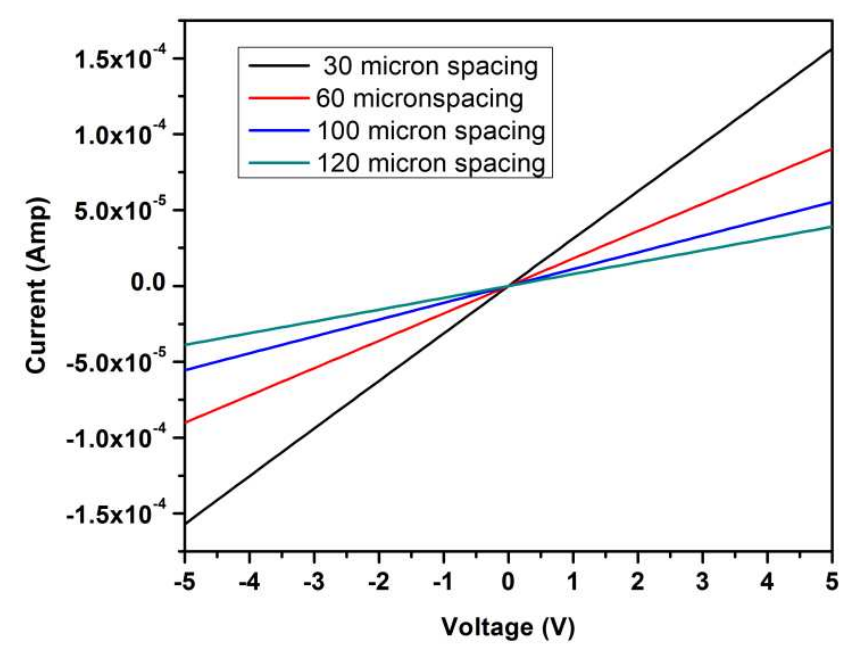

Figure 3.9: $\mathrm{I}-\mathrm{Vs}$ between different $\mathrm{Ni} / \mathrm{Au}$ contact pad spacing

From the I-Vs shown in Figure 3.9, the resistances were calculated for contacts with different pad spacing. A plot is made between the total resistance and the pad spacing, as shown in Figure 3.10. Using Origin 8.0, the data was fitted linearly and the specific contact resistance and transfer lengths were calculated from the plot. The specific contact resistivity value between $\mathrm{Ni}(30 \mathrm{~nm}) / \mathrm{Au}(200 \mathrm{~nm})$ and $\mathrm{p}-\mathrm{GaN}$ is calculated as $\mathbf{1 . 3 4 E - 2} \mathbf{~ o h m . c m} \mathbf{2}^{2}$.

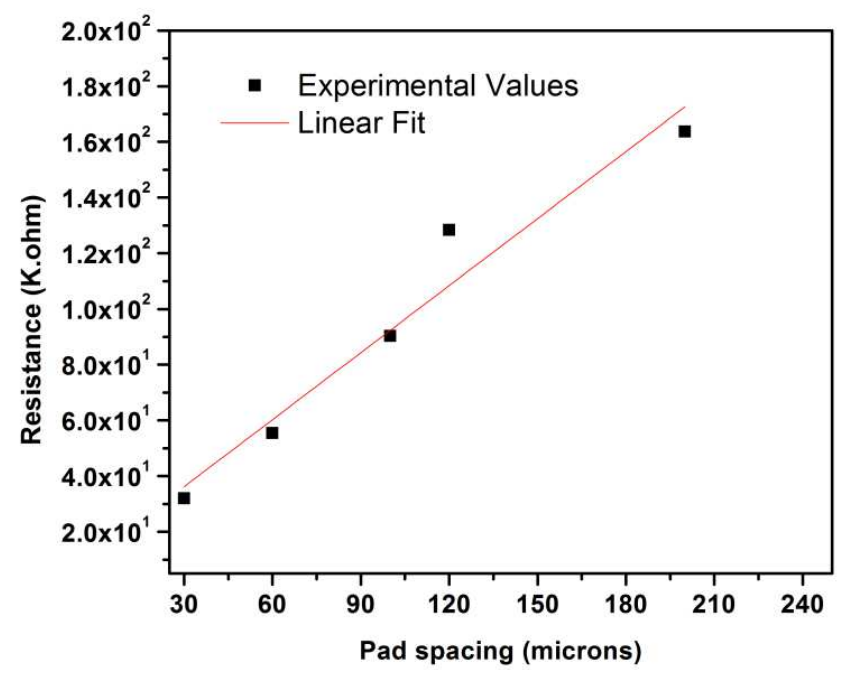

Figure 3.10: Resistance Vs contact pad spacing of rectangular TLM for $\mathrm{p}-\mathrm{GaN}$ 
In a similar study, Ti (2nm)/Al (100nm)/ Ti (30nm)/ Au (200nm) contact is deposited on a 1.5 microns thick $\mathrm{n}-\mathrm{GaN}$ substrate. It was annealed at $600^{\circ} \mathrm{C}$ in air for 3 minutes. Figure 3.11 gives us the I-Vs between $n-G a N$ and contact scheme.

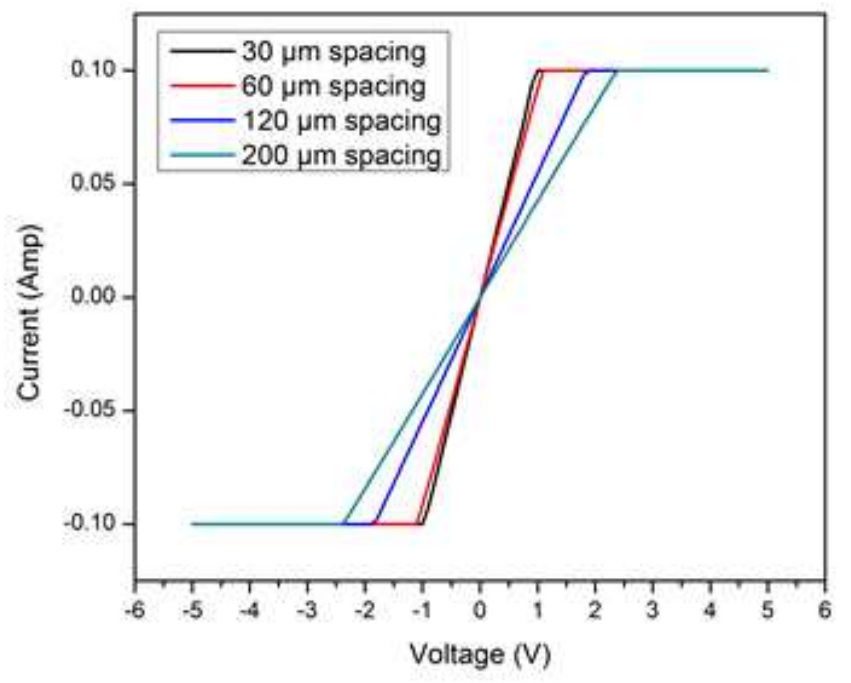

Figure 3.11: I-Vs between different Ti/Al/Ti/Au contact pad spacing with $n-G a N$

From the I-Vs, shown in Figure 3.11, the resistances were calculated for contacts with different pad spacing. A plot is made between the total resistance and the pad spacing, as shown in Figure 3.12. Using Origin 8.0, the data is fitted linearly; the specific contact resistance and transfer lengths were calculated from the plot. The specific contact resistivity value between $\mathrm{Ti}(2 \mathrm{~nm}) / \mathrm{Al}(100 \mathrm{~nm}) / \mathrm{Ti}(30 \mathrm{~nm}) / \mathrm{Au}(200 \mathrm{~nm})$ and $\mathrm{n}-\mathrm{GaN}$ is calculated as $5.43 \mathrm{E}-5 \mathrm{ohm} . \mathrm{cm}^{2}$.

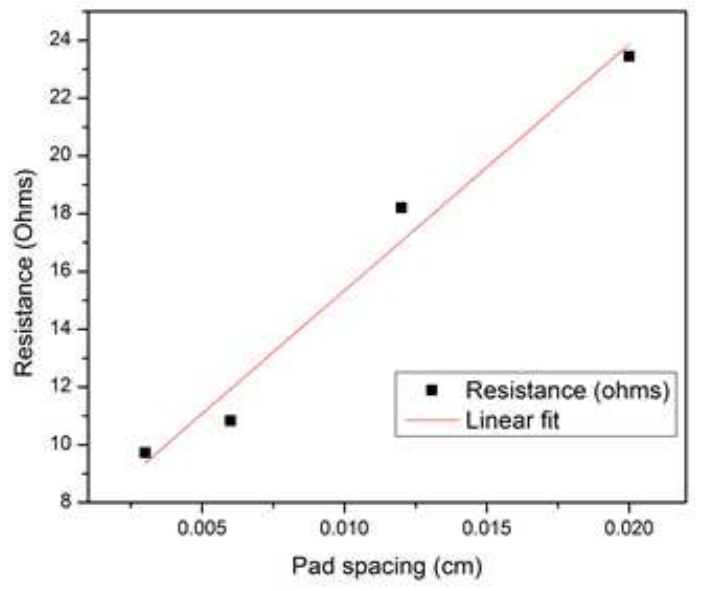

Figure 3.12: Resistance Vs contact pad spacing of rectangular TLM for $n-G a N$ 


\subsubsection{Rapid Thermal Annealing}

Rapid thermal annealing (RTA) is a process in which, a wafer is heated to high temperatures in order to modify its structural properties. It can be used to activate dopants, relax internal stress, diffuse materials in to interface, crystallize an amorphous layer [87]. RTA is an alternative to a standard furnace annealing, with short annealing times and precise control. The computer controlled annealing system that is used in this work in shown in the Figure 3.13.

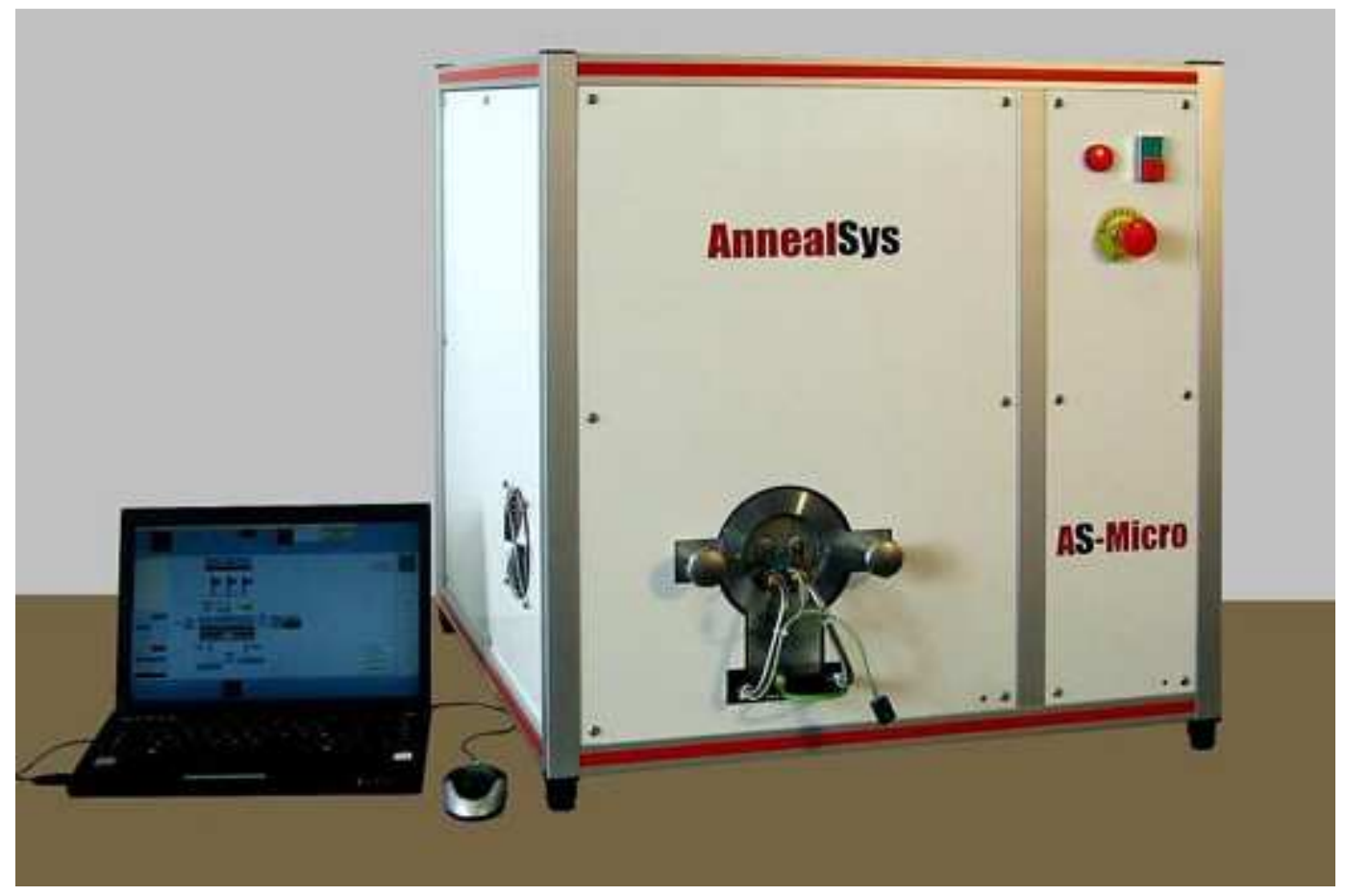

Figure 3.13: The Rapid Thermal Anneal system used in this experiment

The RTA system shown in the above figure consists of a small chamber which can be tightly sealed, to avoid any leakage of ambient gases while processing. The chamber is equipped with two rows of lamps that are necessary to supply sufficient amount of energy to heat the sample. The chamber is coated with reflective coatings to reduce thermal loss and improve the uniformity. This is a computer controlled system in which, a thermocouple is used to measure the chamber temperature, give the feedback in to the computer and adjusts the power given to the lamps to maintain uniform temperature during the process. 
A recipe is run separately for each different process. The first step is purging the chamber with $\mathrm{N}_{2}$, to remove any traces of unwanted gas during the process. The next step is filling the chamber with the chosen ambient gas. The next steps ramp up the heat in the chamber to a certain temperature, keeps it stable for a short while, again ramped up to the process temperature, run the process at hand and then ramp it down to the room temperature, as shown in the Figure 3.14. The substrate is cooled down till it reaches room temperature and once the chamber is at room temperature, the system can be opened.

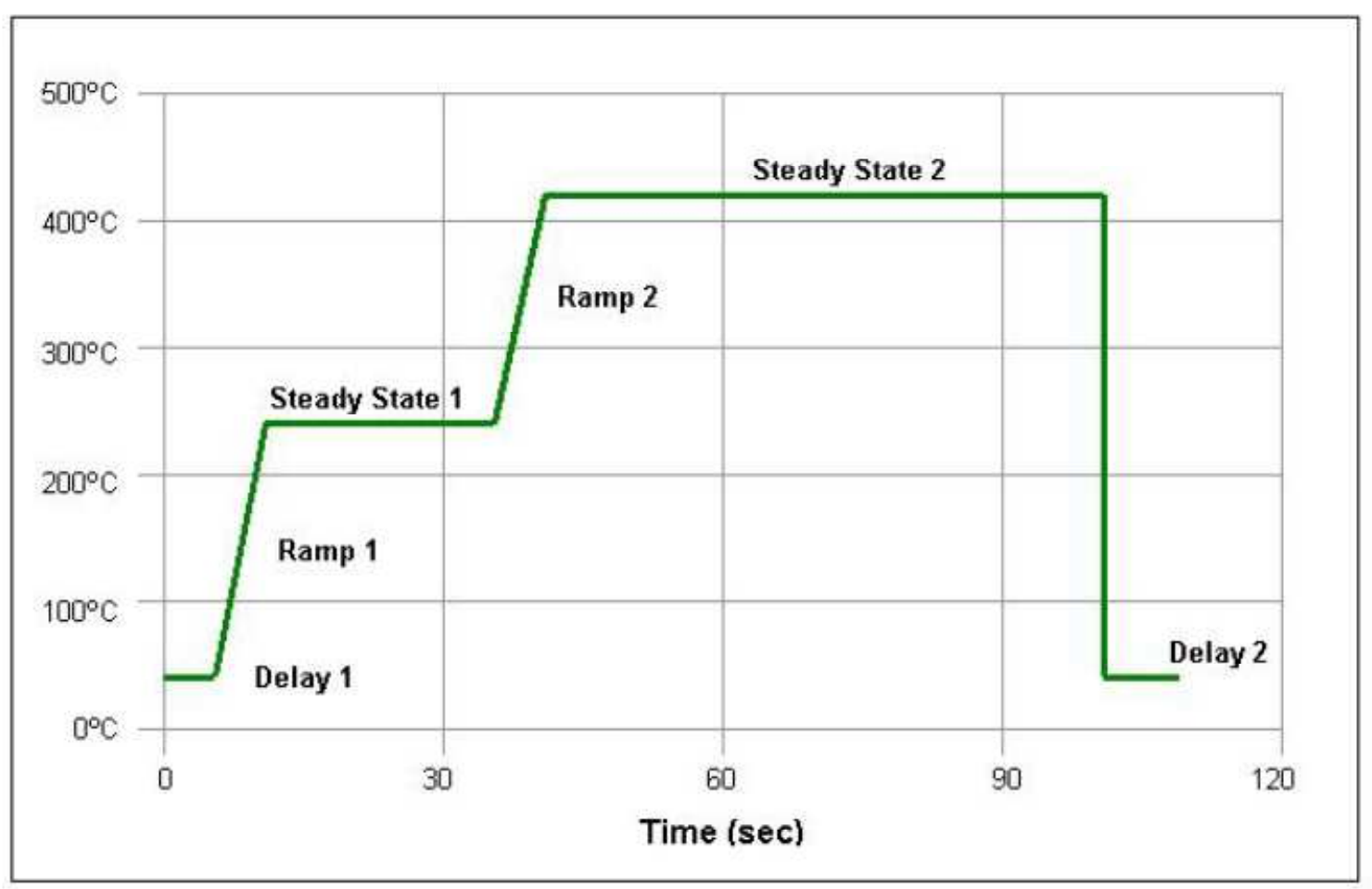

Figure 3.14: The Recipe in a RTA system [88].

Different annealing conditions are used in this work for different processes. The p-GaN is annealed at $800^{\circ} \mathrm{C}$ in $\mathrm{N}_{2}$ ambient for 5 minutes for activation of $\mathrm{Mg}$ dopants. Hall measurements were done on the $\mathrm{p}-\mathrm{GaN}$ samples and the above given conditions gave the best electrical properties in $\mathrm{p}-\mathrm{GaN}$ substrate. The $\mathrm{p}$ and $\mathrm{n}$ contacts to $\mathrm{GaN}$ were annealed at $600^{\circ} \mathrm{C}$ in $\mathrm{O}_{2}$ ambient for 3 minutes for better ohmic contacts. 


\section{Chapter 4}

\section{Electrical and Optical Properties of Ag based metallization scheme}

\subsection{Introduction}

The necessity to replace conventional lighting by solid-state lighting has led to much interest in the development of high brightness Gallium Nitride (GaN) Light Emitting Diodes (LEDs). Efficient LED structures such as a flip chip configurations and Resonant Cavity LEDs (RCLEDs) typically need a highly reflective ohmic contact on p-GaN. RCLEDs are of great interest due their features like, high spectral purity, and high emission intensity when compared conventional GaN based LEDs [89]. Au based contacts are not appropriate for the RCLEDs due to low reflectance in the blue region. Ag films have much higher reflectivity in the visible region when compared to Au films. Furthermore, metallic mirror films provide reflectivity over a wide wavelength range in comparison to the reflectivity of a Distributed Bragg Reflector (DBR) which is usually tuned to operate over a narrow wavelength range.

The metal contacts play a key role in the device performance such as, power consumption, reliability, and light extraction [90]. It is very difficult to achieve high performance $\mathrm{Ag}$ contacts on $\mathrm{p}-\mathrm{GaN}$ because of poor adhesion and post annealing effects including agglomeration, oxidation, and thermal instability [91]. A wide variety of metallization schemes with high work function metals, such as Ni [92-95] and Pt [96-98], have been employed to achieve low resistance ohmic contacts to p-type GaN. Among those schemes, Ni/Au is commonly used as a p-type ohmic electrode for GaN-based LEDs due to its reliably, low contact resistivity, and high light transmittance [99-101]. In this work, with the metallization scheme we used, all the above mentioned problems were addressed and high quality ohmic and reflective contacts were achieved. The importance of annealing the contacts in the $\mathrm{O}_{2}$ ambient is investigated by comparing the specific contact resistivity of the Ag-based contacts to p-GaN in $\mathrm{O}_{2}$ and $\mathrm{N}_{2}$ ambient. Furthermore, the variation in reflectivity and specific contact resistance with the post annealing temperatures is investigated. The interfacial reaction between the contact metal layers, evaluated by Sputter X-ray Photo-electron Spectroscopy (XPS), is also explored. 
Finally, the surface morphology variation with and without the presence of the $\mathrm{Pt}$ as the diffusion barrier layer based on the AFM results will be presented.

Low resistance and high reflectance ohmic contacts on p-type GaN were achieved using an Ag-based metallization scheme. The ohmic nature of the contacts can be obtained by annealing the contacts in the $\mathrm{O}_{2}$ ambient. However, Ag-based contacts degrade due to agglomeration of $\mathrm{Ag}$ when annealed above $400{ }^{\circ} \mathrm{C}$ [102]. In this work a $\mathrm{Ni}(1 \mathrm{~nm}) / \mathrm{Ag}(150$ $\mathrm{nm}) / \mathrm{Pt}(50 \mathrm{~nm}) / \mathrm{Ni}(20 \mathrm{~nm}) / \mathrm{Au}(50 \mathrm{~nm})$ metallization stack is investigated to reduce $\mathrm{Ag}$ agglomeration. The inclusion of platinum as a diffusion barrier is expected to suppress excess oxygen diffusion into the Ag films thereby preventing Ag agglomeration and can also provide high thermal stability when compared to other metallization schemes. The reflectivity of this kind of metallization scheme is around $85-90 \%$ in the wavelength range of 400-600 nm making it suitable for blue and green LEDs, with a specific contact resistivity value comparable to other well developed contacts to $\mathrm{p}-\mathrm{GaN}$.

\subsection{Experiment}

Mg-doped p-type GaN films used in this work were grown on (0001) sapphire substrate using Metal Organic Vapor Phase Epitaxy (MOVPE) in an Aixtron 200/4 RF$\mathrm{S}$ reactor by Dr. Korakakis's group. The $\mathrm{Mg}$ dopants were activated in the $\mathrm{p}-\mathrm{GaN}$ by Rapid Thermal Annealing (RTA) at $800^{\circ} \mathrm{C}$ for $5 \mathrm{~min}$. The p-GaN samples were then degreased by ultrasonication in acetone and methanol for 5 min each and were rinsed in DI water. The p-GaN samples were surface treated in 10:1 Buffered Oxide Etch (BOE) for 3 min and then in HCl: DI (1:1) for $1 \mathrm{~min}$ to remove any native surface oxides that were present. The c-TLM (Circular Transmission Line Method) pattern, as shown in Figure 4.1, was then transferred to the sample using AZ 5214 E photo-resist and standard image reversal photolithography techniques. The $\mathrm{Ni}$ $(30 \mathrm{~nm}) / \mathrm{Au}(200 \mathrm{~nm})$ and $\mathrm{Ni}(1 \mathrm{~nm}) / \mathrm{Ag}(150 \mathrm{~nm}) / \mathrm{Pt}(50 \mathrm{~nm}) / \mathrm{Ni}(20 \mathrm{~nm}) / \mathrm{Au}(50 \mathrm{~nm})$ metallization scheme that is mentioned above was deposited using electron beam evaporation system (Temescal BJD-2000 CV 6S) at a base pressure of 1E-05 Torr for comparison. After lifting-off of the metals deposited on the photo resist, the metals were annealed at temperatures from $300{ }^{\circ} \mathrm{C}$ to $700{ }^{\circ} \mathrm{C}$ for $3 \mathrm{~min}$ in a Rapid Thermal Annealing (RTA) chamber in $\mathrm{O}_{2}$ and $\mathrm{N}_{2}$ 
ambient. The current-voltage (I-V) characteristics were measured using a semiconductor parameter analyzer. The light reflectance measurements were performed using a Xenon lamp and a spectrometer. A Pyrex mirror of $96 \%$ reflectivity is used as a standard reference. X-ray Photoelectron Spectroscopy (XPS) and Atomic Force Microscopy (AFM) were used to examine the interfacial contact layers and surface morphology respectively, before and after annealing.
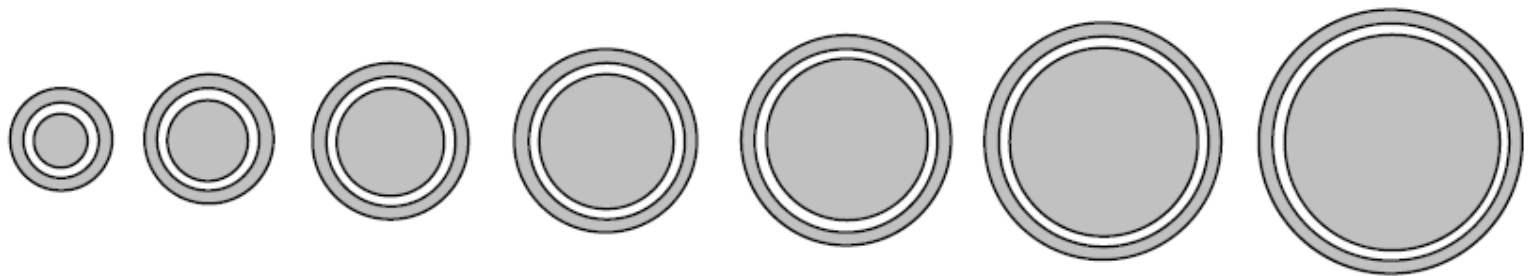

Figure 4.1: C-TLM Pattern that was used to find the specific contact resistivity between p-GaN and the Ag based metal contact.

\subsection{Characterization}

The Ag based metallization scheme that was deposited on $\mathrm{p}-\mathrm{GaN}$ substrates using the experimental procedure that was discussed in the previous section can be characterized by several different techniques such as, the surface morphology and roughness can be characterized using the Scanning Electron Microscopy (SEM) and Atomic Force Microscopy (AFM) respectively. The interfacial contact layers and the oxygen in diffusion can be studied using the X-ray Photoelectron spectroscopy (Depth profiling XPS) studies.

\subsubsection{Atomic Force Microscopy (AFM)}

Atomic Force Microscopy (AFM) is a high-resolution imaging technique that can resolve features as small as an atomic lattice in real space. It is useful to observe and manipulate the molecular and atomic level features [103]. In this experiment we used a Tapping mode AFM. The AFM works by bringing a cantilever tip in contact to the surface to be imaged. An ionic repulsive force from the surface applied to the tip bends the cantilever upwards. The amount of bending, measured by a laser spot reflected on to a split photo detector, 
can be used to calculate the force. By keeping the force constant while scanning the tip across the surface, the vertical movement of the tip follows the surface profile and is recorded as the surface topography by the AFM. AFM has much broader potential and application because it can be used for imaging any conducting or non-conducting surface.

The setup that is used for this AFM experiment is shown in Figure 4.2. The AFM works based on the principle that, whenever there is atomic force acting on the tip there will be movement of the tip, so indeed it causes a deflection of the light that is focused on cantilever from a laser source. The deflection that is caused in the reflected laser light to the photo detector will be used to study the topography of the surface of the sample.

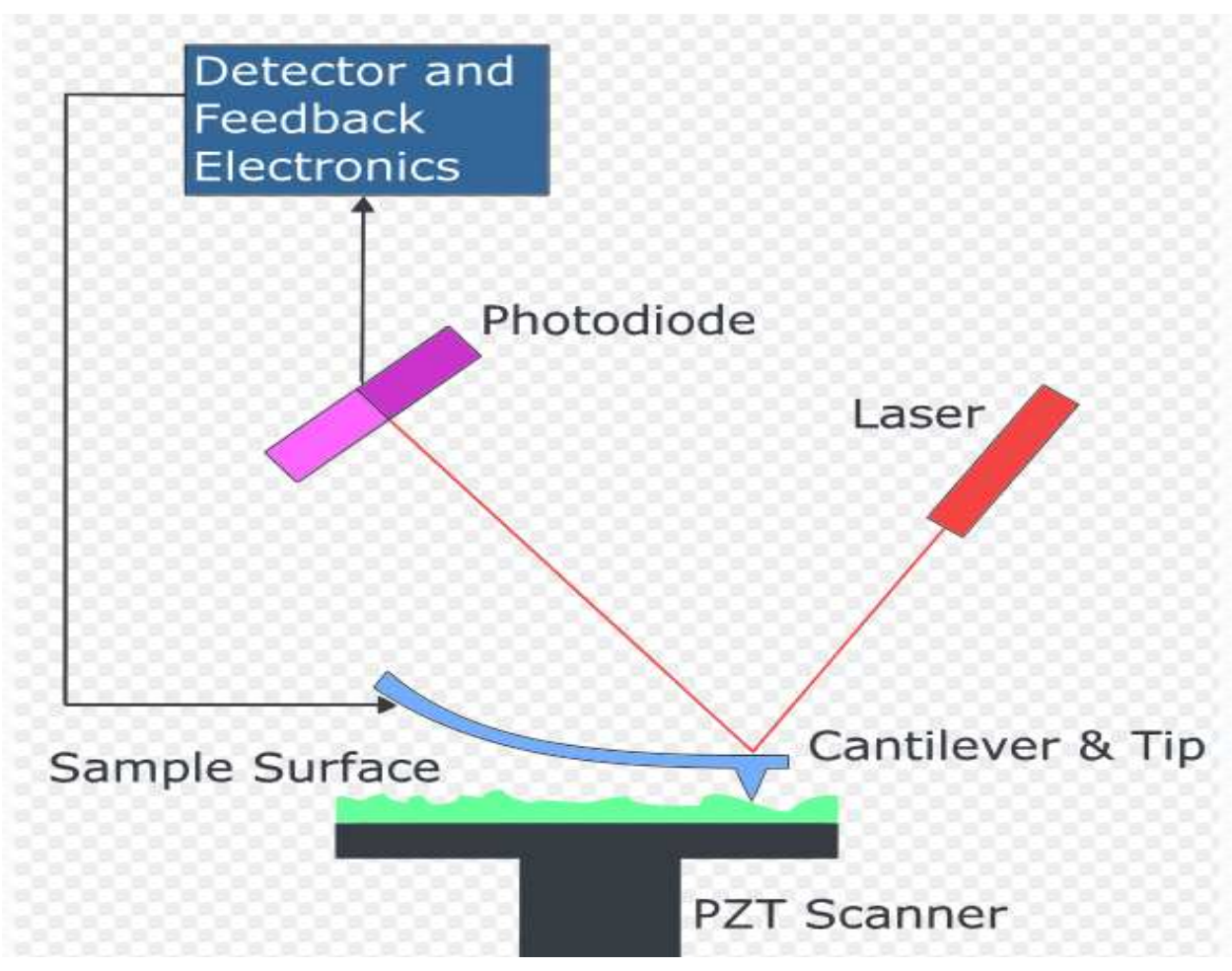

Figure 4.2: The schematic of Atomic Force Microscopy (AFM) setup used in this experiment [103].

The experimental procedure follows the following steps; firstly we discuss the scanner. The scanner used for this AFM setup is from the Pico Scan 3000 series. This scanner is based on the principle of a Piezo electric ceramic. The tip is attached to the scanner; if 
a voltage is applied to the ceramic it moves and causes a deflection of the laser beam. Now as the setup is attached to a computer, we need to find out the resonance frequency of the tip. At resonance the system is most sensitive; however we need to have this done at a frequency close to resonance but not at resonance. The resonance phenomenon depends on the material and geometry of the tip. Sometimes there will be some contaminants placed on the tip which alters its resonance frequency. In general, the resonance frequency range is between $(200-400 \mathrm{KHz})[103]$. A light source is used to see the tip using an optical microscope. Now using the Pico scan software, after the frequency at which resonance occurs is found out, we altered the operating frequency to be $\mathbf{f}=\mathbf{2 9 1 . 4 2 7} \mathbf{K H z}$. The amplitude of resonance voltage will be in the range of 48V. The AFM Tip used in the experiment has the following specifications. The Material with which the tip is made of is n-type Silicon 0.001-0.025 $\Omega / \mathbf{c m}$. The cantilever that is used is having the dimensions Length $\mathbf{L}=\mathbf{1 2 5} \boldsymbol{\mu m}$ and Width $\mathbf{W}=\mathbf{4 5} \boldsymbol{\mu m}$ and Thickness $\mathbf{T}=\mathbf{4} \boldsymbol{\mu m}$. The Tip radius $<10 \mathrm{~nm}$, height $\mathbf{H}=\mathbf{1 2 - 1 6 \mu m}$, Operating frequency is in the range $200-400 \mathrm{KHz}$. The spring constant $\mathbf{K}=\mathbf{2 5 - 7 5} \mathbf{N} / \mathbf{m}$.

Based on the annealing studies performed, it was determined that the Ag based metallization scheme, $\mathrm{Ni}(1 \mathrm{~nm}) / \mathrm{Ag}(150 \mathrm{~nm}) / \mathrm{Pt}(50 \mathrm{~nm}) / \mathrm{Ni}(20 \mathrm{~nm}) / \mathrm{Au}(50 \mathrm{~nm})$ was more stable and less rough after performing post annealing treatments. The study is carried out with and without the presence of $\mathrm{Pt}$ as $\mathrm{O}_{2}$ diffusion barrier layer. The Ag-based metallization scheme should be annealed above $400{ }^{\circ} \mathrm{C}$ to form an ohmic contact with the p-GaN. However, annealing the contact at temperatures above $400{ }^{\circ} \mathrm{C}$ leads to an agglomeration of $\mathrm{Ag}$, which indeed reduces the reflectivity. Therefore, Pt was deposited on top of the Ag layer as oxygen diffusion barrier layer to minimize the agglomeration.

The annealing conditions that were used in this experiment were $380{ }^{\circ} \mathrm{C}, 430{ }^{\circ} \mathrm{C}$ and $480{ }^{\circ} \mathrm{C}$. Further increase in the annealing temperature did degrade the contacts in terms of increase in the specific contact resistance with the p-GAN. The study of the surface morphology of the contact with and without the presence of the Pt diffusion barrier at $380{ }^{\circ} \mathrm{C}$ temperature is shown in Figure 4.3. The RMS roughness of the contact without the presence of Pt diffusion barrier layer was $6.80 \mathbf{~ n m}$, and with the presence of Pt was $\mathbf{3 . 0 0} \mathbf{~ n m}$ at $380{ }^{\circ} \mathrm{C}$. 


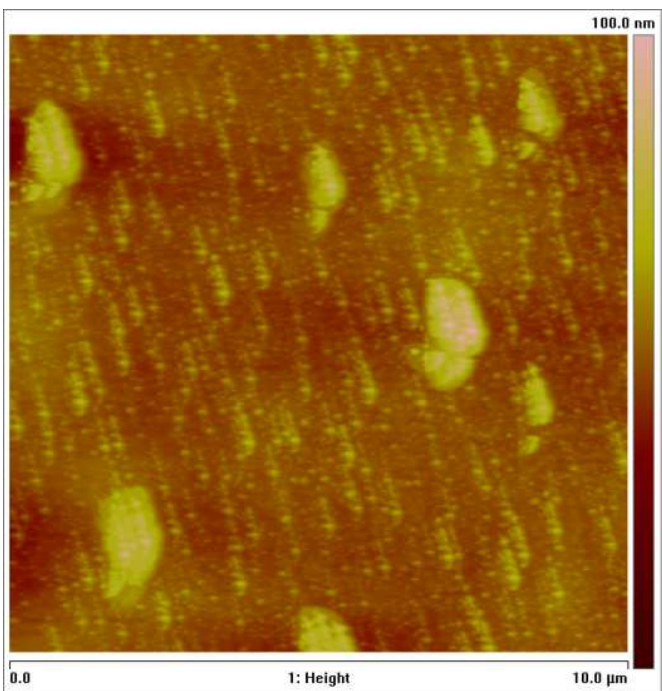

(a)

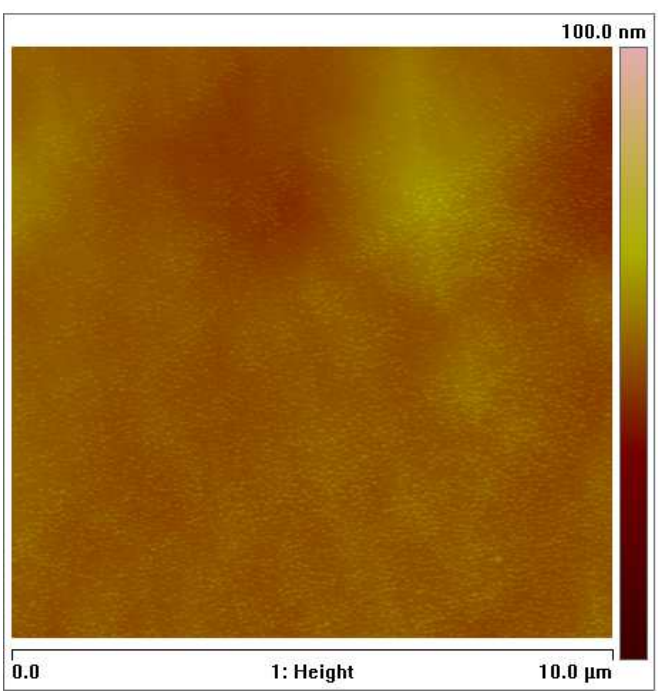

(b)

Figure 4.3: Surface morphology of (a) Ni/Ag contact, (b) Ni/Ag/Pt contact annealed at $380{ }^{\circ} \mathrm{C}$

The study of the surface morphology of the contact with and without the presence of the Pt diffusion barrier at $430{ }^{\circ} \mathrm{C}$ temperature is shown in the Figure 4.4. The RMS roughness of the contact without the presence of Pt diffusion barrier layer was $7.51 \mathbf{~ n m}$, and with the presence of Pt was $2.41 \mathbf{n m}$ at $430{ }^{\circ} \mathrm{C}$.

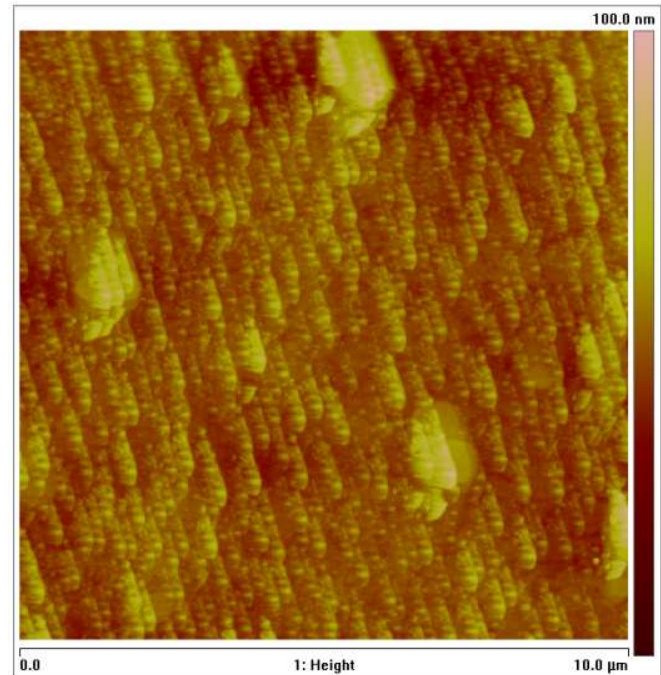

(a)

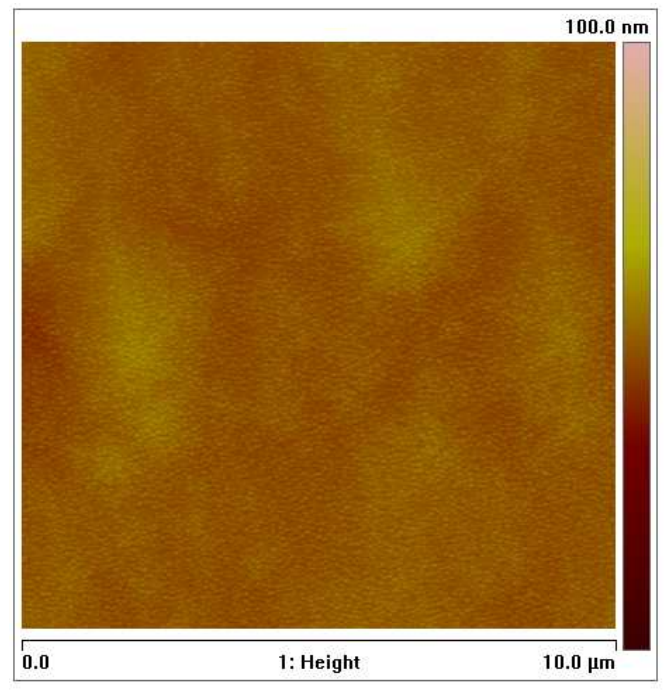

(b)

Figure 4.4: Surface morphology of (a) Ni/Ag contact, (b) Ni/Ag/Pt contact annealed at $430{ }^{\circ} \mathrm{C}$ 
The study of the surface morphology of the contact with and without the presence of the Pt diffusion barrier at $480{ }^{\circ} \mathrm{C}$ temperature is shown in the Figure 4.5. The RMS roughness of the contact without the presence of the Pt diffusion barrier layer was 7.25 $\mathbf{n m}$, and with the presence of Pt was $2.78 \mathbf{~ n m}$ at $480{ }^{\circ} \mathrm{C}$.

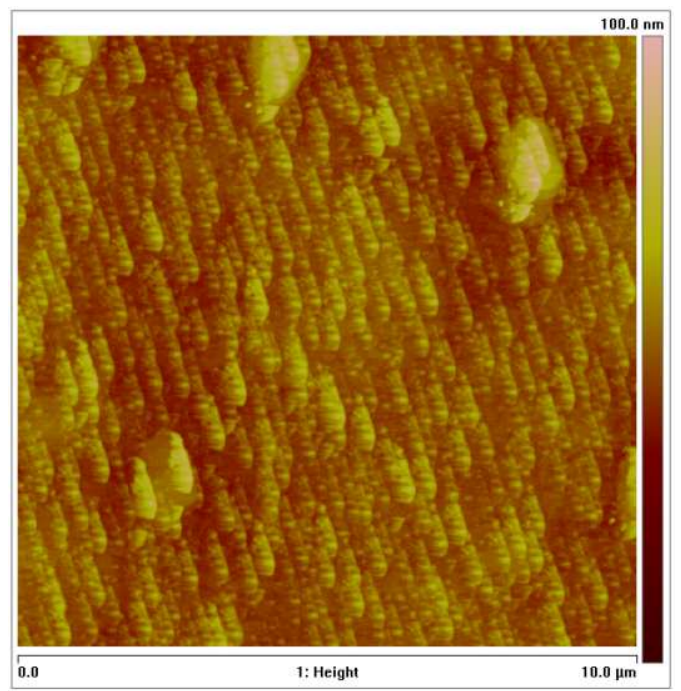

(a)

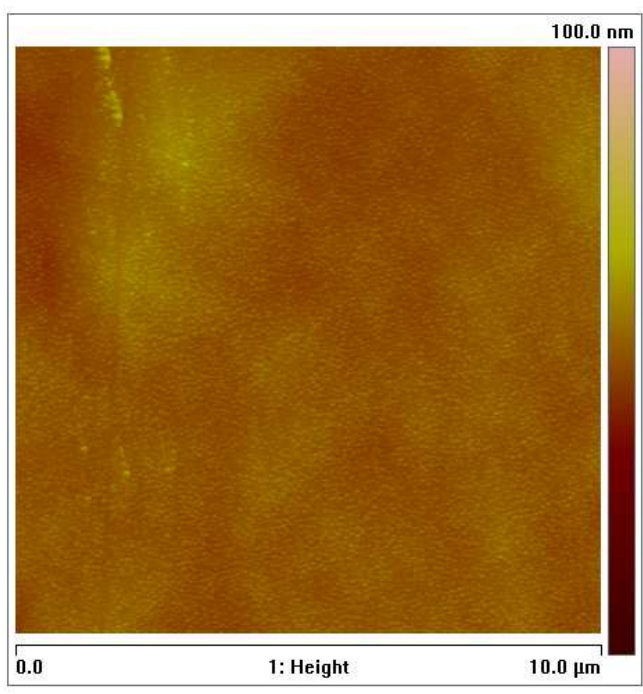

(b)

Figure 4.5: Surface morphology of (a) Ni/Ag contact, (b) Ni/Ag/Pt contact annealed at $480{ }^{\circ} \mathrm{C}$

The Un-annealed Ag contacts with and without the Pt diffusion barrier layer have surface roughness of $1.57 \mathrm{~nm}$ and $1.75 \mathrm{~nm}$ respectively. The contacts should be annealed above $400{ }^{\circ} \mathrm{C}$ to form ohmic contacts to the $\mathrm{p}-\mathrm{GaN}$ substrate.

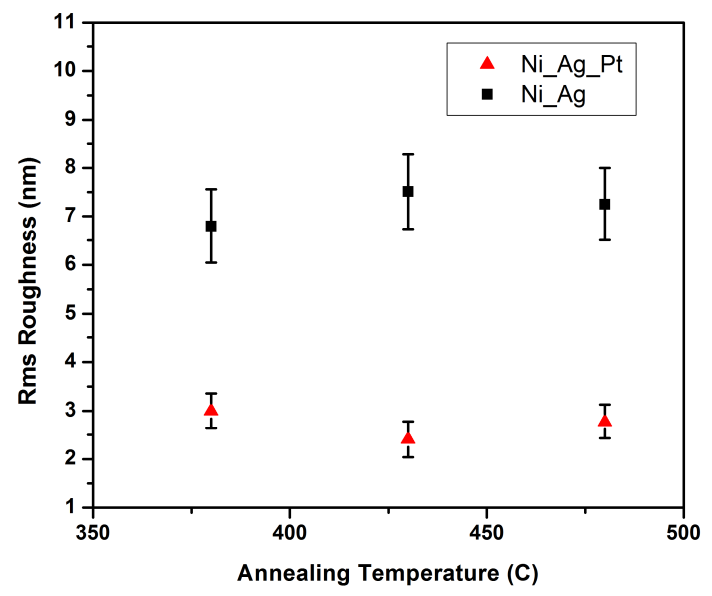

Figure 4.6: RMS roughness of the contacts with different annealing temperatures 
Based on the above mentioned Atomic force microscopy (AFM) studies it can be concluded that, the presence of Pt as an oxygen diffusion barrier layer will prevent the agglomeration of the $\mathrm{Ag}$ and in turn greatly affect the surface morphology (smoothness) of the contact. The variation in the rms surface roughness with different annealing temperatures and the presence of $\mathrm{Pt}$ as a diffusion barrier was shown in Figure 4.6.

\subsubsection{Scanning Electron Microscopy (SEM)}

A Scanning Electron microscopy (SEM) is a type of imaging technique that uses a high energy electron beam to scan the sample surface. From the electrons that will interact with the atoms on the sample surface, signals are produced from secondary electrons produced from collisions that contain the information about the surface topography, composition and electrical conductivity [104]. The different kinds of signals that are produced by an SEM include secondary electrons, back-scattered electrons (BSE), characteristic X-rays. In the SEM that was used in this work, secondary electron detectors are present. A secondary electron imaging or SEI mode can be used to produce very high-resolution images of a sample surface that consists of features of size less than $5 \mathrm{~nm}$ [104].

In a SEM, it will be possible to achieve a wide range of magnifications, from about 10 times to more than 500,000 times. As mentioned earlier, secondary electrons are used to get high resolution images of the sample, the other kind of electrons collected from the sample are Back-scattered electrons (BSE). The back scattered electrons are collected from a sample by elastic scattering. The intensity of the BSE signal is strongly related to the atomic number $(Z)$ of the specimen [104]. Hence, the BSE images can be used to provide information about the distribution of different elements in the sample. For example, BSE imaging can be used to image colloidal gold immuno-labels of 5 or $10 \mathrm{~nm}$ diameter which would otherwise be difficult or impossible to detect in secondary electron images in biological specimens [105]. The third types of signals that are collected from the sample are characteristic X-rays. These X-rays are produced when the electron beam removes an inner shell electron from the sample, causing a higher energy electron to fill the shell and release energy. These characteristic X-rays are used to identify the composition and measure the abundance of 
elements in the sample. The typical SEM setup that was used in the experiment was shown in the Figure 4.7,

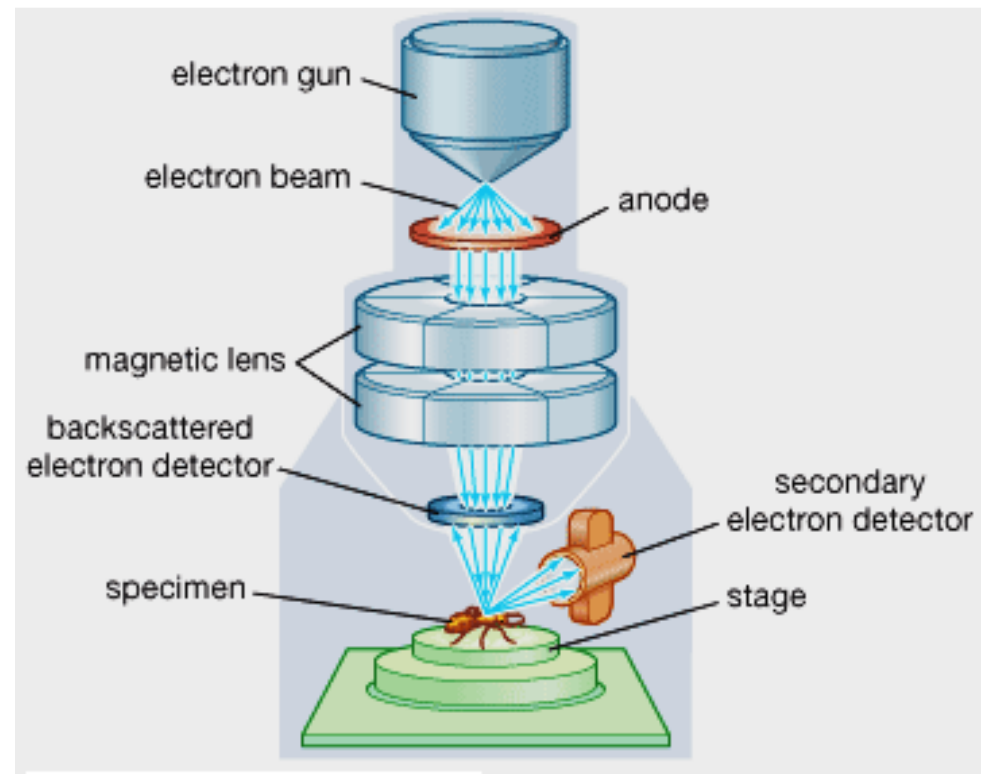

Figure 4.7: The schematic of Scanning Electron Microscopy (SEM) setup used in this experiment [107].

In the SEM shown in the Figure 4.7, a tungsten filament is fitted as a cathode, where, an electron beam is thermionically emitted [108]. The tungsten material has high melting point, low vapor pressure and low cost [109]; hence it is a suitable choice as a material for electron gun. As shown in the Figure 4.7, two magnetic condenser lenses were used to focus the electron beam to a spot about $0.4 \mathrm{~nm}$ to $5 \mathrm{~nm}$ in diameter [106]. The electron beam is then passed through pairs of deflector plates, which deflect the beam in the $\mathrm{x}$ and $\mathrm{y}$ axes so that it scans in a raster fashion over a rectangular area of the sample surface. As shown in the Figure 4.8, when the primary electron beam interacts with the sample, there will be repeated random scattering and absorption in the form of a tear drop shaped volume inside the sample, from less than $100 \mathrm{~nm}$ to around $5 \mu \mathrm{m}$ into the surface. The size of the interaction volume depends on the electron's landing energy, the atomic number and density of the sample [110]. 


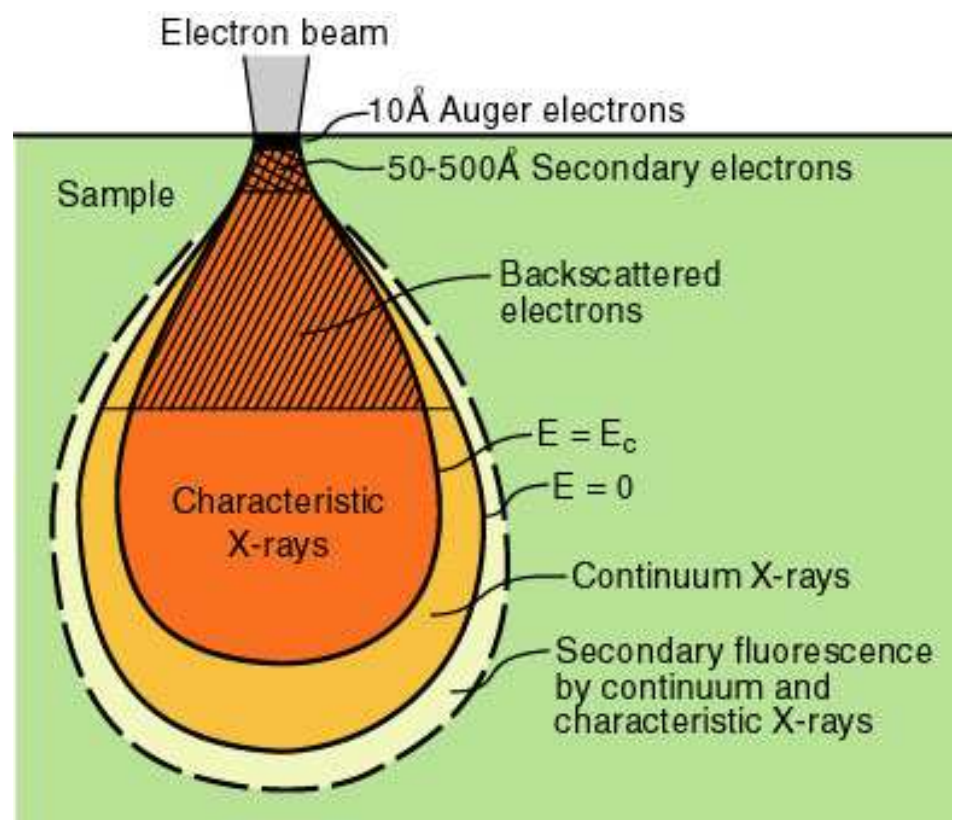

Figure 4.8: Illustration of interaction volumes for various electron-sample interactions [110]

The Ag-based metallization scheme, Ni (1nm)/Ag $(150 \mathrm{~nm}) / \mathrm{Pt}$ $(50 \mathrm{~nm}) / \mathrm{Ni}(20 \mathrm{~nm}) / \mathrm{Au}(50 \mathrm{~nm})$ that was used in this study was annealed at different temperatures. The study was carried out with and without the presence of $\mathrm{Pt}$ as $\mathrm{O}_{2}$ diffusion barrier layer. The annealing conditions that were used in this experiment were $380{ }^{\circ} \mathrm{C}, 430{ }^{\circ} \mathrm{C}$ and $480{ }^{\circ} \mathrm{C}$.

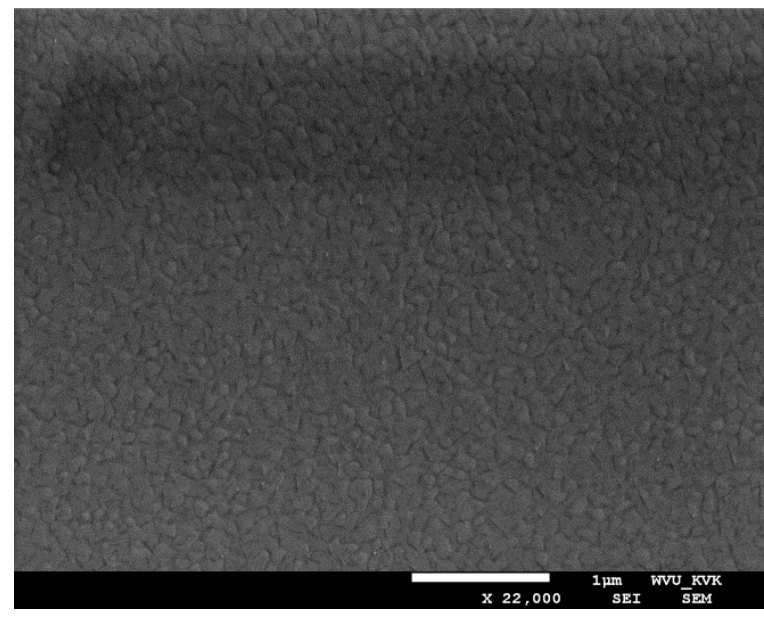

(a)

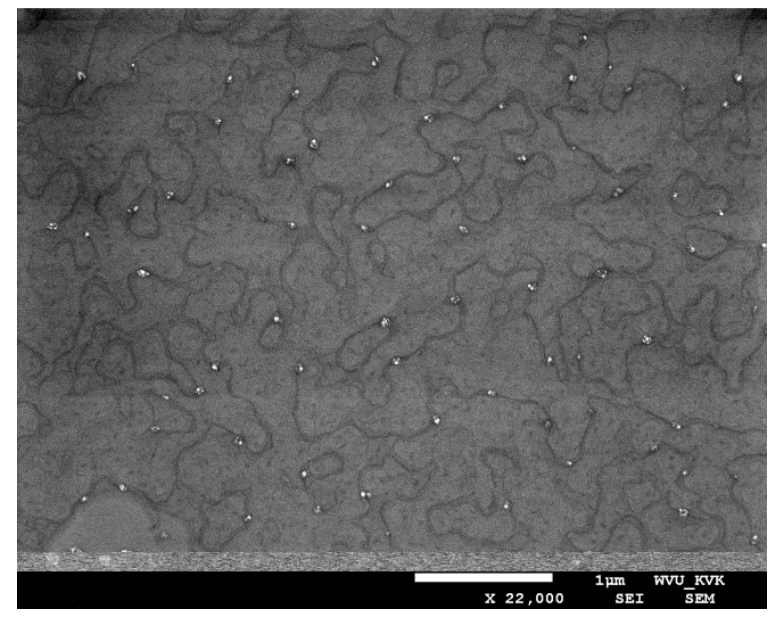

(b)

Figure 4.9: Surface morphology of (a) $\mathrm{Ni} / \mathrm{Ag}$ contact, (b) $\mathrm{Ni} / \mathrm{Ag} / \mathrm{Pt}$ contact annealed at $380{ }^{\circ} \mathrm{C}$ 
The study of the surface morphology of the contact with and without the presence of the Pt diffusion barrier at $380{ }^{\circ} \mathrm{C}$ temperature is shown in the Figure 4.9. It can be observed that the Ag based contact with the presence of Pt diffusion barrier layer was much smoother (less rough) compared to the contact without the presence of Pt. Similarly, it can be observed in the Figure 4.10 that the surface morphology of the Ag-based contact with the presence of Pt layer, annealed at $430{ }^{\circ} \mathrm{C}$, is smooth compared to that of the contact without the presence of Pt diffusion barrier layer.

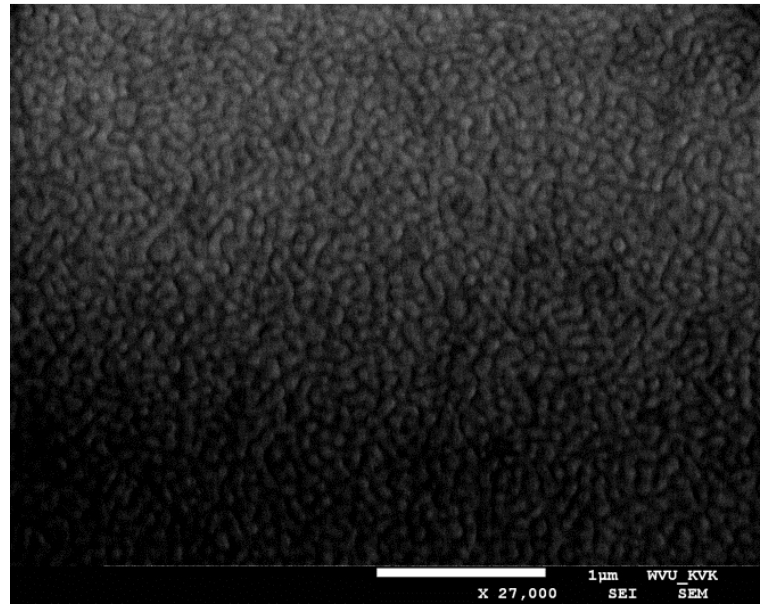

(a)

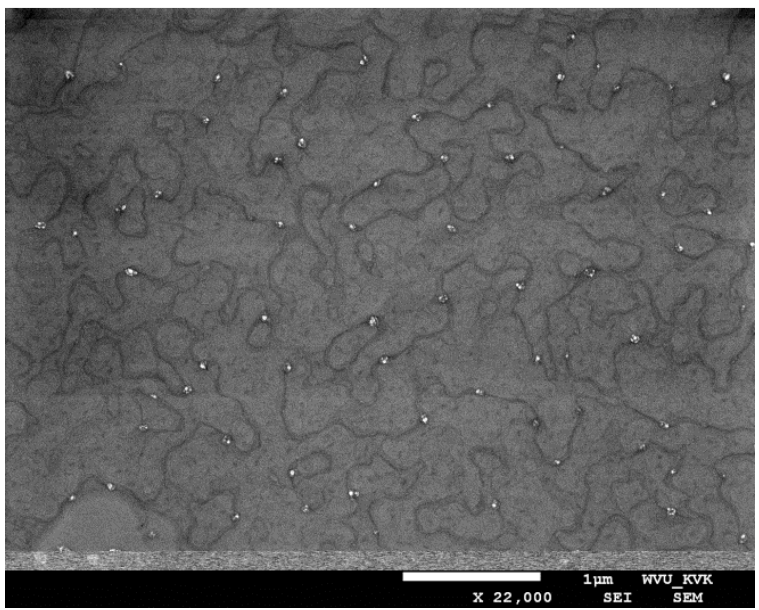

(b)

Figure 4.10: Surface morphology of (a) Ni/Ag contact, (b) Ni/Ag/Pt contact annealed at $430{ }^{\circ} \mathrm{C}$

The surface morphology of the Ag-based metallization scheme with and without the presence of the Pt diffusion barrier layer without performing any post annealing treatment is shown in the Figure 4.11. It was observed that without annealing, in both the cases, the surface morphology looks similar. The main point of using the Ag based contacts when compared to the conventional $\mathrm{Ni} / \mathrm{Au}$ contacts is to achieve high reflectivity for top contact in RCLEDs. From the above mentioned results, it can be concluded that, post annealing treatments will affect the surface morphology (roughness) of the Ni/Ag contacts. Pt as a diffusion barrier layer, reduces the agglomeration in annealed silver $(\mathrm{Ag})$ based contacts and hence the reflectivity is maintained. 


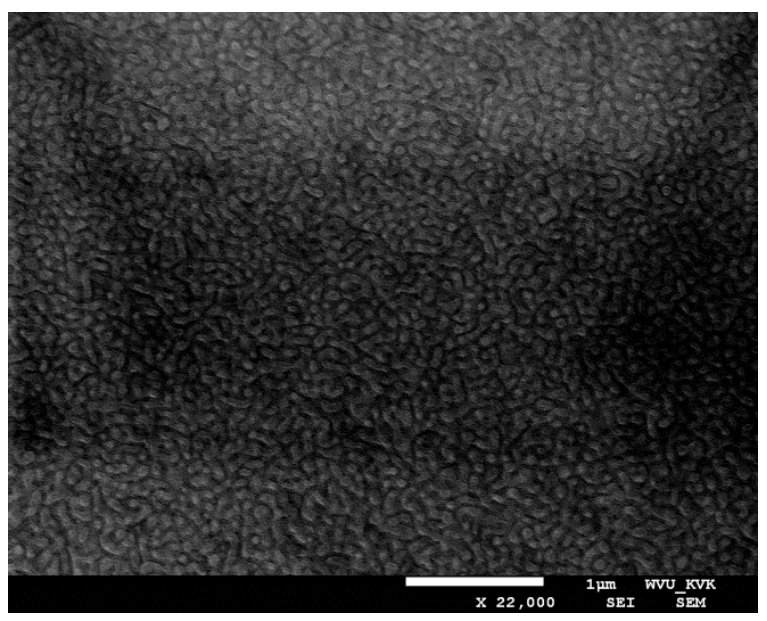

(a)

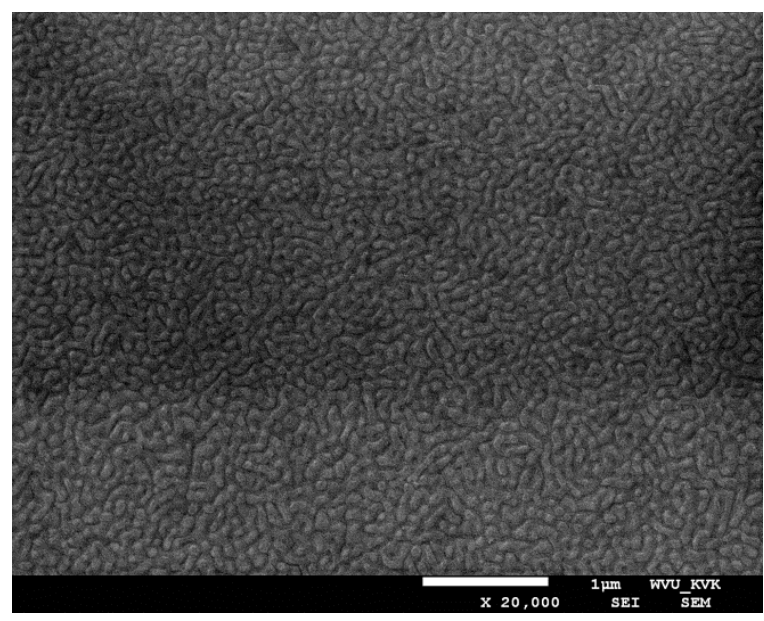

(b)

Figure 4.11: Surface morphology of (a) Ni/Ag contact, (b) Ni/Ag/Pt contact un-annealed

\subsubsection{X-ray Photoelectron Spectroscopy (XPS)}

X-ray photoelectron spectroscopy (XPS) is a spectroscopic technique that is used to measure the elemental composition, chemical state and electronic state of the elements that exist within a material [111]. As shown in the Figure 4.12, when a material is irradiated with a beam of X-rays, the electrons from top 1 to $10 \mathrm{~nm}$ of the material are collected by a lens, and then those electrons were sent through an electron energy analyzer to measure the kinetic energy (KE) and electron detector to count the number of electrons. This data is used to generate XPS spectra. In XPS, the photo-electric effect caused by the x-rays leads to the production of photoelectrons and the energy spectrum can be determined by the spectrometer [112].

In detail, the photoelectric effect can be explained as, when an X-ray beam is directed to the sample surface, the energy of the X-ray photon will be completely adsorbed by the core electron of an atom. If the photon energy, $E_{\text {photon }}$ is large enough, the core electron will then escape from the atom and emit out of the surface. The emitted electron with the kinetic energy of $E_{\text {kinetic }}$ is referred to as the photoelectron. Because the energy of a particular X-ray wavelength is known, the electron binding energy $(\mathrm{BE})$ of each of the emitted electrons can be determined by using an equation 4.1 [111], 


$$
E_{\text {binding }}=E_{\text {photon }}-\left(E_{\text {kinetic }}+\emptyset\right)
$$

Where $E_{\text {binding }}$ is the binding energy of the electron, $E_{\text {photon }}$ is the energy of the X-ray photons being used, $E_{\text {kinetic }}$ is the kinetic energy of the electron as measured by the instrument and $\varphi$ is the work function of the spectrometer (not the material).

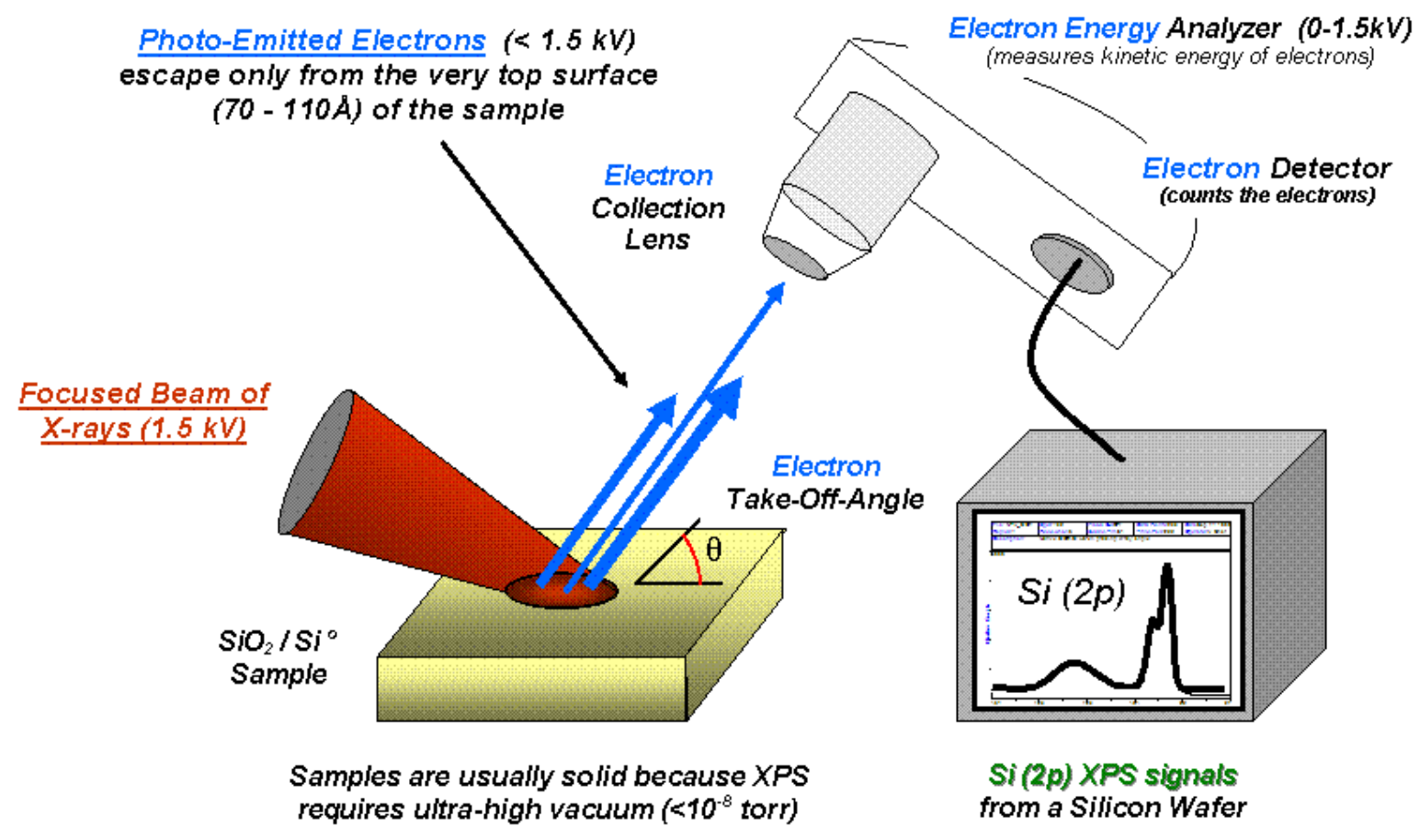

Figure 4.12: Working of an X-ray Photoelectron Spectroscopy system [111]

The applications of XPS include its use to find the elemental composition of the surface, empirical formula of pure materials, elements that contaminate a surface, chemical or electronic state of each element in the surface and uniformity of elemental composition across the top surface [111]. In this work, the XPS is used to study the diffusion of elements like, oxygen between various metal interfaces in the Ag-based contact metallization scheme. For that, a Sputter XPS (Depth profiling) mechanism is employed. The sample is prepared in an Air Clean 600 work station to avoid any contamination in the sample preparation and then the sample is placed on a sample holder of 1 inch or 2 inch diameter. The XPS spectrum is taken from the samples under Ultra High Vacuum (UHV) conditions. Figure 4.13 gives us the 
basic schematic of the system that was used. The sample is first introduced in to the transfer sample chamber. Using a roughing (mechanical) pump, the chamber is pumped down. The pump down time depends on the nature of the material that is to be analyzed. Powder samples needs to be pumped down for a long time compared to the thin film samples because, out gassing and contamination is high in the earlier case. A load lock is used and maintained with a pressure, $\mathrm{P}$ approximately equal to $10^{-8}$ Torr. The load lock is used in order to not have a large loss in vacuum and contaminate the chamber while transferring the sample. Once the chamber pressure is reached, using a transfer rod, the sample is introduced in-to the main chamber. The majority of the tasks are done using the software to avoid unnecessary problems that will be created while handling the machine manually. After the required pressure is reached in the chamber, using the camera present on the back side of the machine, the sample is focused (height between X-ray source and the stage is adjusted) and centered for the further measurements to be taken. The Ar gun is charged for a couple of seconds and it is used for sputtering the films, while taking the date from the scans. An ion gun neutralizer is used if there is more surface charging effects seen. After neutralization, using the software multipack spectrum various measurements are taken after analysis of the sample including operating parameters such as pass energy, scan range of binding energy and number of scans, calibration of the position of XPS peaks, peak intensity etc and peak fitting.

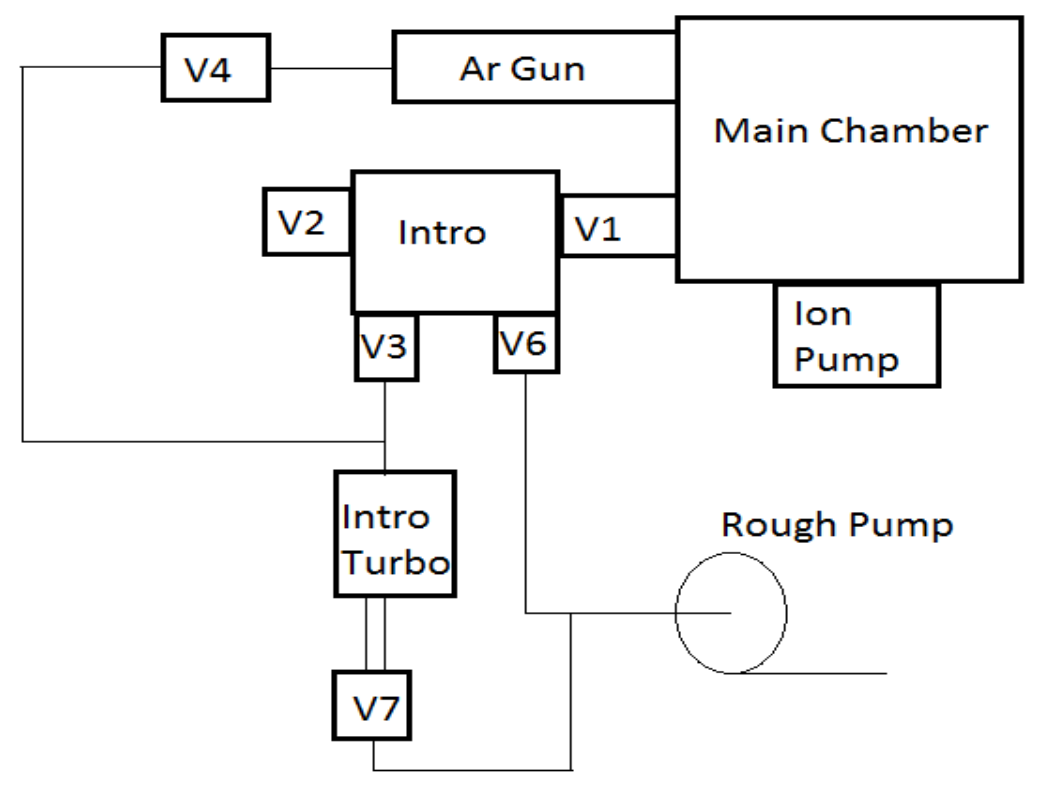

Figure 4.13: Schematic of the system used for this work 
The Ni (2nm)/ Ag (150nm)/ Pt (50nm)/ Ni (20nm)/ Au (50nm) metallization scheme used in this work is deposited on a p-GaN substrate using e-beam evaporation mechanism. The contact is then annealed at $430^{\circ} \mathrm{C}$ to form an ohmic contact with the $\mathrm{p}-\mathrm{GaN}$. The depth profiling spectrum was obtained using the process explained above, as shown in the Figure 4.14. From the Figure 4.14, two things can be explained in detail: 1) How an ohmic contact was formed between the p-GaN and the Ag metallization scheme, and 2) How Pt acted as a diffusion barrier to maintain the reflectivity even after annealing the contact at temperatures above $400^{\circ} \mathrm{C}$.

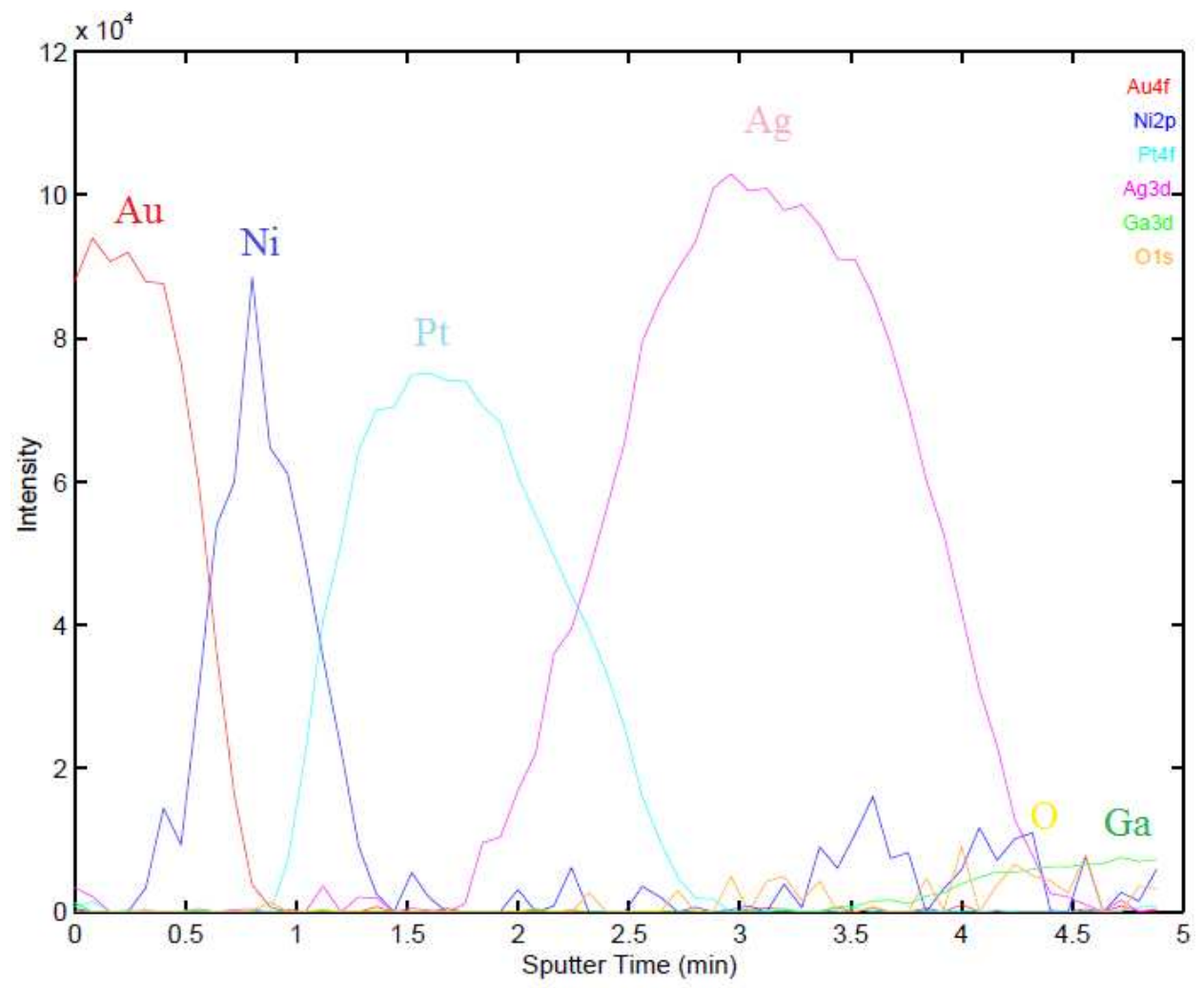

Figure 4.14: Sputter XPS (Depth profiling) analysis on Ni (2nm)/ Ag (150nm)/ Pt (50nm)/ Ni $(20 \mathrm{~nm}) / \mathrm{Au}(50 \mathrm{~nm})$ annealed at $430^{\circ} \mathrm{C}$

Based on the XPS result shown in Figure 4.14, it can be observed that, the $\mathrm{Ga}$ is out-diffused into $\mathrm{Ag}$ and $\mathrm{Ag}$ is in-diffused into Ga. Therefore, a number of $\mathrm{Ga}$ vacancies might be created near the GaN contact interfacial region [113]. The Ga vacancies will act as acceptors for electrons in $\mathrm{GaN}$ and hence the net hole concentration near the surface region will be increased. The depletion layer width below the contact and the effective barrier height for 
the transport of holes might be decreased, leading to the drastic reduction of contact resistivity in the oxidized $\mathrm{Ni} / \mathrm{Ag} / \mathrm{Pt} / \mathrm{Ni} / \mathrm{Au}$ contacts on p-type GaN [23]. The second thing that is observed from the Figure 4.14 is, the oxygen peak height (concentration) that is present in the Ag metal layer is negligible. Hence, Pt acted as an oxygen diffusion barrier layer in the deposited metallization scheme annealed at temperatures above $400^{\circ} \mathrm{C}$, preventing the degradation of reflectivity of the overall Ag contact for a RCLED application.

\subsubsection{Electrical Characterization}

The Ag-based metallization scheme Ni (2nm)/ Ag (150nm)/ Pt $(50 \mathrm{~nm}) / \mathrm{Ni}(20 \mathrm{~nm}) / \mathrm{Au}(50 \mathrm{~nm})$ used in this work is deposited on p-GaN (70nm thick) samples that were grown in a MOVPE chamber. Before the deposition, the $\mathrm{p}-\mathrm{GaN}$ samples were annealed at $800^{\circ} \mathrm{C}$ in $\mathrm{N}_{2}$ ambient for 5 minutes to activate the $\mathrm{Mg}$ dopants. These samples were degreased and treated with acids like $\mathrm{HCl}$ and $\mathrm{BOE}$ to remove any native oxides present on the surface. The TLM and c-TLM patterns were transferred using AZ5214 EIR Image reversal PR. Using e-beam evaporation deposition, the Ag metallization scheme mentioned above is deposited on the surface treated p-GaN substrate. The deposited contacts were annealed at $380{ }^{\circ} \mathrm{C}, 430{ }^{\circ} \mathrm{C}$ and $480{ }^{\circ} \mathrm{C}$ in $\mathrm{O}_{2}$ ambient for 3 minutes. The current-voltage (I-V) characteristics were measured using a semiconductor parameter analyzer. Figure 4.15 gives the $\mathrm{I}-\mathrm{V}$ with different annealing temperatures.

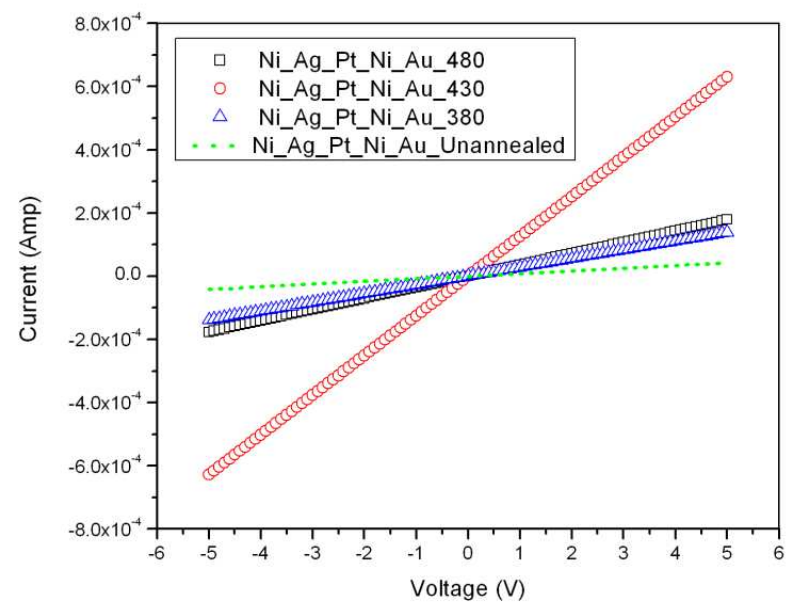

Figure 4.15: $\mathrm{I}-\mathrm{Vs}$ of $\mathrm{Ni} / \mathrm{Ag} / \mathrm{Pt} / \mathrm{Ni} / \mathrm{Au}$ contact pads with different annealing conditions 
From the I-Vs shown in Figure 4.15, the resistances were calculated for contacts with different pad spacing. A plot is made of the total resistance and the pad spacing. Using Origin 8.0, the data was fitted linearly and the specific contact resistance and transfer lengths were calculated from the plot. The specific contact resistivity values of the contact annealed at different temperatures is shown in the Figure 4.16. From Figure 4.16, the Agbased metallization scheme has the lowest specific contact resistivity at the annealing temperature $430^{\circ} \mathrm{C}$. Hence, $430^{\circ} \mathrm{C}$ annealing temperature is chosen as the optimum temperature for all further studies.

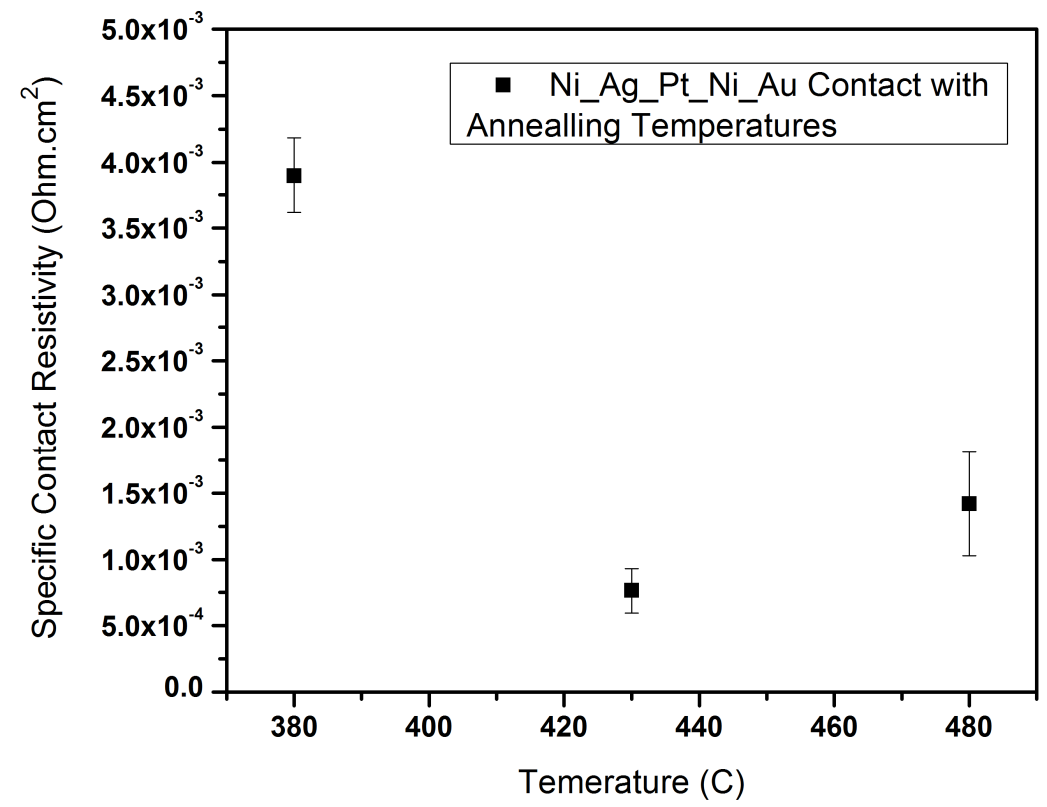

Figure 4.16: Specific Contact resistivity of the contact annealed at different temperatures

$\mathrm{N}_{2}$ annealed samples showed a nonlinear rectifying behavior, but $\mathrm{O}_{2}$ annealed samples showed linear ohmic characteristics after annealing at $380-600{ }^{\circ} \mathrm{C}$. Optimization of $\mathrm{Ni}$ thickness is also important for both electrical and optical characteristics. When the thickness of the $\mathrm{Ni}$ was increased to $5 \mathrm{~nm}$, the reflectivity was reduced by $\sim 35 \%$ due to the strong absorption of $\mathrm{Ni}$ in the UV and visible region. For Ni thickness less than $1 \mathrm{~nm}$, poor adhesion of the contacts was observed. Therefore, $2 \mathrm{~nm} \mathrm{Ni}$ was employed for this study. The specific contact resistivity is also increased with the increase in Ni thickness. The minimum specific contact obtained at $430^{\circ} \mathrm{C}$ annealing temperature was 7.64E-04 $\mathbf{\Omega . c m}{ }^{2}$. 


\subsubsection{Optical Characterization}

The light reflectance measurements were performed using a Xenon lamp and a spectrometer. A Pyrex mirror of $96 \%$ reflectivity is used as a standard reference. Based on the annealing studies performed, it was determined that the Ag-based metallization scheme, Ni (2 nm)/Ag (150 nm)/Pt (50 nm)/Ni $(20 \mathrm{~nm}) / \mathrm{Au}(50 \mathrm{~nm})$, should be annealed above $400^{\circ} \mathrm{C}$ to form an ohmic contact with the $\mathrm{p}-\mathrm{GaN}$. When the contact was annealed at temperatures above $400^{\circ} \mathrm{C}$, agglomeration of $\mathrm{Ag}$ is observed. Therefore, $\mathrm{Pt}$ was deposited on top of the $\mathrm{Ag}$ layer as oxygen diffusion barrier layer to minimize the agglomeration.

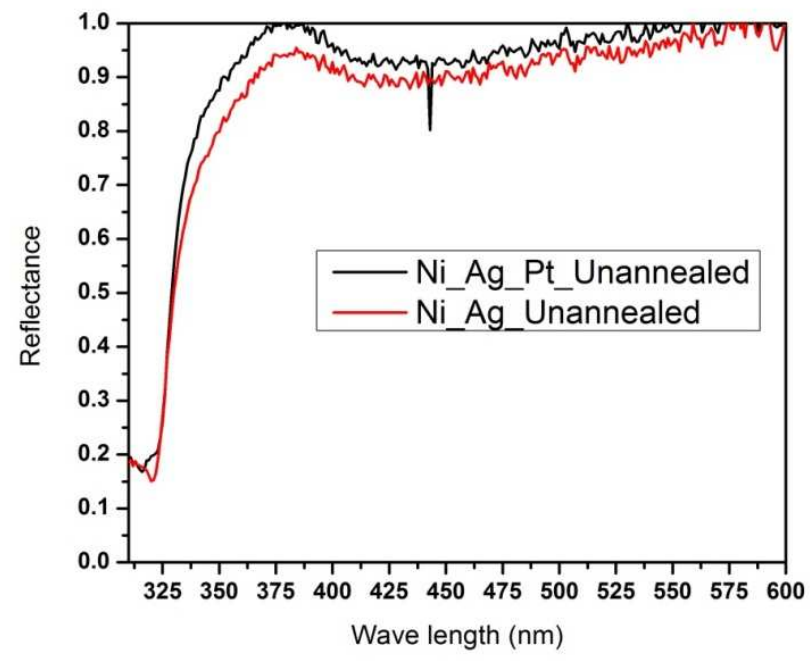

Figure 4.17: Reflectivity measurement of as deposited, $\mathrm{Ni} / \mathrm{Ag}$ and $\mathrm{Ni} / \mathrm{Ag} / \mathrm{Pt}$ contacts

The variation of reflectivity of the contact with and without the presence of platinum and without annealing is shown in Figure 4.17. It can be observed that, in the as-deposited contact, with and without the presence of Pt, the reflectivity remains almost equal. As shown in the Figure 4.18 (a), when annealed at $380^{\circ} \mathrm{C}$, the contact degraded to some extent and the reflectivity was reduced to $75 \%$. From the Figure 4.18 (b), annealing at $430^{\circ} \mathrm{C}$ further degraded the $\mathrm{Ag}$ contact and the reflectivity reduced to $\sim 50 \%$. However, with the $\mathrm{Pt}$ insertion layer, the reflectivity remains almost constant over the temperature range of interest. 


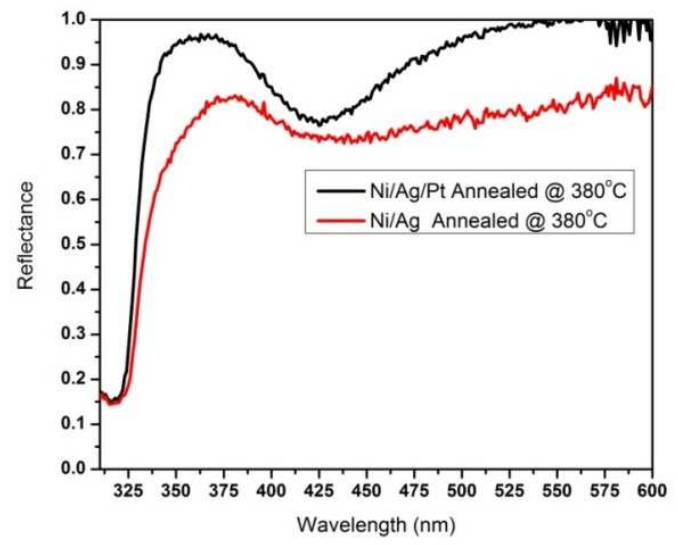

(a)

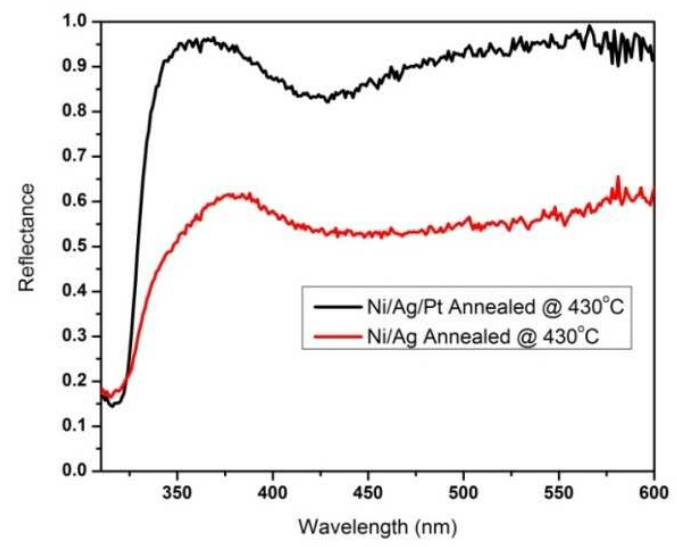

(b)

Figure 4.18: Reflectivity measurement of, (a) $\mathrm{Ni} / \mathrm{Ag}$ and $\mathrm{Ni} / \mathrm{Ag} / \mathrm{Pt}$ contacts annealed at $380^{\circ} \mathrm{C}$, (b) Annealed at $430^{\circ} \mathrm{C}$

Based on the above shown reflectivity measurements, it can be concluded that $\mathrm{Pt}$ as a diffusion barrier layer, prevents agglomeration of the Ag-based contact, there-by preserving the reflectivity for the RCLED applications.

\subsection{Comparison with Conventional Ni/Au Contacts}

The $\mathrm{Ni} / \mathrm{Au}$ contacts are the conventionally used contacts on the InGaN based blue and green LEDs [114]. For the Resonant Cavity Light Emitting Diodes (RCLEDs) used in this work, the bottom mirror constitute a digital $\mathrm{AlGaN} / \mathrm{GaN}$ Distributed Bragg Reflector (DBR), an Ag-based metallization scheme is developed to have a high reflective bottom mirror. Ni/Au forms good ohmic contacts with the $\mathrm{p}-\mathrm{GaN}$ layer, but it cannot be used as a top mirror because, they have low reflectance in the blue region. Ag films have much higher reflectivity when compared to the $\mathrm{Au}$ contacts in the visible region. Furthermore, the metallic mirror films provide reflectivity over a wide wavelength range in comparison to the reflectivity of a Distributed Bragg Reflector (DBR) which is usually tuned to operate over a narrow wavelength range. The basic schematic of the InGaN based RCLED used in this work is shown in the Figure 4.19. 


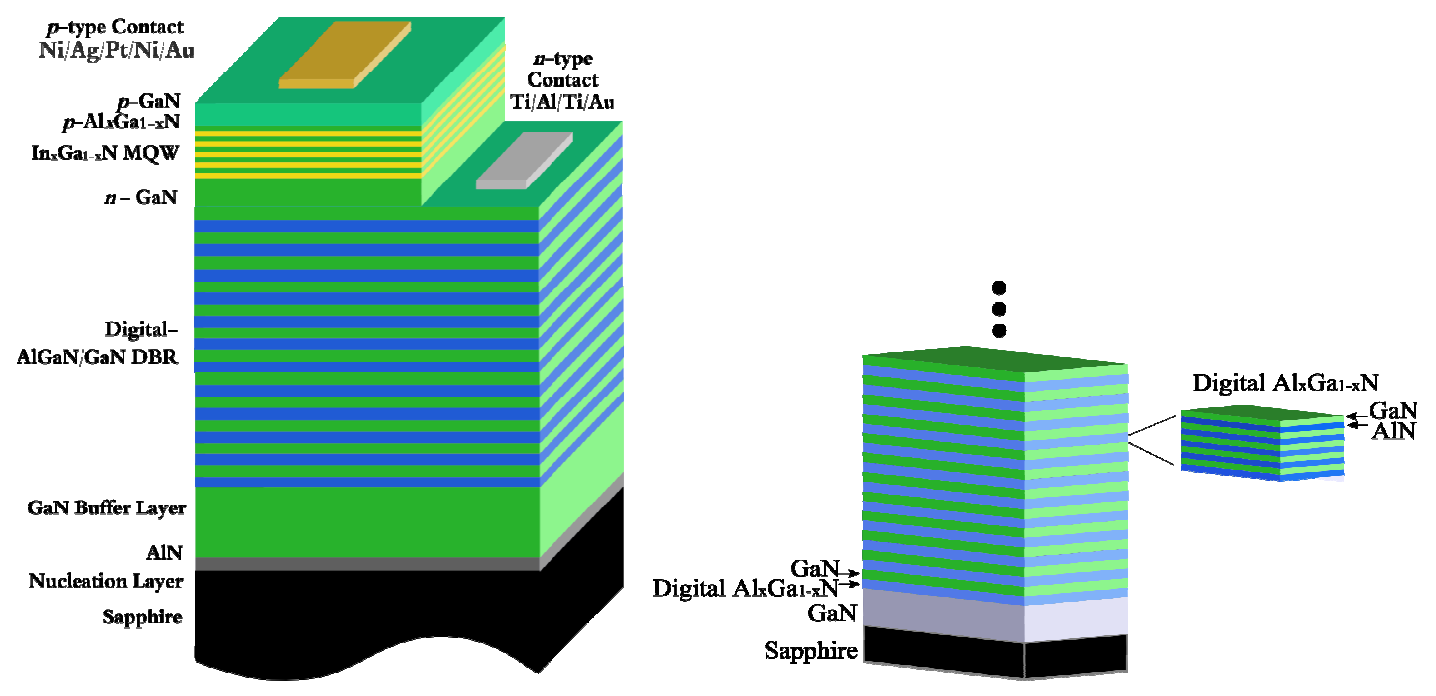

Figure 4.19: Resonant Cavity LED structure used in this work.

The GaN/ $\operatorname{In}_{\mathrm{x}} \mathrm{Ga}_{1-\mathrm{x}} \mathrm{N}$ MQW RCLED with the Distributed Bragg Reflectors (DBR) and Planar LED were grown in a MOVPE chamber by Korakakis group. The two different kinds of DBRs that were used in this work were, a 6 period and a 12 period. The grown LEDs were fabricated using the process explained in Chapter 3. Optical and electrical characterization was done on the processed LEDs. The Electro luminescence (EL) spectrum obtained using a B\&W Tek Spectrometer at $6 \mathrm{~V}$ of bias voltage in a 6 period DBR and 12 periods DBR LED is shown in the Figure 4.20 (a) and Figure 4.20 (b) respectively.

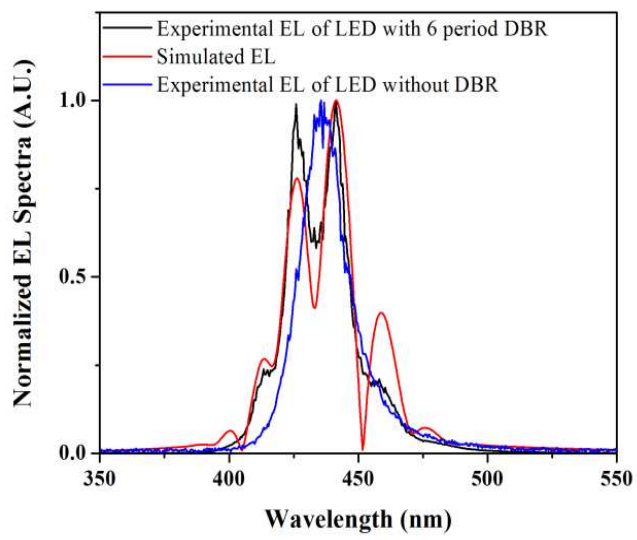

(a)

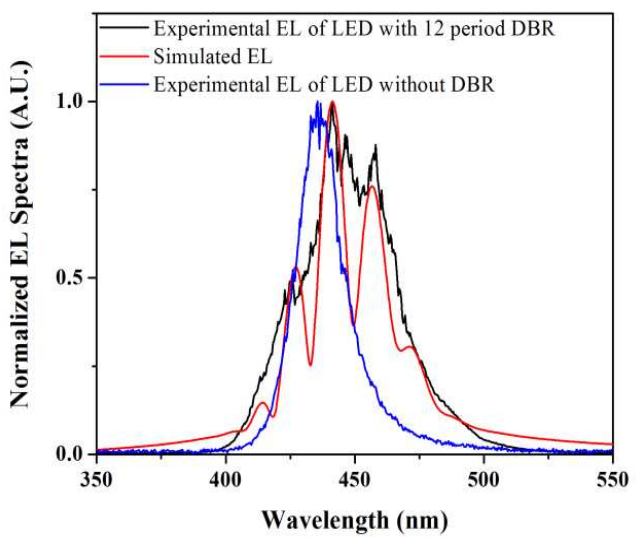

(b)

Figure 4.20: EL spectrum of GaN/InGaN MQW LED with and without at 6V bias voltage, (a), 6 period DBR, (b), 12 period DBR 
The comparison between the electrical properties of the LEDs with the conventional $\mathrm{Ni} / \mathrm{Au}$ contacts and the Ag-based metallization scheme on a $\mathrm{GaN} / \operatorname{In}_{\mathrm{x}} \mathrm{Ga}_{1-\mathrm{x}} \mathrm{N}$ MQW RCLED as the p-contact in shown in Figure 4.21. I-V characteristics when compared with $\mathrm{Ni} / \mathrm{Au}$ contacts on the same LED structure are shown the Figure 4.21 (a). The series resistance and the turn-on voltages comparison is shown in the Figure 4.21(b).

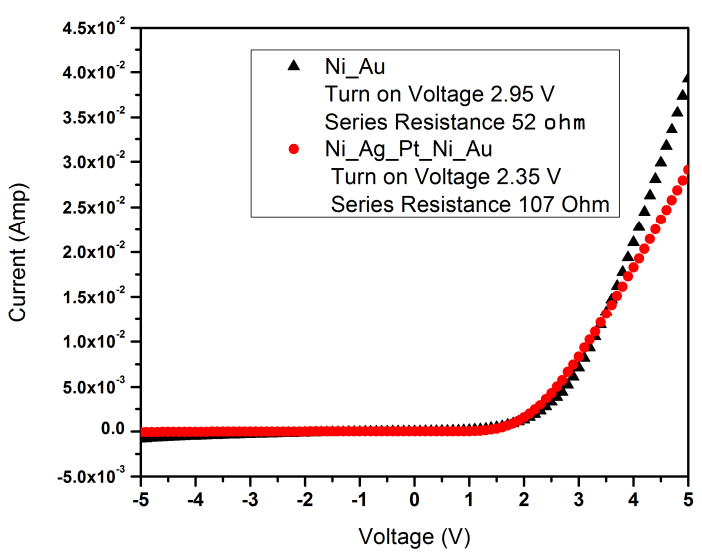

(a)

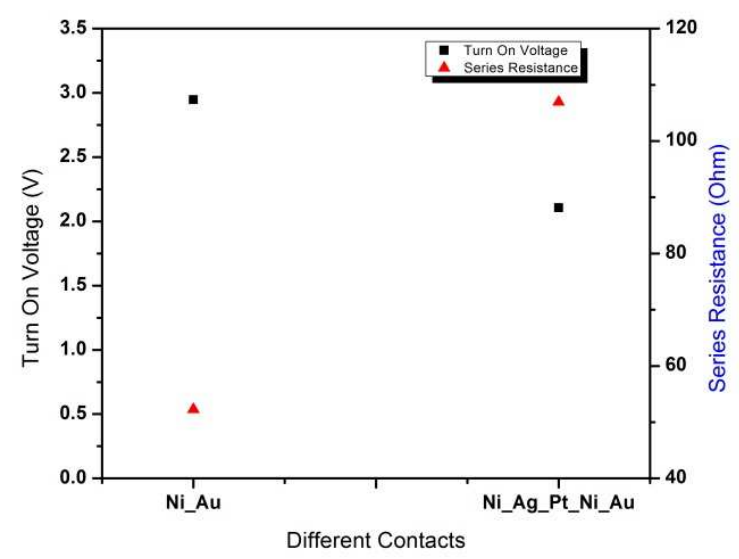

(b)

Figure 4.21: Comparison of electrical characteristics between $\mathrm{Ni} / \mathrm{Au}$ and $\mathrm{Ni} / \mathrm{Ag} / \mathrm{Pt} / \mathrm{Ni} / \mathrm{Au}$ contacts, (a), I-V characteristics, (b), Series resistance and turn-on voltages

It is observed that with the Ag-based metallization scheme mentioned above, the turn-on voltage of the RCLED is reduced by $\sim 0.6 \mathrm{~V}$ when compared to the conventional $\mathrm{Ni} / \mathrm{Au}$ contact based LED. The series resistance is high for the $\mathrm{Ni} / \mathrm{Ag} / \mathrm{Pt} / \mathrm{Ni} / \mathrm{Au}$ contact when compared to the conventional Ni/Au based LED, but this might be due to the presence of the large stack of metals. 


\section{Chapter 5}

\section{Electrical and Optical Properties of $\mathrm{ZnO}$ thin films}

\subsection{Introduction}

Transparent conducting oxide (TCO) films have been widely used for mobile display applications, such as organic lighting diodes, liquid crystal displays (LCD), micro displays, and solar cells [115]. Zinc oxide ( $\mathrm{ZnO})$ has been considered an ideal alternative material to Indium Tin Oxide (ITO) due to its lower cost and wide availability [116]. We considered aluminum alloyed $\mathrm{ZnO}$ thin films for transparent electrode applications in our study. The ZnO films can be deposited using several different mechanisms, Sputtering [117-120], Pulsed laser deposition (PLD) [121], thermal evaporation [122]. Ion Beam Assisted e-beam evaporation and RF Sputtering mechanisms had been used to deposit $\mathrm{ZnO}$ thin films. The electrodes play a key role in the device performance such as, power consumption, reliability, and light extraction [123]. A wide variety of metallization schemes with high work function metals, such as Ni [124-127] and Pt [128-130], have been employed to achieve low resistance ohmic contacts to p-type GaN. Among those schemes, $\mathrm{Ni} / \mathrm{Au}$ is commonly used as a p-type ohmic electrode for GaN-based LEDs due to its reliability, low contact resistivity. The $\mathrm{Al}$ alloyed $\mathrm{ZnO}$, ITO and $\mathrm{Ni} / \mathrm{Au}(5 \mathrm{~nm} / 5 \mathrm{~nm})$ films can be used to spread the current along the whole device, thereby increasing the light extraction efficiency. The Ni/Au $(5 \mathrm{~nm} / 5 \mathrm{~nm})$ had low transparency between $60-80 \%$ and high specific contact resistivity [131]; ITO had better transparency and conductivity but thermally unstable [132].

In this work, with the $\mathrm{Al}$ alloyed $\mathrm{ZnO}$ transparent contact scheme

we used, all the above mentioned problems were addressed. The $\mathrm{ZnO}$ films were opaque and highly resistive after deposition on $\mathrm{p}-\mathrm{GaN}$ substrate, so a post annealing treatment had been employed to improve its transparency up to $\sim 85 \%$ in the near UV and visible wavelength ranges and resistivity as low as $3 \mathrm{E}-03 \Omega . \mathrm{cm}$. In this study, we investigate the effects of Al doping and $\mathrm{O}_{2}$ flow rate on the structural, electrical, and optical properties of Al-doped $\mathrm{ZnO}$ (AZO) films. Different deposition mechanisms are used for different transparent electrode applications, for InGaN based LEDs the $\mathrm{ZnO}$ films are deposited at room temperatures and are annealed at high $\left(500^{\circ} \mathrm{C}-800^{\circ} \mathrm{C}\right)$ temperatures in $\mathrm{N}_{2}$ ambient to make it transparent and conductive. The variation 
in transmission with $\mathrm{O}_{2}$ flow rates is discussed, the effect of $\mathrm{Al}$ alloying can be studied by Sputter X-ray Photo-electron Spectroscopy (XPS) result. ZnO films are characterized for crystalline nature, based on the X-Ray Diffraction (XRD) studies, thermal stability and roughness using AFM and SEM techniques, electrical properties using Hall Effect and circular Transmission Line Method (c-TLM) measurements, and optical properties using Transparency and Ellipsometry measurements.

$\mathrm{ZnO}$ films form Ohmic and Schottky contacts with p-GaN substrate for InGaN LED applications, depending upon the method of deposition and post annealing treatments performed. As explained in Chapter 2, increasing the doping concentration or adding a thin metal layer in between, can increase the tunneling mechanism. In this work, effects of increasing the $\mathrm{Al}$ doping concentrations on the film quality (electrically and optically) and adding a thin $\mathrm{Ni}$ layer in between $\mathrm{Al}$ alloyed $\mathrm{ZnO}$ and $\mathrm{p}$-GaN were studied.

\subsection{Modeling}

The $\mathrm{ZnO}$ thin films are used on the GaN/InGaN MQW LEDs as current spreading layers (CSL) for better light extraction mechanism applications. The thickness of the film plays a role in the current spreading and extraction; hence a transmission line model was developed to find the optimum thickness for less reflection (more transmission). Schematic of the basic transmission line model used in this work is shown in the Figure 5.1 (a) and Figure 5.1 (b) gives model between $\mathrm{ZnO}$ and $\mathrm{p}-\mathrm{GaN}$.
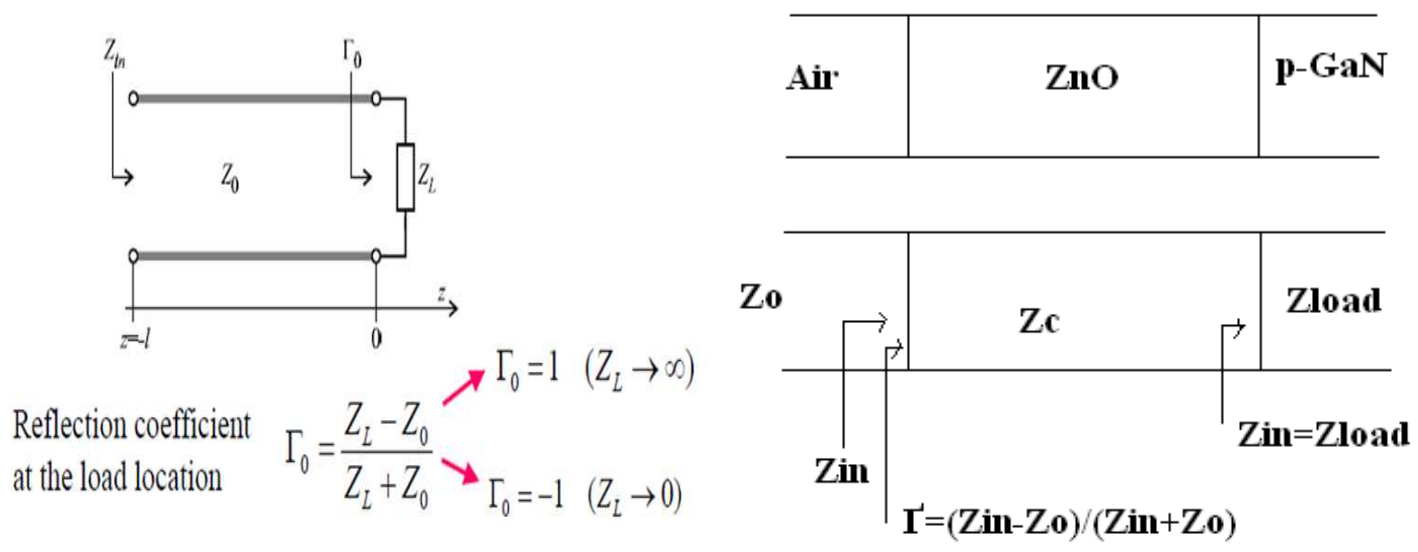

Figure 5.1: Transmission line model, (a), Schematic [133], (b), with $\mathrm{ZnO}$ and $\mathrm{p}-\mathrm{GaN}$ substrate 
The reflection coefficient is the ratio of the amplitude of the reflected wave to that of the amplitude of incident wave. Equation 5.1 [133] gives the reflection coefficient.

$$
\Gamma=\frac{Z_{L}-Z_{S}}{Z_{L}+Z_{S}}
$$

Where, $Z_{L}$ is the impedance towards the load and $Z_{S}$ is the impedance toward the source. The input impedance $Z_{\text {in }}$ is given by the equation 5.2 [134].

$$
Z_{i n}(z)=Z_{o}\left[\frac{1+\Gamma e^{j 2 \beta z}}{1-\Gamma e^{j 2 \beta z}}\right]
$$

Where, $Z_{o}$ is the intrinsic impedance and $\beta$ is the wave number. From the equations 5.1 and 5.2, the reflection coefficient can be calculated as,

$$
\Gamma=e^{-j 2 \beta z}\left[\frac{Z_{\text {in }}(z)-Z_{o}}{Z_{\text {in }}(z)+Z_{o}}\right]
$$

Where, $\beta=\frac{2 \pi}{\lambda}$, gives the wave number. $\lambda$, is the wavelength. Using Matlab, a plot is drawn between thickness of $\mathrm{ZnO}$ and reflection coefficient using the equation 5.3 and is shown in the Figure 5.2. The Matlab code used to get the plot shown the Figure 5.2 is given in detail in the Appendix. The wavelength of the light used in this case was $460 \mathrm{~nm}$.

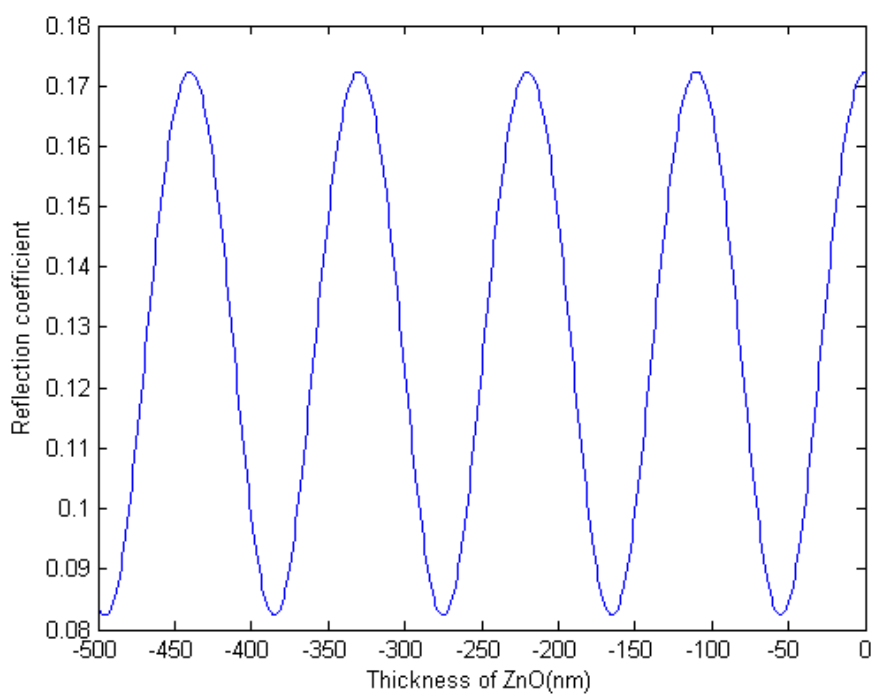

Figure 5.2: The plot showing Reflection coefficient $\mathrm{Vs}$ Thickness of $\mathrm{ZnO}$ for $460 \mathrm{~nm}$ blue light. 


\subsection{Experiment}

Mg-doped p-type GaN films used in this work were grown on (0001) sapphire substrate using Metal Organic Vapor Phase Epitaxy (MOVPE) in an Aixtron 200/4 RF$\mathrm{S}$ reactor by Dr. Korakakis's group. The Mg dopants were activated in the p-GaN by Rapid Thermal Annealing (RTA) at $800^{\circ} \mathrm{C}$ for $5 \mathrm{~min}$. The p-GaN samples were then degreased by ultrasonication in acetone and methanol for $5 \mathrm{~min}$ each and were rinsed in DI water. The p-GaN samples were surface treated in 10:1 Buffered Oxide Etch (BOE) for 3 min and then in HCl: DI (1:1) for $1 \mathrm{~min}$ to remove any native surface oxides that were present.

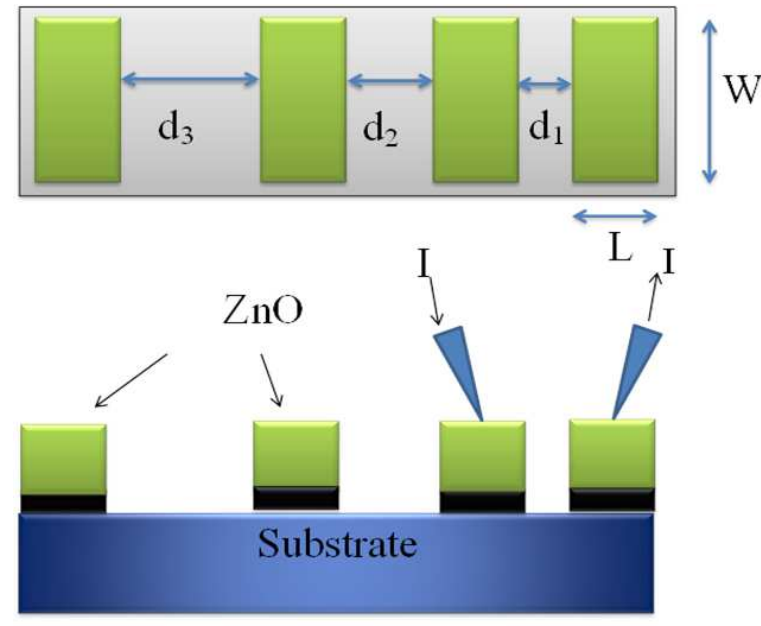

(a)

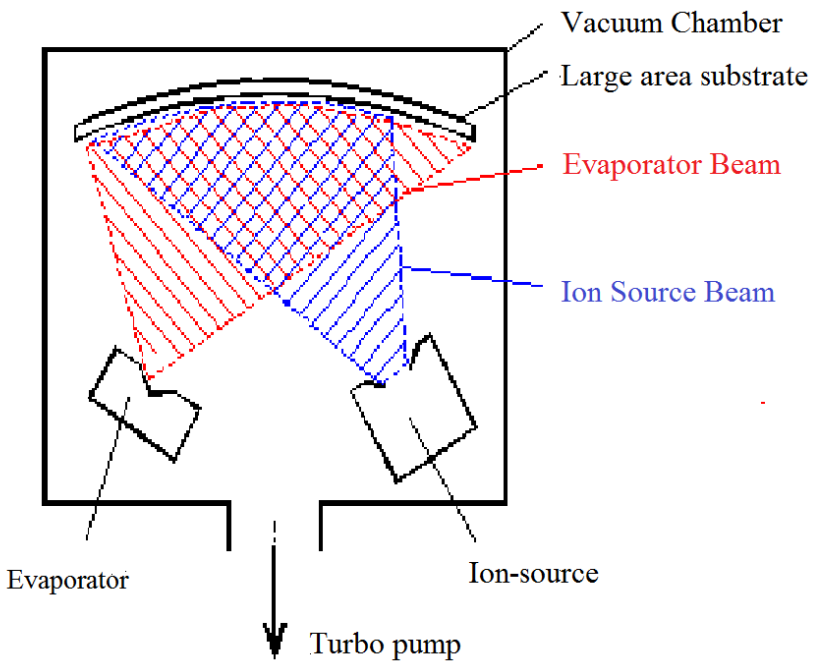

(b)

Figure 5.3: (a) TLM Pattern that was used to find the specific contact resistivity between p-GaN and the $\mathrm{ZnO}$ contact. (b) Schematic of Ion beam assisted e-beam evaporation system [46]

The $\mathrm{Al}$ alloyed $\mathrm{ZnO}$ films were deposited on, (a) surface treated $\mathrm{p}$ GaN substrates for contact resistivity and surface morphology measurements, (b) glass and sapphire substrates for Hall, transmission and XPS depth profiling measurements, (c) p-type silicon (100) for Ellipsometry, using Ion beam Assisted Evaporation deposition and RF Sputtering techniques. The TLM (Transmission Line Method) pattern, as shown in Figure 5.3 (a), was transferred to the sample using AZ 5214 E photo-resist and standard image reversal photolithography techniques. The Ni (2 nm)/Al alloyed (undopped, 2\%wtAl, 5\%wtAl) (150 nm) $\mathrm{ZnO}$ was deposited using electron beam evaporation system (Temescal BJD-2000 CV 6S) at a 
base pressure of 1E-05 Torr. After lifting-off of the films deposited on the photo resist, the contacts were annealed at temperatures from $300{ }^{\circ} \mathrm{C}$ to $800{ }^{\circ} \mathrm{C}$ for $1 \mathrm{~min}$ in a Rapid Thermal Annealing (RTA) chamber in $\mathrm{N}_{2}$ ambient.

\subsection{Characterization}

The Ni (2 nm)/Al alloyed (undopped, 2\%wtAl, 5\%wtAl) ZnO $(150 \mathrm{~nm})$ was deposited on $\mathrm{p}-\mathrm{GaN}$, glass, sapphire and Silicon substrates using the experimental procedure that was discussed in the previous section. The current-voltage (I-V) characteristics were measured using a semiconductor parameter analyzer. The light transmission measurements were performed using a Xenon lamp and a spectrometer. Atomic Force Microscopy (AFM) and Scanning Electron Microscopy (SEM) are used to examine the surface morphology, before and after annealing. Hall measurement system was used to measure the sheet resistance and electrical properties of the films. XPS is used to find the stoichiometry the films deposited. A White light Ellipsometry was used to calculate the refractive indices of the films.

\subsubsection{Atomic Force Microscopy (AFM)}

The working of Atomic Force Microscopy (AFM) setup used in this work was explained in detail in Chapter 4.

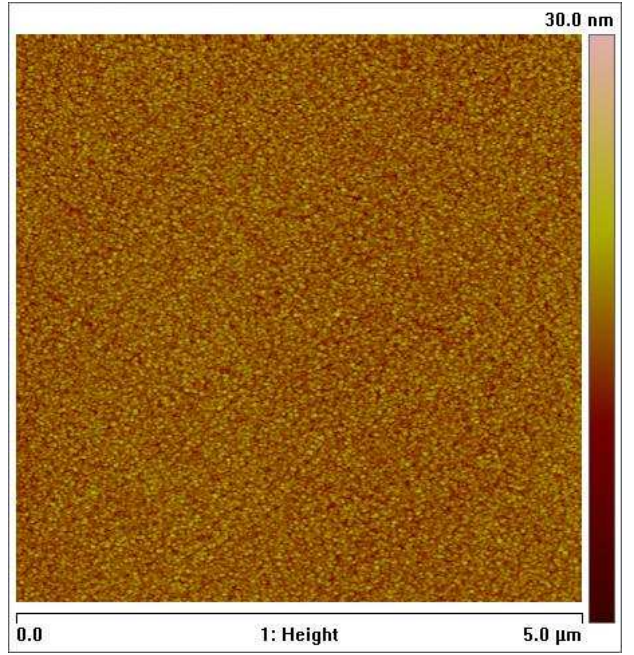

(a)

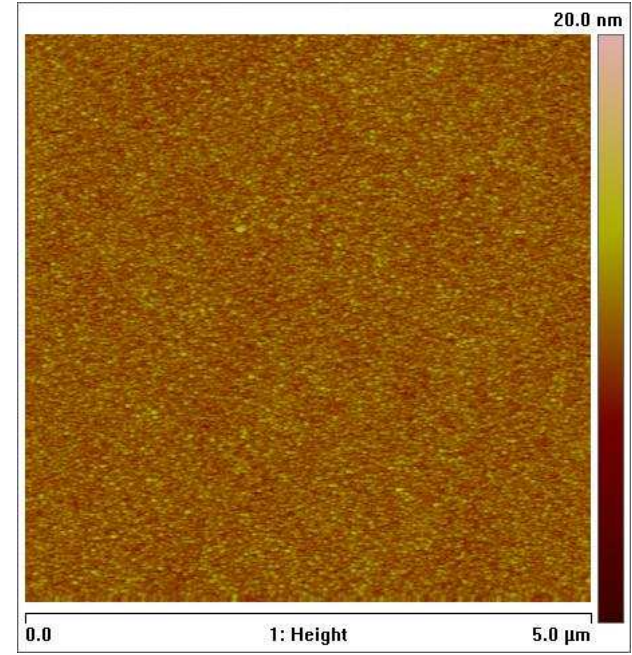

(b)

Figure 5.4: Surface morphology of (a) As deposited contact, (b) $\mathrm{ZnO}$ contact annealed at $300{ }^{\circ} \mathrm{C}$ 
The Ni (2nm)/ Al (2\%wt) alloyed $\mathrm{ZnO}$ films (150nm) were deposited on p-GaN substrates. The films were annealed at $300^{\circ} \mathrm{C}, 500^{\circ} \mathrm{C}$ and $700^{\circ} \mathrm{C}$ temperatures in a $\mathrm{N}_{2}$ ambient for $1 \mathrm{~min}$. Further increase in the annealing temperature did degrade the contacts in terms of increase in the sheet resistance. The surface morphology of the as deposited contact is shown in the Figure 5.4 (a) and the RMS roughness is $\mathbf{1 . 6 7} \mathbf{~ n m}$. In the Figures 5.4 (b), 5.5 (a), 5.5 (b) surface morphology of the contact annealed at $300^{\circ} \mathrm{C}, 500^{\circ} \mathrm{C}$ and $700^{\circ} \mathrm{C}$ temperatures are shown. The RMS roughness values are $0.868 \mathbf{n m}, 0.269 \mathbf{~ n m}$ and 1.13 nm for contacts annealed at $300^{\circ} \mathrm{C}, 500^{\circ} \mathrm{C}$ and $700^{\circ} \mathrm{C}$ temperatures respectively. From the annealing studies, it can be observed that, $\mathrm{ZnO}$ contacts are morphologically stable even when annealed at high temperatures.

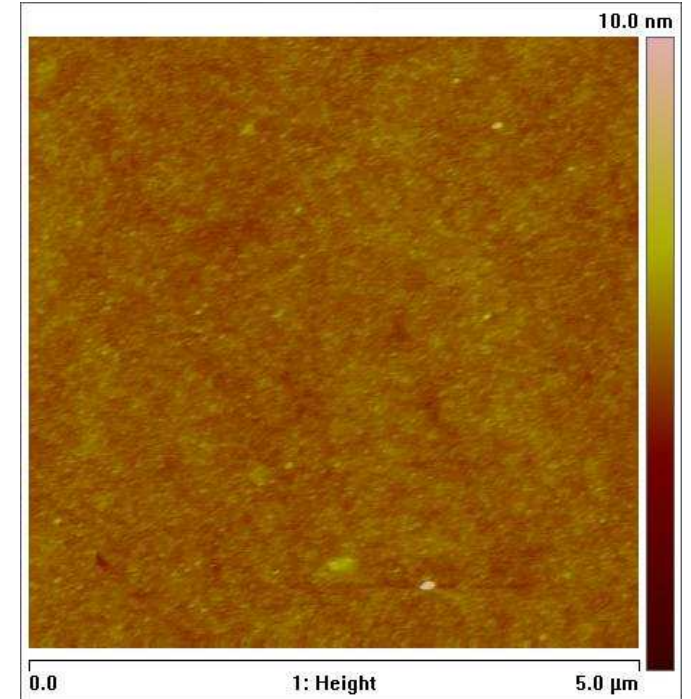

(a)

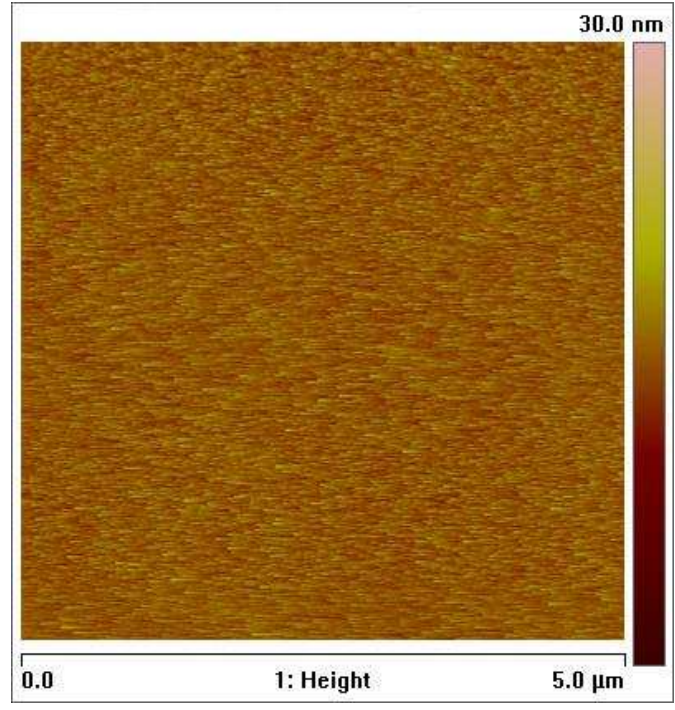

(b)

Figure 5.5: Surface morphology of (a) $\mathrm{ZnO}$ contact annealed at $500{ }^{\circ} \mathrm{C}$, (b) $\mathrm{ZnO}$ contact annealed at $700{ }^{\circ} \mathrm{C}$

\subsubsection{Scanning Electron Microscopy (SEM)}

The working of Scanning Electron Microscopy (SEM) setup used in this work was explained in detail in Chapter 4. The $\mathrm{Ni}(2 \mathrm{~nm}) / \mathrm{Al}(2 \% \mathrm{wt})$ alloyed $\mathrm{ZnO}$ films $(150 \mathrm{~nm})$ were deposited on $\mathrm{p}-\mathrm{GaN}$ substrates. The films were annealed at $300^{\circ} \mathrm{C}, 500^{\circ} \mathrm{C}$ and $700^{\circ} \mathrm{C}$ temperatures in a $\mathrm{N}_{2}$ ambient for 1 min. Further increase in the annealing temperature did 
degrade the contacts in terms of increase in the sheet resistance. The surface morphology of the as deposited contact is shown in the Figure 5.6 (a).

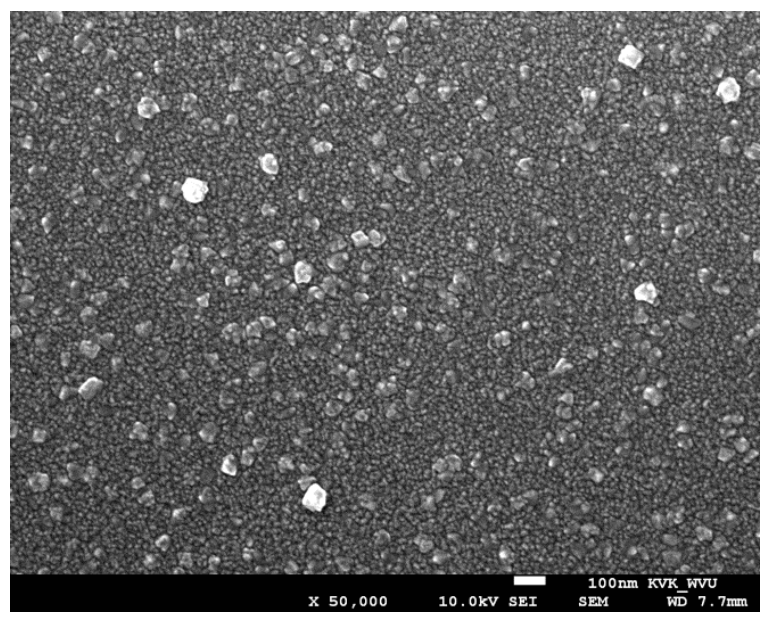

(a)

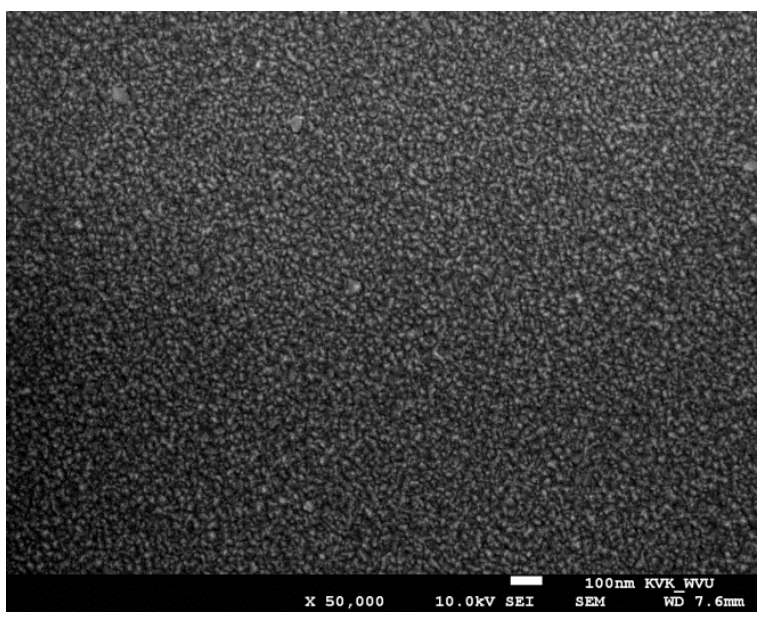

(b)

Figure 5.6: Surface morphology of (a) As deposited contact, (b) $\mathrm{ZnO}$ contact annealed at $300{ }^{\circ} \mathrm{C}$

In the Figures 5.6 (b), 5.7 (a), 5.7 (b) surface morphology of the contact annealed at $300^{\circ} \mathrm{C}, 500^{\circ} \mathrm{C}$ and $700^{\circ} \mathrm{C}$ temperatures are shown. From the annealing studies, it can be observed that, $\mathrm{ZnO}$ contacts are morphologically stable (smooth) even when annealed at high temperatures.

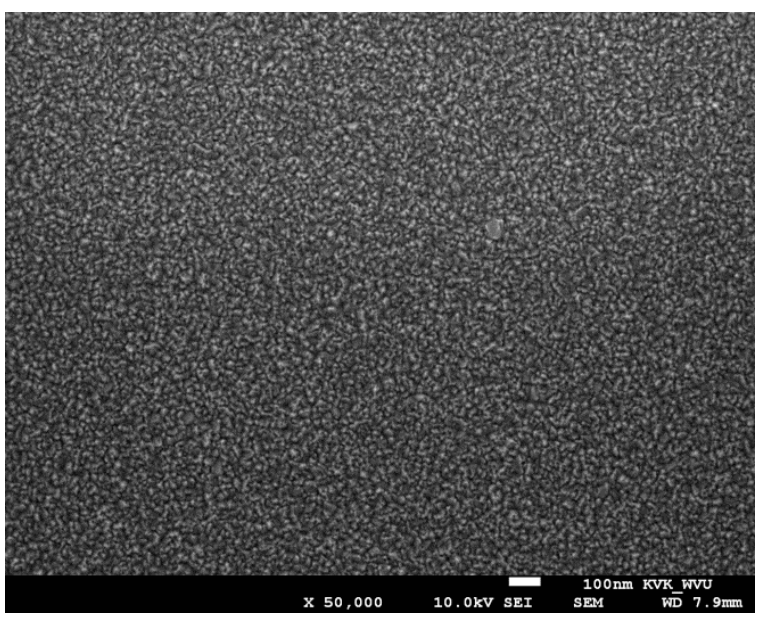

(a)

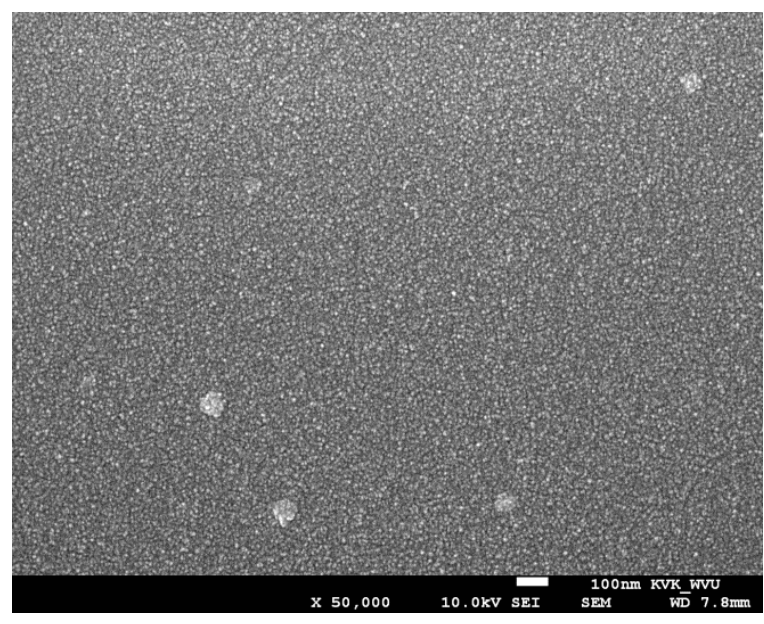

(b)

Figure 5.7: Surface morphology of (a) $\mathrm{ZnO}$ contact annealed at $500{ }^{\circ} \mathrm{C}$, (b) $\mathrm{ZnO}$ contact annealed at $700{ }^{\circ} \mathrm{C}$ 


\subsubsection{X-ray Photoelectron Spectroscopy (XPS)}

The detailed working mechanism of the XPS used in this work is explained in chapter 4. In this work, the XPS is used to find the elemental composition in the Al alloyed $\mathrm{ZnO}$ films. The $\mathrm{ZnO}$ films were deposited on glass substrates using e-beam evaporation mechanism. Al alloying is used to increase the doping concentration in the $\mathrm{ZnO}$ films to make them more conductive. The Al wt $\%$ is decided based on the XPS results. For that, a Sputter XPS (Depth profiling) mechanism is employed. The sample is prepared in an Air Clean 600 work station to avoid any contamination in the sample preparation and then the sample is placed on a sample holder of 1 inch or 2 inch diameter. The XPS spectrum is taken from the samples under Ultra High Vacuum (UHV) conditions. Figure 5.8 gives the surface scan on the $\mathrm{Al}$ alloyed $\mathrm{ZnO}$ films. The Zinc to Oxygen concentration ratio was calculated to be equal to 1:0.8 respectively in the deposited films.

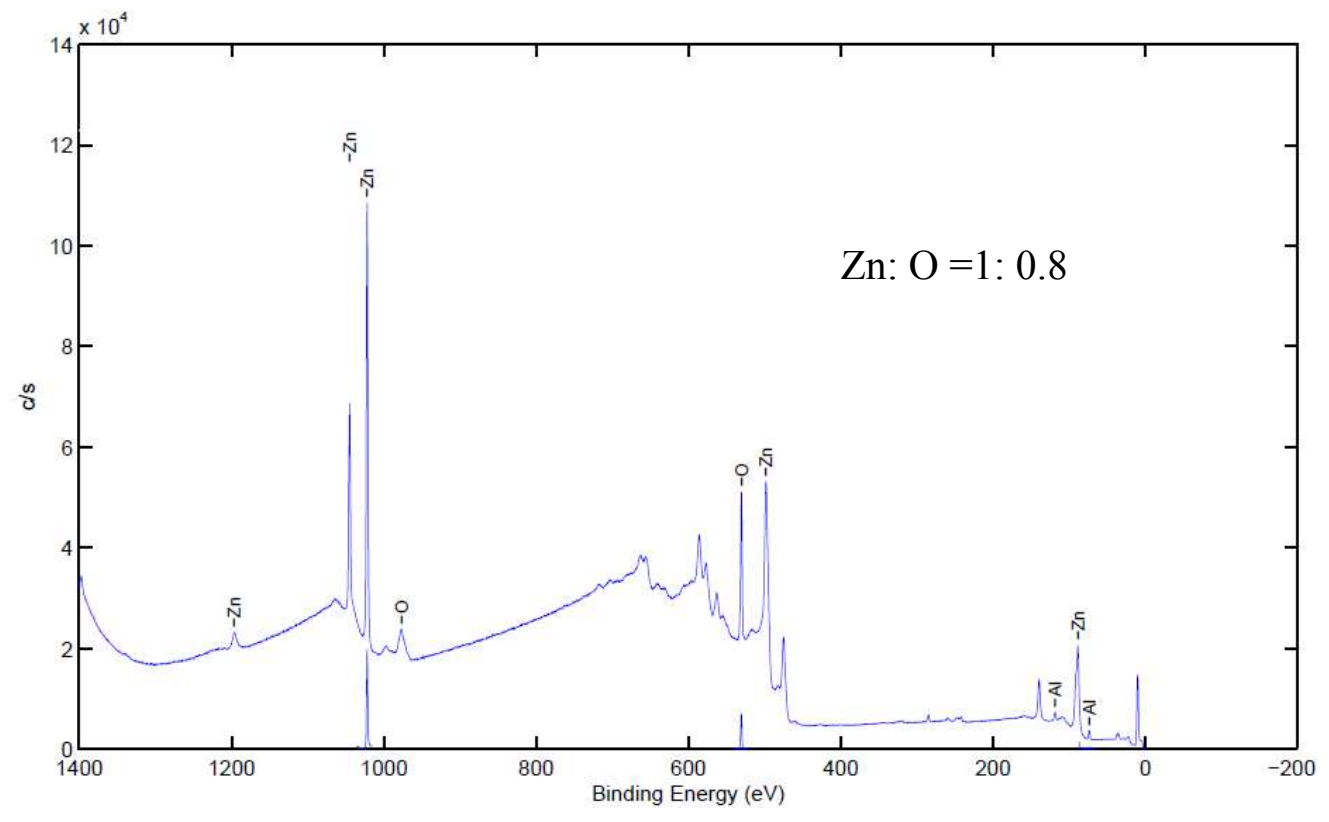

Figure 5.8: Surface scan of $\mathrm{Al}$ alloyed (5\%wt) $\mathrm{ZnO}(150 \mathrm{~nm})$ contact deposited on the glass substrate.

The Ni (2nm)/ Al alloyed (5\%wt) $\mathrm{ZnO}(150 \mathrm{~nm})$ used in this work is deposited on a glass substrate using ion beam assisted e-beam evaporation mechanism. The 
contact is then annealed at $500^{\circ} \mathrm{C}$. Figure 5.9 gives us the (a) $\mathrm{Zn} 2 \mathrm{p} 3$ peak in $\mathrm{ZnO}$ with binding energy $1021.8 \mathrm{eV}$ [135] and (b) $\mathrm{O} 1 \mathrm{~s}$ peak with binding energy $530.4 \mathrm{eV}$ [136]. Based on these binding energy results, it can be confirmed that the film deposited is a $\mathrm{ZnO}$ film.

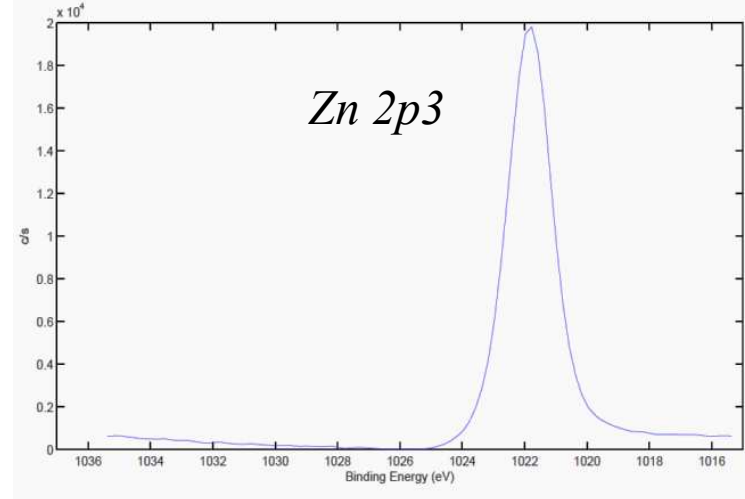

(a)

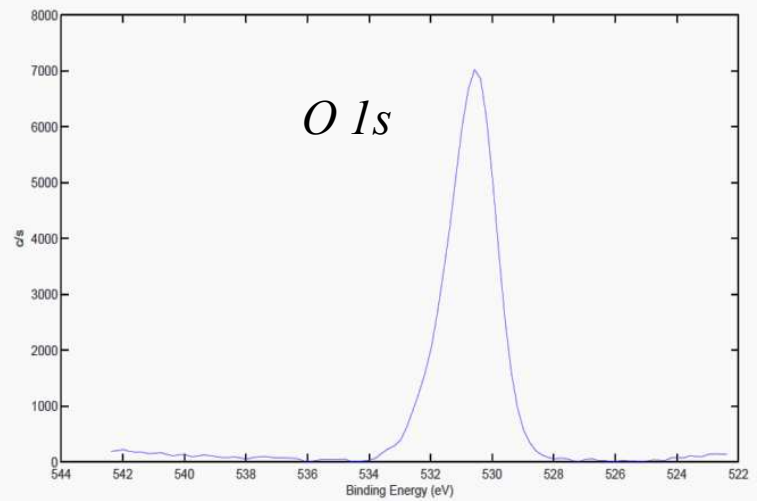

(b)

Figure 5.9: Depth profiling scan of (a) $\mathrm{Zn} 2 \mathrm{p} 3$ peak, (b) $\mathrm{O}$ 1s peak in $\mathrm{Al}$ alloyed $\mathrm{ZnO}$ films

Figure 5.10, gives us the $\mathrm{Al} 2 \mathrm{p}$ peak in the $\mathrm{Al}$ alloyed (5\%wt) $\mathrm{ZnO}$ films. The binding energy of $\mathrm{Al} 2 \mathrm{p}$ peak obtained from the plot is $74.0 \mathrm{eV}$. From the database [137], $\mathrm{Al} 2 \mathrm{p}$ peak in $\mathrm{Al}_{2} \mathrm{O}_{3}$ have the binding energy of $74.0 \mathrm{eV}$. The conduction characteristics of $\mathrm{ZnO}$ are primarily dominated by electrons generated by $\mathrm{O}^{2-}$ vacancy and $\mathrm{Zn}$ interstitials. $\mathrm{Al}$ alloyed $\mathrm{ZnO}$ have high conductivity due to the contribution from $\mathrm{Al}^{3+}$ ions on substitutional sites of $\mathrm{Zn}^{2+}$ hence $\mathrm{Al}$ alloyed films have higher conduction than un-alloyed $\mathrm{ZnO}$ films.

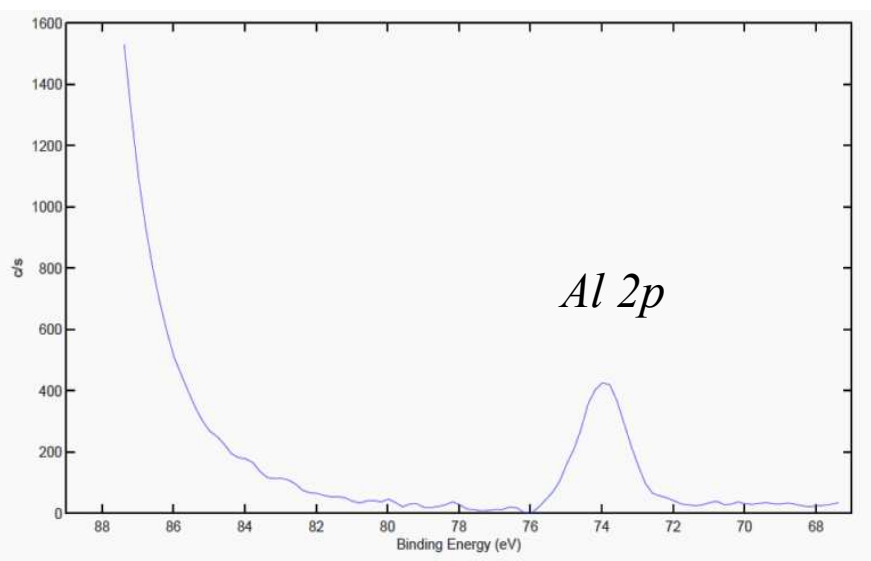

Figure 5.10: Depth profiling scan of (a) $\mathrm{Al} 2 \mathrm{p}$ peak in $\mathrm{Al}(5 \% \mathrm{wt})$ alloyed $\mathrm{ZnO}$ films 
Based on the result shown in Figure 5.10, it can be observed that, with increase in the $\mathrm{Al}$ alloying in $\mathrm{ZnO}$ (for 5\% wt $\mathrm{Al}$ ), $\mathrm{Al}$ was bonded to oxygen forming more resistive $\mathrm{Al}_{2} \mathrm{O}_{3}$ instead of acting as a source for more charge carriers (electrons), reducing the overall conductivity of the films deposited. Therefore, the amount of $\mathrm{Al}$ alloying in the $\mathrm{ZnO}$ for better electrical properties should be limited to $2 \% \mathrm{wt}$.

\subsubsection{Electrical Characterization}

The $\mathrm{ZnO}$ based contact $\mathrm{Ni}(2 \mathrm{~nm}) / \mathrm{Al}$ alloyed (2\%wt) $\mathrm{ZnO}$ $(150 \mathrm{~nm})$ used in this work is deposited on, $\mathrm{p}-\mathrm{GaN}$ (70nm thick) samples that were grown in a MOVPE chamber by Dr. Korakakis's group and on plain glass substrates. Before the deposition, the p-GaN samples were annealed at $800^{\circ} \mathrm{C}$ in $\mathrm{N}_{2}$ ambient for 5minutes to activate the $\mathrm{Mg}$ dopants. These samples were degreased and treated with acids like $\mathrm{HCl}$ and $\mathrm{BOE}$ to remove any native oxides present on the surface. The TLM and c-TLM patterns were transferred using AZ5214 EIR Image reversal PR. Using ion beam assisted e-beam evaporation deposition, the $\mathrm{ZnO}$ based contact scheme mentioned above is deposited on the surface treated p-GaN substrate and glass substrates. The deposited contacts were annealed at $500{ }^{\circ} \mathrm{C}, 600{ }^{\circ} \mathrm{C}, 700^{\circ} \mathrm{C}$ and $800^{\circ} \mathrm{C}$ in $\mathrm{N}_{2}$ ambient for 1 minute. The current-voltage (I-V) characteristics were measured using a semiconductor parameter analyzer. The electrical properties were measured using a Hall measurement system.

The Hall measurement system is used to calculate the sheet resistance, mobility and carrier concentration in a semiconductor film. Hall Effect is defined as, the production of a voltage difference across an electrical conductor, transverse to an electric current in the conductor and a magnetic field perpendicular to the current. The Hall coefficient is the ratio of the induced electric field to the product of the current density and the applied magnetic field [138]. In this case, we will be using it on a semiconductor film, when a currentcarrying film is kept in a magnetic field, the charge carriers of the semiconductor experience a force in a direction perpendicular to both the magnetic field and the current. The Hall coefficient can be calculated using the equation 5.4 [138]. 


$$
R_{H}=\frac{E_{y}}{j_{x} B}
$$

Where, $\mathrm{j}$ is the current density, $\mathrm{E}$ is the induced electric field and $\mathrm{B}$ is the magnetic field. The expression for the Hall coefficient in semiconductors can be given in the equation 5.5 [139],

$$
R_{H}=\frac{p \mu_{h}^{2}-n \mu_{e}^{2}}{e\left(p \mu_{h}+n \mu_{e}\right)^{2}}
$$

Where, $\mathrm{n}$ is the electron concentration, $\mathrm{p}$ is the hole concentration, $\mu_{\mathrm{e}}$ is the electron mobility and $\mu_{\mathrm{h}}$ is the hole mobility. The set-up used in this experiment is shown in the Figure 5.11 [140].

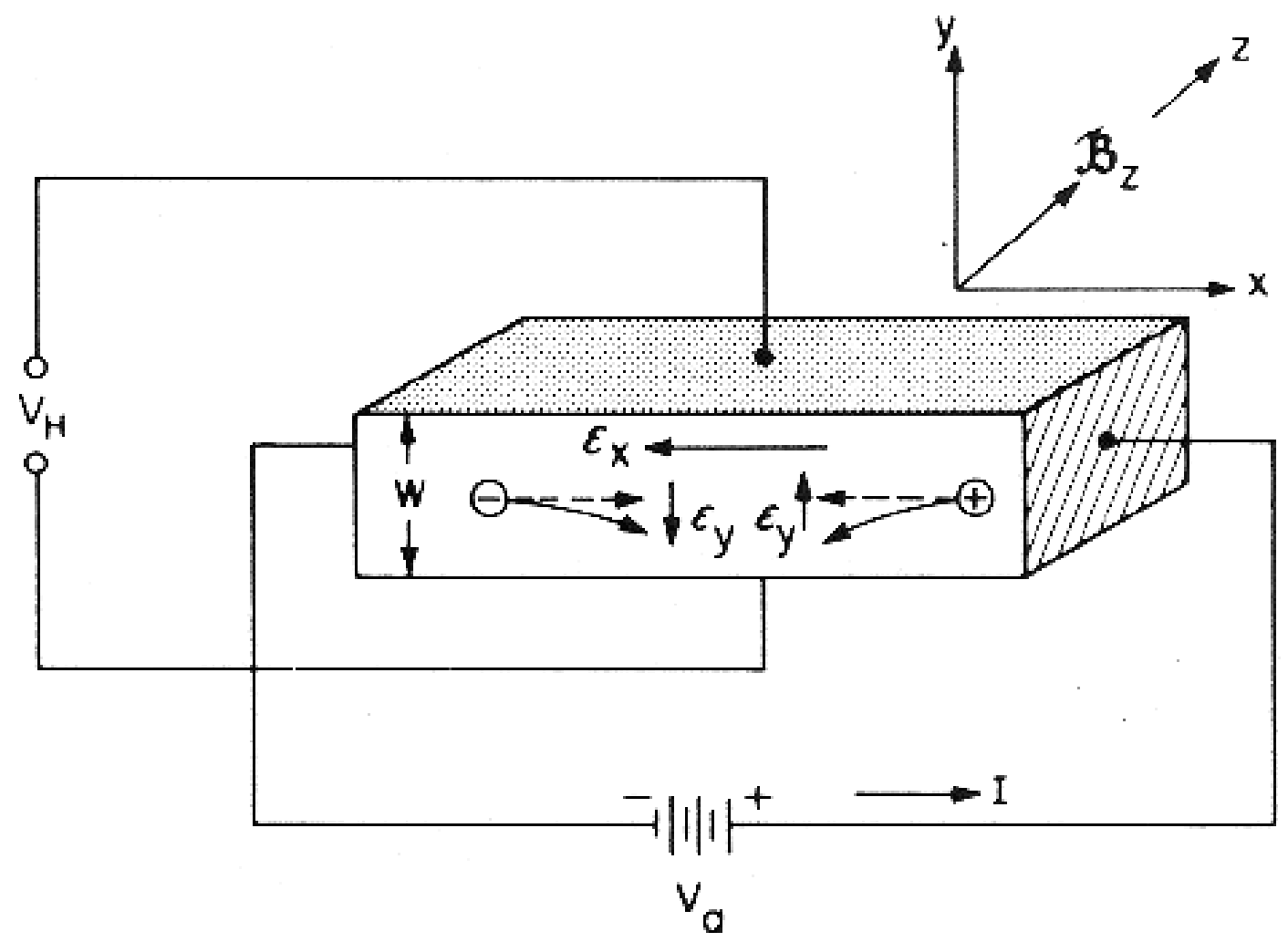

Figure 5.11: The basic schematic of the hall measurement system [140]

In this experiment, several different samples were prepared for hall measurements using an ion beam assisted e-beam evaporation deposition. The parameters that are varied during the experiment were oxygen flow rates during the deposition and post annealing temperatures. Table 5.1 gives us the variation of electrical properties with different oxygen flows and annealed at $800^{\circ} \mathrm{C}$ in $\mathrm{N}_{2}$ ambient for 1 minute. 
Table 5.1: Hall measurements with varying oxygen flow rates during deposition.

\begin{tabular}{|c|c|c|c|}
\hline & $\begin{array}{c}\text { Mobility } \\
\left(\mathrm{cm}^{2} / \mathrm{V} . s\right)\end{array}$ & $\begin{array}{c}\text { Resistivity } \\
(\text { Ohm.cm) }\end{array}$ & Transmission \\
\hline $\begin{array}{c}\text { ZnO 5sccm } \\
\text { O2 flow }\end{array}$ & 67.875 & $6.6225 \mathrm{E}-4$ & $\sim 50 \%$ \\
\hline $\begin{array}{c}\text { ZnO 9sccm } \\
\text { O2 flow }\end{array}$ & 14.725 & $6.45 \mathrm{E}-03$ & $80-85 \%$ \\
\hline $\begin{array}{c}\text { Expected* } \\
\text { (Literature) }\end{array}$ & 18 to 60 (high) & $1.4 \mathrm{E}-4$ to 2E-4 & $\sim 85 \%$ \\
\hline
\end{tabular}

It is observed that, by increasing the oxygen flow rates, the sheet resistance is increased. Further increase in the oxygen did increase the resistance; hence for further studies an oxygen flow rate of $9 \mathrm{sccm}$ is used. This flow rate gives the optimum transmission and electrical properties. The above shown results were taken from the films that were annealed at $800^{\circ} \mathrm{C}$ in $\mathrm{N}_{2}$ ambient for 1 minute.

Table 5.2: Hall measurements with varying substrate temperatures.

\begin{tabular}{|c|c|c|c|}
\hline & $\begin{array}{c}\text { Carrier Concentration } \\
\left(\mathrm{cm}^{3}\right)\end{array}$ & $\begin{array}{c}\text { Mobility } \\
\left(\mathrm{cm}^{2} / \mathrm{V} . \mathrm{s}\right)\end{array}$ & $\begin{array}{c}\text { Resistivity } \\
(\text { Ohm.cm) }\end{array}$ \\
\hline \begin{tabular}{r|c|}
$\mathrm{ZnO} @$ \\
$150^{\circ} \mathrm{C}$
\end{tabular} & $-1.18 \mathrm{E} 20$ & 0.516 & $6.34 \mathrm{E}-2$ \\
\hline $\mathrm{ZnO} @$ & $-8.87 \mathrm{E} 19$ & 0.836 & $2.47 \mathrm{E}-2$ \\
\hline $200^{\circ} \mathrm{C}$ & $-7.89 \mathrm{E} 19$ & 0.879 & $1.29 \mathrm{E}-2$ \\
\hline $\mathrm{ZnO} @$ & & & \\
\hline $250^{\circ} \mathrm{C}$ & & & \\
\hline
\end{tabular}


But these high annealing temperatures which result in low sheet resistance cannot be used in an LED fabrication process due to some process/material compatibility issues. Hence, instead of annealing the films after depositing, increasing the substrate temperatures during the deposition is employed to deposit poly crystalline films. The variation of sheet resistance, mobility and carrier concentration with varying deposition temperature conditions in shown in the Table 5.2. We had some issues with the e-beam evaporator that was being used for the deposition; hence further studies were made by depositing films using RF sputtering mechanism.

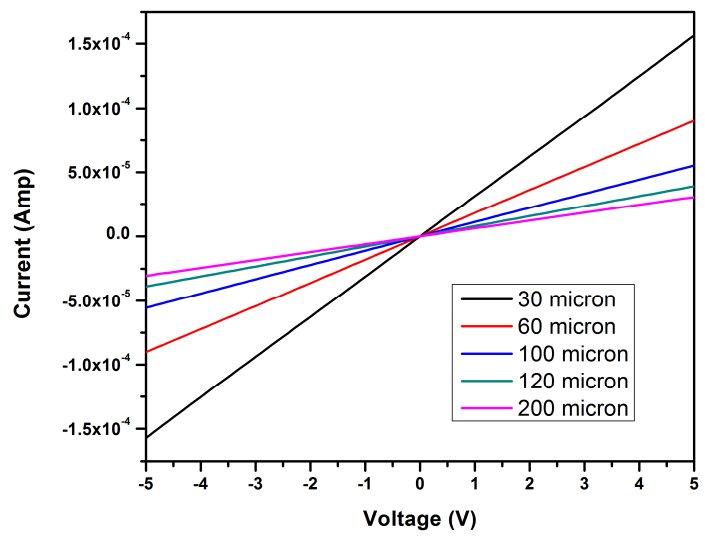

(a)

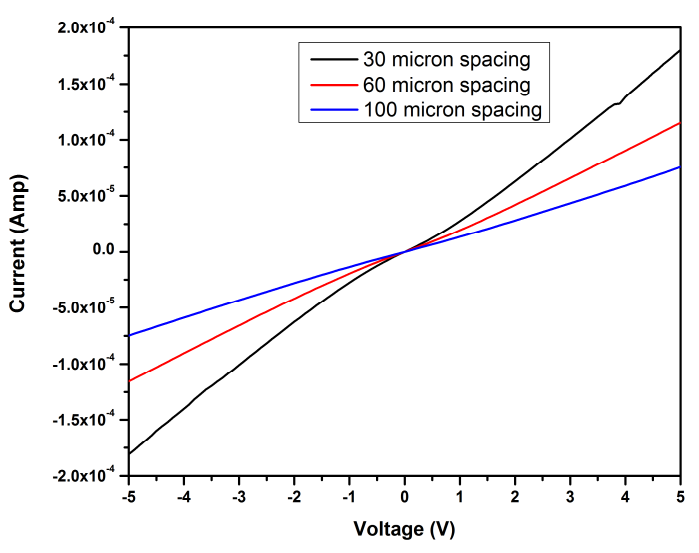

(b)

Figure 5.12: I-Vs of, (a) $\mathrm{Ni}(2 \mathrm{~nm}) / \mathrm{ZnO}(100 \mathrm{~nm})$, (b) $\mathrm{Ni}(25 \mathrm{~nm}) / \mathrm{ZnO}(100 \mathrm{~nm})$ contact pads

From the I-Vs shown in Figure 5.12 (a), it can be observed that, the contact scheme forms an ohmic contact with $\mathrm{p}-\mathrm{GaN}$ and the behavior with increase in $\mathrm{Ni}$ thickness to $25 \mathrm{~nm}$. The resistances were calculated for contacts with different pad spacing. In Figure 5.13 (a), a plot is made between the total resistance and the pad spacing. Using Origin 8.0, the data was fitted linearly and the specific contact resistance and transfer lengths were calculated from the plot. The specific contact resistivity value of the contact is shown in the Figure 5.13 (b). Optimization of $\mathrm{Ni}$ thickness is important for both, electrical and optical characteristics. When the thickness of the $\mathrm{Ni}$ was increased up to $5 \mathrm{~nm}$, the transmission was reduced by $\sim 50 \%$ in the UV and visible region. For Ni thickness $2 \mathrm{~nm}$, the electrical and optical properties of the films were optimal, with around $80 \%$ transmission and good ohmic contact with 
p-GaN. Therefore, $2 \mathrm{~nm} \mathrm{Ni}$ was employed for this study. The minimum specific contact obtained was 1.95E-01 $\Omega . \mathrm{cm}^{2}$.

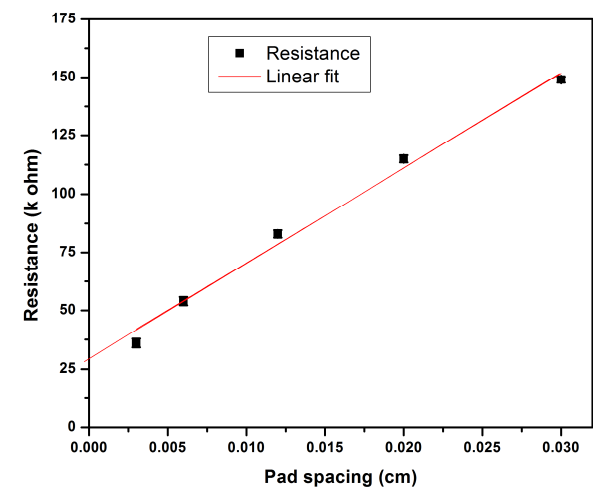

(a)

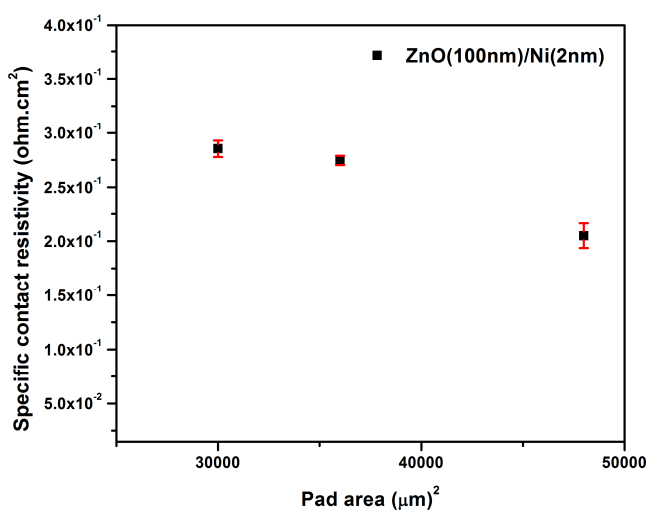

(b)

Figure 5.13: (a) Plot showing pad spacing Vs Total resistance, (b) Specific contact resistivity of the $\mathrm{Ni}(2 \mathrm{~nm}) / \mathrm{ZnO}(100 \mathrm{~nm})$ contact pads with $\mathrm{p}-\mathrm{GaN}$.

\subsubsection{Optical Characterization}

The light transmission measurements were performed using a Xenon lamp and a spectrometer. A glass substrate is used as a standard reference. The Ni $(2 \mathrm{~nm}) / 100 \mathrm{~nm}$ $(\mathrm{ZnO})$ samples were deposited on glass substrates by varying the oxygen flow rates as shown in Figure 5.14.

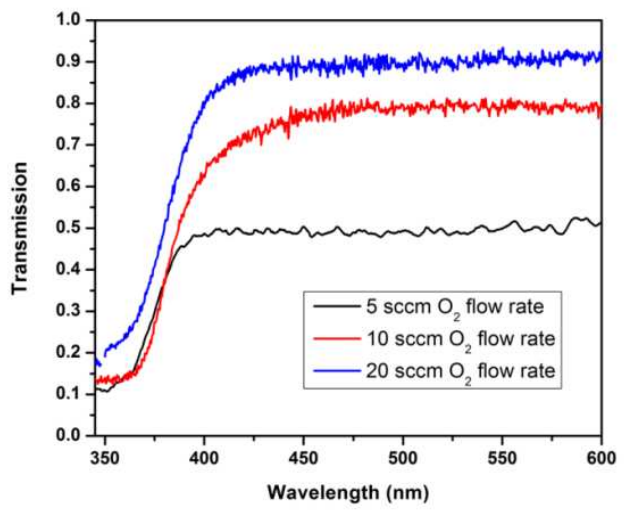

Figure 5.14: Transmission measurement of $\mathrm{Ni}(2 \mathrm{~nm}) / \mathrm{ZnO}(100 \mathrm{~nm})$ with varying oxygen flow rates. 
From the Figure 5.14, it can be observed that, for $\mathrm{Ni}(2 \mathrm{~nm}) / \mathrm{ZnO}$ $(100 \mathrm{~nm})$ contact, for different oxygen flow rates, $5 \mathrm{sccm} \mathrm{O}_{2}$ flow gives the low transmission and $20 \mathrm{sccm}$ flow rate gives better transmission. But $10 \mathrm{sccm} \mathrm{O}_{2}$ flow rate is used in this work, because, this condition gives the optimum transmission and electrical characteristics. The next optical characterization employed in this work was use of Ellipsometry to calculate the refractive indices of the films deposited. The refractive indices were used in the simulation model developed for comparison with the experimental model. The basic schematic of the Ellipsometry setup used in this experiment is shown in the Figure 5.15 [141].

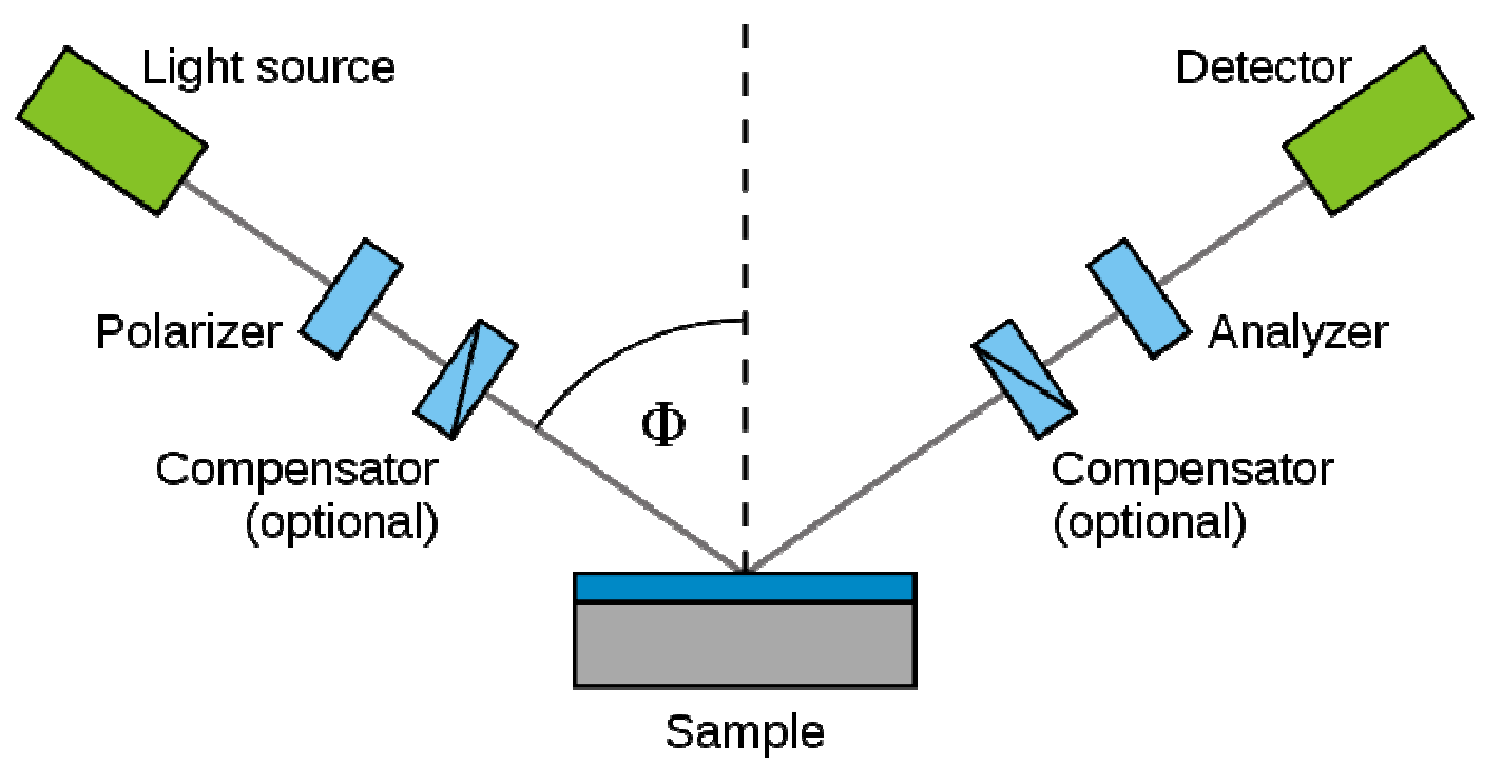

Figure 5.15: The basic schematic of the Ellipsometry setup used in this experiment [141]

The white light is projected on-to the sample, at different angles and the reflected light is collected by the detector. The change in the polarization of light reflected off the sample is used to calculate the thickness and the refractive index of the layer [141. The angle of incidence is varied from 50 to 65 degrees. The experimental data is fitted using the Cauchy model to calculate the thickness and refractive indices. Figure 5.16 (a), gives the plot showing the experimental data fitted using the Cauchy model and Figure 5.16 (b), gives the plot showing the variation of refractive indices of the $\mathrm{ZnO}$ film with wave length. 


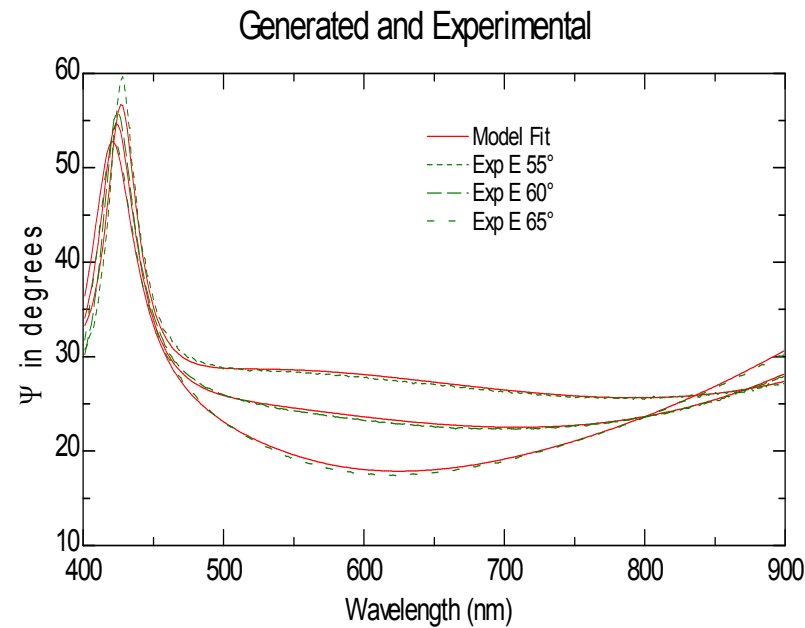

(a)

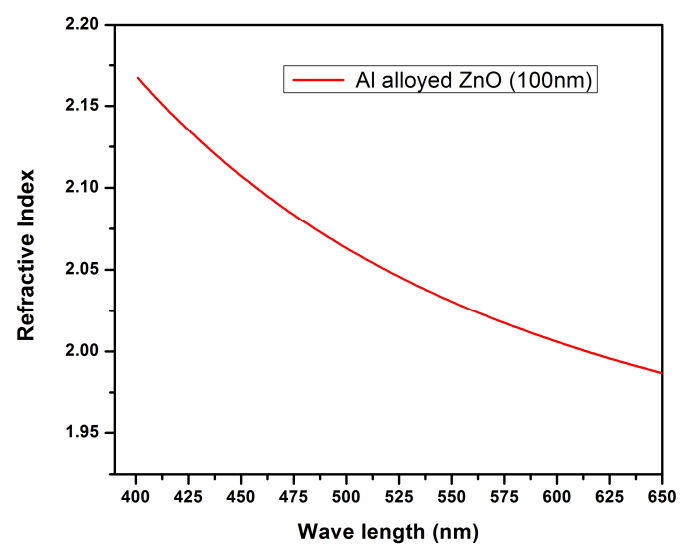

(b)

Figure 5.16: (a) Ellipsometry data is fitted using Cauchy model, (b) Refractive Indices Vs wave length

\section{5. $\mathrm{ZnO}$ contacts integrated to GaN/InGaN MQW LEDs}

The $\mathrm{Ni} / \mathrm{Au}$ contacts are the conventionally used contacts on $\mathrm{InGaN}$ based blue and green LEDs [114]. For current spreading and better extraction, Al alloyed $\mathrm{ZnO}$ contacts were deposited on InGaN LEDs. The basic schematic of the InGaN based LED used in this work is shown in Figure 5.17.

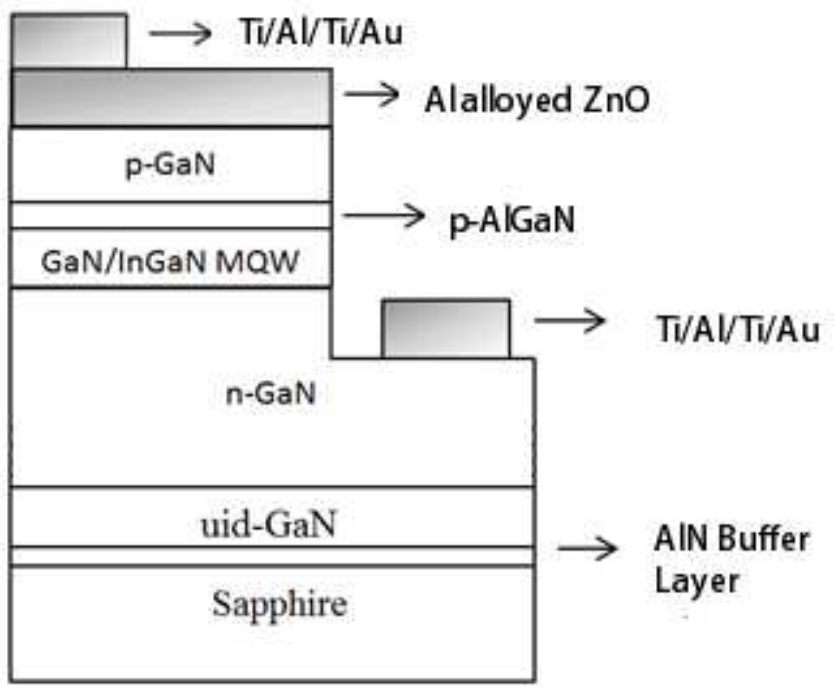

Figure 5.17: InGaN LED structure with $\mathrm{ZnO}$ contacts used in this work. 
The $\mathrm{Ti}(2 \mathrm{~nm}) / \mathrm{Al}(100 \mathrm{~nm}) / \mathrm{Ti}(30 \mathrm{~nm}) / \mathrm{Au}(200 \mathrm{~nm})$ contact is deposited on a $\mathrm{Ni}(2 \mathrm{~nm}) / \mathrm{ZnO}(100 \mathrm{~nm})$ contacts as a metal pads. It was annealed at $350^{\circ} \mathrm{C}$ in air for 3 minutes. Figure 5.18 gives us the $\mathrm{I}-\mathrm{Vs}$ between $\mathrm{ZnO}$ contact and $\mathrm{Ti} / \mathrm{Al}$ (a) unannealed, (b) annealed, contact scheme.

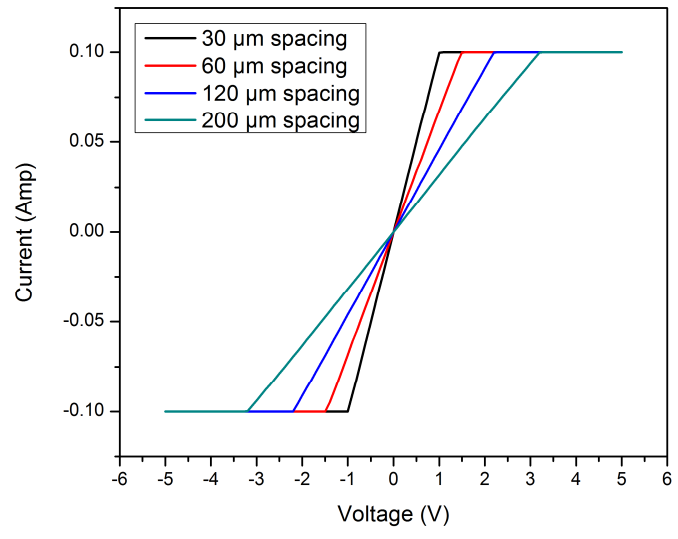

(a)

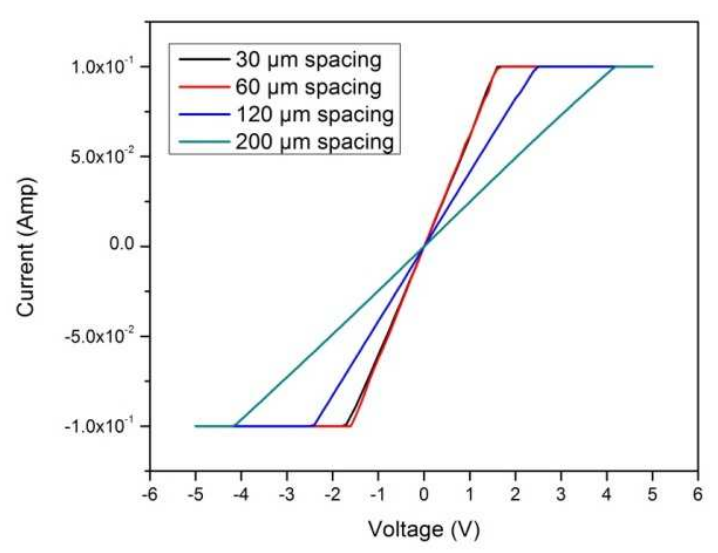

(b)

Figure 5.18: $\mathrm{I}-\mathrm{V}$ between $\mathrm{Ti} / \mathrm{Al} / \mathrm{Ti} / \mathrm{Au}$ and $\mathrm{Ni} / \mathrm{ZnO}$ (a) unannealed contacts, (b) annealed at $350^{\circ} \mathrm{C}$

From the I-Vs, shown in Figure 5.18, the resistances were calculated for contacts with different pad spacing. A plot is made between the total resistance and the pad spacing. Using Origin 8.0, the data is fitted linearly and the specific contact resistance and transfer lengths were calculated from the plot.

Table 5.3: Specific Contact resistance for unannealed contact scheme.

\begin{tabular}{|c|c|c|c|}
\hline Un-annealed & $400 \mu \mathrm{m} \times 120 \mu \mathrm{m}$ & $300 \mu \mathrm{m} \times 120 \mu \mathrm{m}$ & $300 \mu \mathrm{m} \times 100 \mu \mathrm{m}$ \\
\hline $\mathrm{R}_{\mathrm{c}}(\Omega)$ & 3.4052 & 3.3710 & 4.2168 \\
\hline $\mathrm{L}_{\mathrm{t}}(\mu \mathrm{m})$ & 0.40 & 0.27 & 0.097 \\
\hline $\mathrm{W}(\mu \mathrm{m})$ & 400 & 300 & 300 \\
\hline$\rho_{\mathrm{c}}\left(\Omega \cdot \mathrm{cm}^{2}\right)$ & $5.4390 \mathrm{E}-04$ & $2.7525 \mathrm{E}-04$ & $1.2271 \mathrm{E}-04$ \\
\hline
\end{tabular}


The specific contact resistivity values between unannealed $\mathrm{Ti}(2 \mathrm{~nm}) /$ $\mathrm{Al}(100 \mathrm{~nm}) / \mathrm{Ti}(30 \mathrm{~nm}) / \mathrm{Au}(200 \mathrm{~nm})$ and $\mathrm{Ni}(2 \mathrm{~nm}) / \mathrm{ZnO}(100 \mathrm{~nm})$ is shown in Table 5.3 and contacts annealed at $350^{\circ} \mathrm{C}$ is shown in Table 5.4. Hence, a lower specific contact resistivity of 2.6358E-05 $\Omega . \mathrm{cm}^{2}$ is obtained by annealing the contact at $350^{\circ} \mathrm{C}$.

Table 5.4: Specific Contact resistance for contact scheme annealed at $350^{\circ} \mathrm{C}$.

\begin{tabular}{|c|c|c|c|}
\hline $\begin{array}{c}\text { Annealed @350 C } \\
\text { in Air }\end{array}$ & $400 \mu \mathrm{m} X 120 \mu \mathrm{m}$ & $300 \mu \mathrm{m} X 120 \mu \mathrm{m}$ & $300 \mu \mathrm{m} \times 100 \mu \mathrm{m}$ \\
\hline $\mathrm{R}_{\mathrm{c}}(\Omega)$ & 1.204 & 3.5441 & 3.9168 \\
\hline $\mathrm{L}_{\mathrm{t}}(\mu \mathrm{m})$ & 0.054 & 0.041 & 0.057 \\
\hline $\mathrm{W}(\mu \mathrm{m})$ & 400 & 300 & 300 \\
\hline$\rho_{\mathrm{c}}\left(\Omega . \mathrm{cm}^{2}\right)$ & $2.6358 \mathrm{E}-05$ & 4.1884E-05 & 4.9273E-05 \\
\hline
\end{tabular}

The $\mathrm{GaN} / \mathrm{In}_{\mathrm{x}} \mathrm{Ga}_{1-\mathrm{x}} \mathrm{N}$ MQW LED with the Distributed Bragg Reflectors (DBR) and Planar LED were grown in a MOVPE chamber by Dr. Korakakis group. The grown LEDs were fabricated using the process explained in Chapter 3.

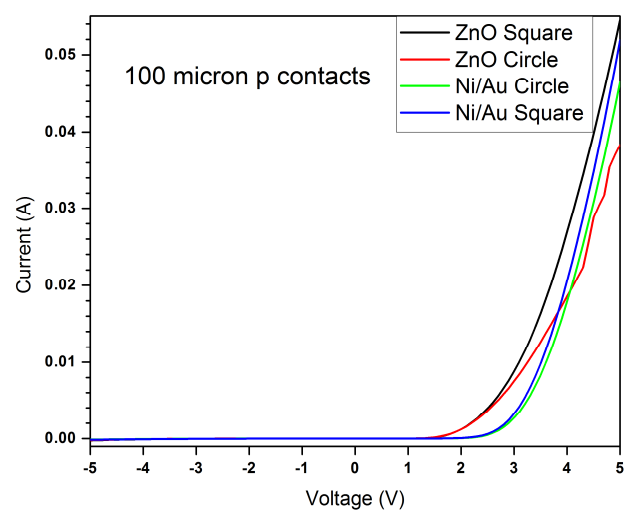

(a)

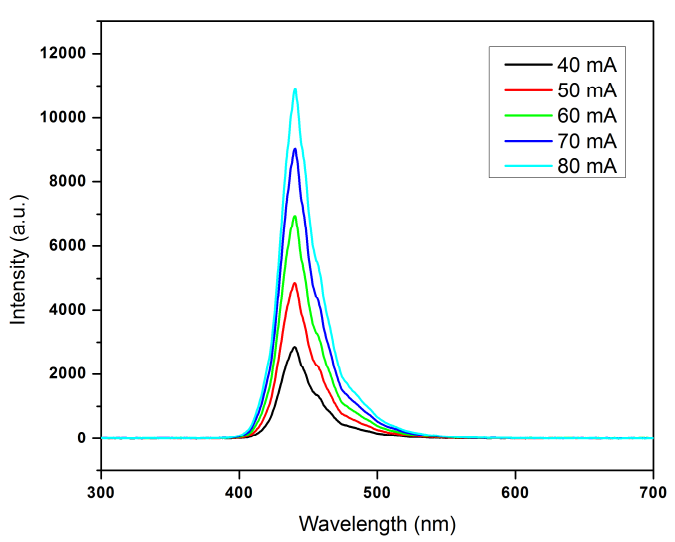

(b)

Figure 5.19: (a) $\mathrm{I}-\mathrm{V}$ comparison with conventional $\mathrm{Ni} / \mathrm{Au}$ contacts (b) EL spectrum of GaN/InGaN MQW LED @ 455nm emission 
Optical and electrical characterization was done on the processed LEDs. The Electro luminescence (EL) spectrum obtained using a B\&W Tek Spectrometer at $6 \mathrm{~V}$ of bias voltage in a LED is shown in Figure 5.19 (b). Figure 5.19 (a) gives the comparison in the I-Vs with the conventional Ni/Au contacts. The plot shows that the turn on voltages and series resistance is comparable to that of $\mathrm{Ni} / \mathrm{Au}$ contacts for $\mathrm{ZnO}$ contacts.

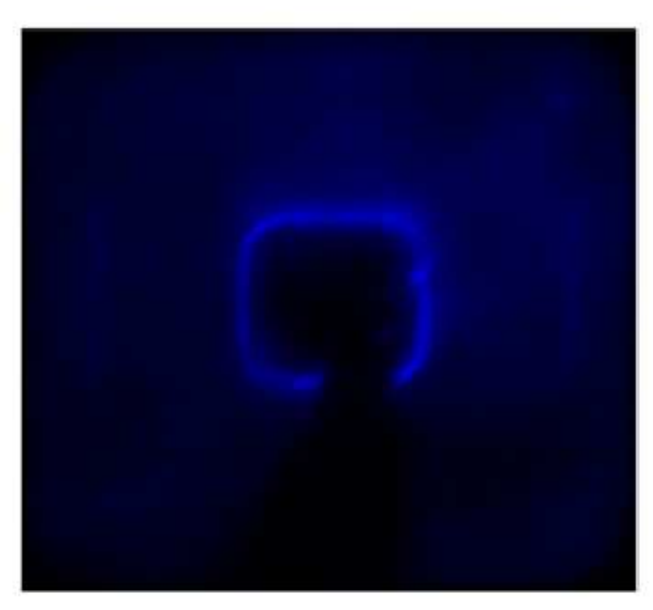

(a)

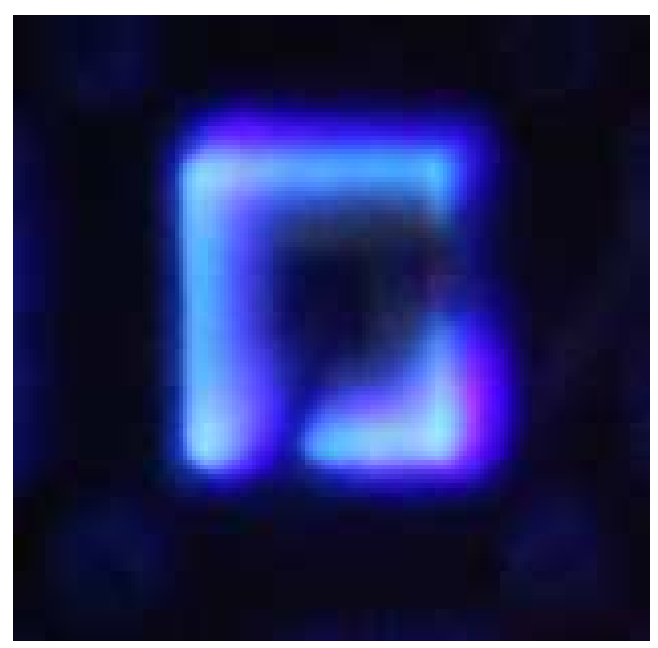

(c)

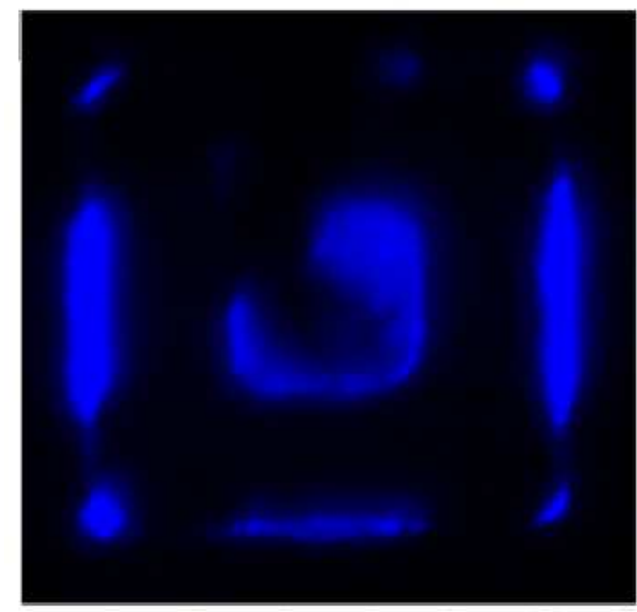

(b)

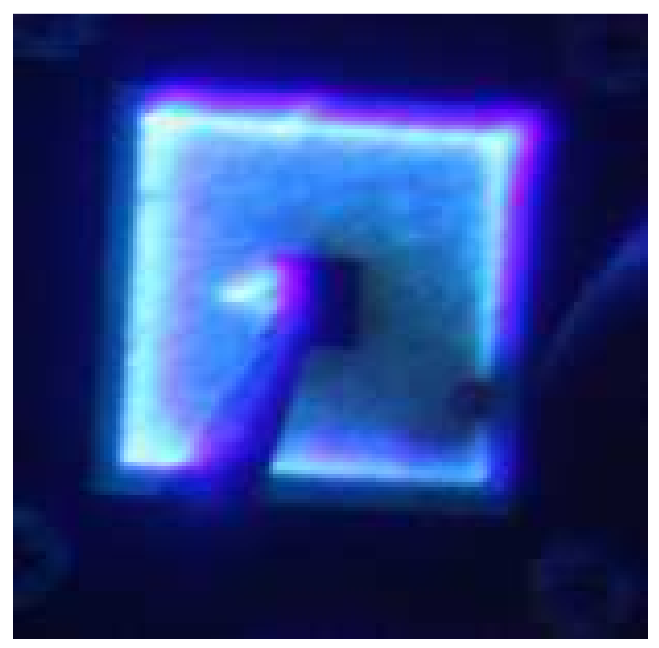

(d)

Figure 5.20: (a) Ni/Au contact on a Planar GaN/InGaN LED (b) Ni/Au contact on a 12 period DBR GaN/InGaN LED (c) Ni/ZnO contact on a Planar GaN/InGaN LED (d) Ni/ZnO contact on a DBR GaN/InGaN LED 
From the Figure 5.20, it can be observed that, in conventional $\mathrm{Ni} / \mathrm{Au}$ contact LEDs, the light is concentrated more around the metal contact region, whereas in $\mathrm{Ni} / \mathrm{ZnO}$ a contact, the light is spread over more of the mesa, hence more light extraction may be possible. With $\mathrm{Ni} / \mathrm{ZnO}$ contacts of low sheet resistance and better ohmic contacts with p-GaN, it may be possible to have even more light extraction than we observed in these preliminary studies. 


\section{Chapter 6}

\section{Conclusions and Future work}

In this work, an Ag-based metallization scheme was developed for Resonant Cavity LED applications and $\mathrm{Al}$ alloyed $\mathrm{ZnO}$ electrodes using the Ion beam assisted E-beam evaporation deposition (IBAD) technique. For the Ag-based metallization scheme, the effect of post annealing treatments on the electrical and optical properties was studied. It was observed that the presence of $\mathrm{Pt}$ as an oxygen diffusion barrier layer prevents agglomeration of the contact, preserving its reflectivity. For the $\mathrm{Al}$ alloyed $\mathrm{ZnO}$ electrodes, the effect of deposition conditions and post annealing treatments on its electrical and optical properties and the usage of thin metal layer to form ohmic contacts with $\mathrm{p}-\mathrm{GaN}$ was studied. It was observed that, annealing the $\mathrm{Ni} / \mathrm{ZnO}$ contact in a nitrogen ambient at high temperatures did reduce the sheet resistance when compared to that of as deposited films, but while processing the GaN/InGaN LEDs, it was not possible for us to include the high temperature annealing step to the process flow, hence a low temperature substrate heating step during deposition was employed in order to deposit polycrystalline conductive films. The specific contact resistivity values between the $\mathrm{ZnO}$ contacts and the $\mathrm{p}-\mathrm{GaN}$ are high when compared to the values reported in the literature, however these values were adequate for the experimental device studies undertaken.

Future work includes the development of highly transparent and conductive $\mathrm{ZnO}$ thin films by optimizing the $\mathrm{Al}$ doping, thickness, annealing and deposition conditions suitable for GaN/InGaN LED fabrication process flow. It is expected that use of low resistance transparent $\mathrm{ZnO}$ contacts will lead to improved external quantum efficiency and operational life-time. The light extraction efficiency of the blue LEDs may be further improved by incorporating micro-patterns or photonic crystals into the $\mathrm{ZnO}$ contacts layers. 


\section{References}

[1] Shih-Yung Huang, Ray-Hua Horng, Yu-Ju Tsai, Po-Rung Lin, Wei-Kai Wang, Zhe Chuan Feng, Dong-Sing Wuu, Semicond. Sci. Technol. 25, 035013 (2010).

[2] "Nick Holonyak, Jr. 2004 Lemelson-MIT Prize Winner". Lemenson-MIT Program. http://web.mit.edu/invent/a-winners/a-holonyak.html. Retrieved 2007-08-13.

[3] J.I. Pankove, J. Luminescence 4, 63, 1971.

[4] http://en.wikipedia.org/wiki/File:PnJunction-LED-E.svg.

[5] S. Nakamura, T. Mukai, M. Senoh (1994). "Candela-Class High-Brightness InGaN/AlGaN Double-Heterostructure Blue-Light-Emitting-Diodes". Appl. Phys. Lett. 64: 1687.

[6] http://en.wikipedia.org/wiki/LED.

[7] "Haitz's law". Nature Photonics 1 (1): 23. 2007.

[8] http://en.wikipedia.org/wiki/File:Haitz_law.svg.

[9] E. Fred Schubert Light-emitting diodes 2nd ed., Cambridge University Press, 2006 ISBN 0521865387 page $16-17$.

[10] "Major Business and Product Milestones". Cree, Inc.

[11] "GaN-based blue light emitting device development by Akasaki and Amano". Takeda Award 2002 Achievement Facts Sheet. The Takeda Foundation. 2002-04-05. Retrieved 2007-11-28.

[12] "Light-emitting gallium nitride-based compound semiconductor device" Nakamura et al., Issue date: November 26, 1996.

[13] http://dels-old.nas.edu/banr/gates1/docs/mtg5docs/bgdocs/fundamentals_applications.pdf.

[14] "Light-emitting diodes", second edition, E.Fred Schubert.

[15] Franklin A. R. and Newman R. "Shaped electroluminescent GaAs diodes" J. Appl. Phys. 35, $1153(1964)$

[16] Fujii T., Gao Y., Sharma R., Hu E. L., DenBaars S. P., and Nakamura S. "Increase in the extraction efficiency of GaN-based light-emitting diodes via surface roughening" Appl. Phys. Lett. 84, 855 (2004)

[17] Gao Y., Fujii T., Sharma R., Fujito K., DenBaars S. P., Nakamura S., and Hu E. L. "Roughening hexagonal surface morphology on laser lift-off (LLO) N-face GaN with simple photo-enhanced chemical wet etching” Jpn. J. Appl. Phys. 43, L 637 (2004) 
[18] Pankove J. I. Optical Processes in Semiconductors" p. 75 and section on Urbach tail (Dover, New York, (1971)

[19] Schnitzer I., Yablonovitch E., Caneau C., Gmitter T. J., and Scherer A. "30\% external quantum efficiency from surface-textured, thin-film light-emitting diodes" Appl. Phys. Lett. 63, 2174 (1993)

[20] Windisch R., Rooman C., Dutta B., Knobloch A., Borghs G., Doehler G. H., and Heremans P. "Light- extraction mechanisms in high-efficiency surface-textured light-emitting diodes" IEEE J. Sel. Top. Quantum Electron. 8, 248 (2002)

[21] Schubert E. F., Wang Y.-H., Cho A. Y., Tu L.-W., and Zydzik G. J. "Resonant cavity lightemitting diode" Appl. Phys. Lett. 60, 921 (1992a)

[22] Nakayama T., Itoh Y., and Kakuta A. "Organic photo- and electroluminescent devices with double mirrors” Appl. Phys. Lett. 63, 594 (1993)

[23] V. Kumbham, S. Kuchibhatla, K. Lee, L.E. Rodak, V. Narang, D. Korakakis, and L.A. Hornak, "Ohmic and Highly Reflective Ag based contacts on p-GaN for Resonant Cavity Light Emitting Diodes", MRS Fall 2010 symposium.

[24] http://en.wikipedia.org/wiki/Transparent_conducting_film.

[25] http://en.wikipedia.org/wiki/Metal.

[26] http://en.wikipedia.org/wiki/Insulator_(electricity).

[27] Edwards, P. P.; Porch, A.; Jones, M. O.; Morgan, D. V.; Perks, R. M. (2004). "Basic materials physics of transparent conducting oxides". Dalton Transactions (19): 2995-3002.

[28] http://en.wikipedia.org/wiki/Transparent_conducting_film\#Transparent_conducting_oxides. [29] http://en.wikipedia.org/wiki/Mott_Criterion.

[30] Fierro, J. L. G (2006). Metal Oxides: Chemistry \& Applications. 6000 Broken Sound Parkway NW, Suite 300: Taylor \& Francis Group. pp. 182. ISBN 0-8247-237-6.

[31] Hadis Morkoç and Ümit Özgür, "Zinc Oxide, Fundamentals, Materials and Device Technology", 2009 WILEY-VCH Verlag GmbH \& Co. KGaA, Weinheim.

[32] M.D. McCluskey, S.J. Jokela, "Sources of n-type conductivity in ZnO”, Physica B 401-402 (2007) 355-357.

[33] http://en.wikipedia.org/wiki/ZnO.

[34] S.J. Lim, Soonju Kwon, H. Kim " $\mathrm{ZnO}$ thin films prepared by atomic layer deposition and rf sputtering as an active layer for thin film transistor", Thin Solid Films 516 (2008) 1523-1528. 
[35] Yuvaraj, D and Rao, Narasimha K, "Optical and electrical properties of $\mathrm{ZnO}$ films deposited by activated reactive evaporation", Vacuum, 82 (11). pp. 1274-1279, 2008.

[36] Anderson Janotti, Chris G Van de Walle, "Fundamentals of zinc oxide as a semiconductor", Phys. 72 (2009) 126501 (29pp).

[37] Hadis Morkoç, Ümit Özgür, "Zinc Oxide: Fundamentals, Materials and Device Technology."

[38] C. J. Tun, J. K. Sheu, M. L. Lee, C. C. Hu, C. K. Hsieh, and G. C. Chi, "Effects of Thermal Annealing on Al-Doped ZnO Films Deposited on p-Type Gallium Nitride", Journal of The Electrochemical Society, 153, 4, G296-G298, 2006.

[39] Özgür, Ü.; Alivov, Ya. I.; Liu, C.; Teke, A.; Reshchikov, M. A.; Doğan, S.; Avrutin, V.; Cho, S.-J. et al. (2005). "A comprehensive review of $\mathrm{ZnO}$ materials and devices". Journal of Applied Physics 98: 041301.

[40] http://refractiveindex.info/?group=CRYSTALS\&material=ZnO.

[41]http://www.oxinst.com/products/etching-deposition-growth/processes/depositionprocesses/Pages/zno.aspx.

[42] D. Calestani, M. Z. Zha, L. Zanotti, M. Villani and A. Zappettini, "Low temperature thermal evaporation growth of aligned $\mathrm{ZnO}$ nanorods on $\mathrm{ZnO}$ film: a growth mechanism promoted by $\mathrm{Zn}$ nanoclusters on polar surfaces", CrystEngComm, 2011, 13, 1707-1712.

[43] M.Di Giulio, A. Valentini and L. Vasanelli, "Deposition of $\mathrm{ZnO}$ films by rf sputtering", Materials Chemistry and Physics, Volume 9, Issues 1-3, September 1983, Pages 197-203.

[44] http://upload.wikimedia.org/wikipedia/commons/f/ff/Electron_Beam_Deposition_001.jpg.

[45] http://en.wikipedia.org/wiki/Electron_beam_physical_vapor_deposition.

[46] http://www.pvdproducts.com/products/evaporation_systems.aspx

[47] http://en.wikipedia.org/wiki/Ion_beam_assisted_deposition.

[48] http://ecee.colorado.edu/ bart/book/book/chapter3/ch3_5.htm.

[49] http://www.iue.tuwien.ac.at/phd/ayalew/node56.html

[50] http://www.globalsino.com/micro/1/1 micro9825.html.

[51] http://en.wikipedia.org/wiki/Work_function.

[52] http://en.wikipedia.org/wiki/Electron_affinity

[53] http://cnx.org/content/m1006/latest/.

[54] http://www.tmi.vu.lt/legacy/pfk/funkc_dariniai/diod/schottky.htm. 
[55] CRC Handbook of Chemistry and Physics version 2008, p. 12-114.

[56] http://en.wikipedia.org/wiki/Electron_affinity_(data page).

[57] Semiconductor Optoelectronic devices by Pallab bhattacharya, Prentice Hall 1997.

[58] http://www.globalsino.com/micro/1/1micro9826.html.

[59] http://www.ee.sc.edu/personal/faculty/simin/ELCT871/11\%20Ohmic\%20contacts.pdf

[60] S. M. Sze, Physics of semiconductor devices, John Wiley \& Sons, p. 245-311, 1981.

[61] http://www.stanford.edu/class/ee311/NOTES/Ohmic_Contacts.pdf

[62] D. K. Schroder, Semiconductor material and device characterization, John Wiley \& Sons, p. 99-146, 1990.

[63] http://ecee.colorado.edu/ bart/book/book/chapter3/ch3_5.htm\#3_5_1.

[64] http://www.ecse.rpi.edu/ schubert/Course-Teaching-modules/

[65] Kinnari N. Patela, E. Stokesa, Jennifer Paganb, Casey C. Burkhartc, Michael Hodgec and Paolo Batonic, "Circular Transmission Line Model (CTLM) Analysis for Non-Linear VI Characteristics on Mg doped GaN", ECS Trans. 2007 volume 11, issue 5, 203-208.

[66] http://scholarbank.nus.edu.sg/handle/10635/14040

[67] R. H. Cox and H Strack, "Solid State Electronics", 10, 1213 (1967).

[68] C. J. Bernard, 'Ohmic contacts to compound semiconductors', Ph.D. Thesis, Auburn University (1992).

[69] W. G. Bickley, “"Bessel Functions”, pp. 220-225, University Press, Cambridge (1960).

[70] D. K. Schroder, "Semiconductor material and device characterization", (Wiley New York) 1998.

[71] Adivarahan, 'Very-low-specific-resistance $\mathrm{Pd} / \mathrm{Ag} / \mathrm{Au} / \mathrm{Ti} / \mathrm{Au}$ alloyed ohmic contact to $\mathrm{p} \mathrm{GaN}$ for high-current devices,' Appl. Phys. Lett. 78, Issue 18, Pages 2781-2783 (2001).

[72] L. L. Smith, S. W. King, R. J. Nemanich and R. F. Davis, "Cleaning of GaN surfaces", Journal of Electronic materials, Vol 25, No 6, 1996.

[73] Eugene S. Meieran, "21st Century Semiconductor Manufacturing Capabilities”, Technology Manufacturing Engineering, Intel Corp.

[74] M. Senthil Kumar, R.R. Sumathi, N.V. Giridharan, R. Jayavel, J. Kumar, "On the capacitance-voltage characteristics of $\mathrm{Al} / \mathrm{BaTiO} / \mathrm{GaN}$ MFS structures", Journal of Crystal Growth 237-239 (2002) 1176-1179.

[75] http://en.wikipedia.org/wiki/Photolithography. 
[76] http://www.cnf.cornell.edu/cnf_process_photo_resists.html\#cleaning.

[77] http://en.wikipedia.org/wiki/Etching_(microfabrication).

[78] S.A. Campbell, "The science and engineering of microelectronic fabrication", Second edition, Oxford University Press, NY 2004.

[79] http://www.memsnet.org/mems/processes/etch.html.

[80] http://home.comcast.net/ dwdm2/MEMS_micromachining.html.

[81] D.C. Hays, "Selective etching of compound semiconductors", Master's thesis, University of Florida 1999.

[82] http://personal.cityu.edu.hk/ appkchu/AP4120/6.PDF.

[83] http://inst.eecs.berkeley.edu/ ee143/fa08/lectures/Section\%203\%20-\%20Etching.pdf.

[84] D.M. Manos and D.L. Flamm, "Plasma etching: an introduction", Academic press Inc. 1989.

[85] S. A. Smith, C. A. Wolden, M. D. Bremser, A. D. Hanser, and R. F. Davis, "High rate and selective etching of GaN, AlGaN, and AlN using an inductively coupled plasma”, Appl. Phys. Lett. 71 (25), 22 December 1997.

[86] http://en.wikipedia.org/wiki/Evaporation_(deposition).

[87] http://en.wikipedia.org/wiki/Rapid_thermal_anneal.

[88] http://microlab.berkeley.edu/labmanual/chap5/heatpulse1.pdf.

[89] Shih-Yung Huang, Ray-Hua Horng, Yu-Ju Tsai, Po-Rung Lin, Wei-Kai Wang, Zhe Chuan Feng, Dong-Sing Wuu, Semicond. Sci. Technol. 25, 035013 (2010).

[90] S. J. Pearton, J. C. Zolper, R. J. Shul, and F. Ren, J. Appl. Phys., 86, 1 (1999).

[91] Ho Won Jang, Jun Ho Son, and Jong-Lam Lee, Journal of The Electrochemical Society, 155 (8) H563-H568 (2008).

[92] C. L. Tseng, M. J. Youh, G. P. Moore, M. A. Hopkins, R. Stevens, and W. N. Wang, Appl. Phys. Lett., 83, 3677 (2003).

[93] J. O. Song, K.-K. Kim, S.-J. Park, and T.-Y. Seong, Appl. Phys. Lett., 83, 479 (2003).

[94] S.-P. Jung, D. Ullery, C.-H. Lin, H. P. Lee, J.-H. Lim, D.-K. Hwang, J.-Y. Kim, E.-J. Yang, and S.-J. Park, Appl. Phys. Lett., 87, 181107 (2005).

[95] S.-M. Pan, R.-C. Tu, Y.-M. Fan, R.-C. Yeh, and J.-T. Hsu, IEEE Photon. Technol. Lett., 15, 646 (2003). 
[96] J.-R. Lee, S.-I. Na, J.-H. Jeong, S.-N. Lee, J.-S. Jang, S.-H. Lee, J.-J. Jung, J.-O. Song, T.-Y. Seong, and S.-J. Park, J. Electrochem. Soc., 152, G92 (2005).

[97] V. Rajagopal Reddy, S.-H. Kim, J.-O. Song, and T.-Y. Seong, Solid-State Electron., 48, 1563 (2004).

[98] J.-S. Jang, S.-J. Park, and T.-Y. Seong, Appl. Phys. Lett., 76, 2898 (2000).

[99] J. Narayan, H. Wang, T.-H. Oh, H. K. Choi, and J. C. C. Fan, Appl. Phys. Lett., 81, 3978 (2002).

[100] H. W. Jang, S. Y. Kim, and J.-L. Lee, J. Appl. Phys., 94, 1748 (2003).

[101] M.-S. Oh, D.-K. Hwang, J.-H. Lim, C.-G. Kang, and S.-J. Park, Appl. Phys. Lett., 89, 042107 (2006).

[102] Jun Ho Son, Yang Hee Song, Hak Ki Yu, and Jong-Lam Lee, Appl. Phys. Lett., 95, 062108 (2009).

[103] http://en.wikipedia.org/wiki/Atomic_force_microscope.

[104] http://en.wikipedia.org/wiki/Scanning_electron_microscope.

[105] Suzuki E, "High-resolution scanning electron microscopy of immuno gold-labelled cells by the use of thin plasma coating of osmium", Journal of Microscopy, 208 (3), 153-157.

[106] http://www.uiowa.edu/ cmrf/methodology/sem/index.html.

[107] http://m.eb.com/assembly/110970.

[108] http://en.wikipedia.org/wiki/Thermionically.

[109] http://en.wikipedia.org/wiki/Tungsten.

[110] http://www4.nau.edu/microanalysis/Microprobe/Interact-Effects.html.

[111] http://en.wikipedia.org/wiki/X-ray_photoelectron_spectroscopy.

[112] http://goliath.emt.inrs.ca/surfsci/arxps/fundamentalscss.html.

[113] Ho Won Jang, Jun Ho Son, and Jong-Lam Lee, "Journal of The Electrochemical Society", 155 (8) H563-H568 (2008).

[114] Hyunsoo Kim, Dong-Joon Kim, Seong-Ju Park, and Hyunsang Hwanga, "Effect of an oxidized $\mathrm{Ni} / \mathrm{Au} \mathrm{p}$ contact on the performance of $\mathrm{GaN} / \mathrm{InGaN}$ multiple quantum well lightemitting diodes", Journal of applied Physics, Volume 89, Number 2, 2001.

[115] K. Matsubara, P. Fons, K. Iwata, A. Yamada, K. Sakurai, H. Tampo, and S. Niki, Thin Solid Films 431-432, 369 (2003). 
[116] E. Fortunato, P. Barquinha, A. Pimentel, A. Gonçalves, A.Marques, L. Pereira, and R.Martins, Thin Solid Films 487, 205 (2005).

[117] S. Yasushi Sato, Kei Yanagisawa, Nobuto Oka, Shin-ichi Nakamura, and Yuzo Shigesato, J. Vac. Sci. Technol. A 27, 1166 (2009).

[118] Jae Bin Lee, Hyeong Joon Kim, Soo Gil Kim, Cheol Seong Hwang, Seong-Hyeon Hong, Young Hwa Shin, Neung Hun Lee, Thin Solid Films 435 (2003) 179-185.

[119] Chitanu Elena, Ionita Gheorghe, International Journal of computers, Issue 4, Volume 4, 2010.

[120] Hyung-Kyu Choi, Jang-Ho Park, Sang-Hun Jeong and Byung-Teak Lee, Semicond. Sci. Technol. 24105003 (2009).

[121] M. Lorenz, H. Hochmuth, R. Schmidt-Grund, E. M. Kaidashev, and M. Grundmann, Ann. Phys. (Leipzig) 13, No. 1 -2, 59 - 60 (2004).

[122] O.A. Fouad, A.A. Ismail, Z.I. Zaki, R.M. Mohamed, Applied Catalysis B: Environmental Volume 62, Issues 1-2, 10 January 2006, Pages 144-149.

[123] S. J. Pearton, J. C. Zolper, R. J. Shul, and F. Ren, J. Appl. Phys., 86, 1 (1999).

[124] C. L. Tseng, M. J. Youh, G. P. Moore, M. A. Hopkins, R. Stevens, and W. N. Wang, Appl. Phys. Lett., 83, 3677 (2003).

[125] J. O. Song, K.-K. Kim, S.-J. Park, and T.-Y. Seong, Appl. Phys. Lett., 83, 479 (2003).

[126] S.-P. Jung, D. Ullery, C.-H. Lin, H. P. Lee, J.-H. Lim, D.-K. Hwang, J.-Y. Kim, E.-J. Yang, and S.-J. Park, Appl. Phys. Lett., 87, 181107 (2005).

[127] S.-M. Pan, R.-C. Tu, Y.-M. Fan, R.-C. Yeh, and J.-T. Hsu, IEEE Photon. Technol. Lett., 15, 646 (2003).

[128] J.-R. Lee, S.-I. Na, J.-H. Jeong, S.-N. Lee, J.-S. Jang, S.-H. Lee, J.-J. Jung, J.-O. Song, T.Y. Seong, and S.-J. Park, J. Electrochem. Soc., 152, G92 (2005).

[129] V. Rajagopal Reddy, S.-H. Kim, J.-O. Song, and T.-Y. Seong, Solid-State Electron., 48, 1563 (2004).

[130] J.-S. Jang, S.-J. Park, and T.-Y. Seong, Appl. Phys. Lett., 76, 2898 (2000).

[131] J. K. Sheu, Y. K. Su, G. C. Chi, P. L. Koh, M. J. Jou, C. M. Chang, C. C. Liu and W. C. Hun, Applied Physics letters, volume 74,16 (1999).

[132] E. Fortunato, P. Barquinha, A. Pimentel, A. Gonçalves, A.Marques, L. Pereira, and R.Martins, Thin Solid Films 487, 205 (2005). 
[133] http://en.wikipedia.org/wiki/Reflection_coefficient.

[134] http://en.wikipedia.org/wiki/Transmission_line.

[135] Scho73a, WRDM79 database.

[136] NFS82, NGDS7S, NSLS77, Scho73, WZR80 database.

[137] WPHK82, Barr83 database.

[138] http://en.wikipedia.org/wiki/Hall_effect\#cite_note-0.

[139] Kasap, Safa. "Hall Effect in Semiconductors".

[140] http://physlab.lums.edu.pk/images/7/7a.

[141] http://en.wikipedia.org/wiki/Ellipsometry. 


\section{Appendix}

\section{A1. Process parameters for GaN/InGaN MQW RCLED Fabrication}

1. The LED samples were degreased in Acetone, Methanol and DI waters each for 5 minutes using Ultra-sonication.

2. Mg dopants were activated in $\mathrm{p}-\mathrm{GaN}$ by annealing the samples in a RTA chamber for 5 minutes in $\mathrm{N}_{2}$ ambient.

3. The samples were then surface treated to remove native oxides by treating them in, BOE (10:1) for 3 minutes, 2 minutes DI water rinse, Dilute $\mathrm{HCl}$ (1:1) for 1.5 minutes, 2 minutes DI water rinse and blow dry using $\mathrm{N}_{2}$ gun.

4. The samples were baked in a conventional oven or hot plate at $120^{\circ} \mathrm{C}$ for 15 minutes to remove any moisture left on the surface.

5. AZ5214 EIR photo resist is spun over the samples at $4000 \mathrm{rpm}$ for 30 seconds and then pre baked (soft bake) at $95^{\circ} \mathrm{C}$ for 45 seconds.

6. Using a Mask Aligner, the samples were exposed to $320 \mathrm{~nm}$ UV light under a Cr mask for a $50 \mathrm{~mJ}$ power to transfer the p-contact pattern on to the sample.

7. An image reversal (post) bake at $120^{\circ} \mathrm{C}$ is done for 120 seconds to enhance the cross linking of polymer (photo resist).

8. Using a Flood Exposure system, the samples were exposed to $365 \mathrm{~nm} \mathrm{UV} \mathrm{light} \mathrm{for} \mathrm{a} 2000 \mathrm{~mJ}$ power.

9. The samples were rinsed in AZ 300MIF developer for 45 seconds and DI water for 2 minutes to get the patterns for p-contact deposition, the height of the photo-resist was measured using a profilometer and based on the photo-resist spinning conditions, the trenches should be around 1.6 microns in height, if not, the developing time should be increased accordingly.

10. Using e-beam evaporator, Ni (2nm)/ Ag (150nm)/ Pt (50nm)/ Ni (20nm)/ Au (50nm), was deposited. The vacuum pressure is $1 \mathrm{E}-05$ Torr and the power was varied depending upon the material that was being deposited.

11. The samples were placed in acetone for 10-15 minutes for lift-off process.

12. The samples were baked in a conventional oven or hot plate at $120^{\circ} \mathrm{C}$ for 15 minutes to remove any moisture left on the surface. 
13. AZ4400 photo resist is spun over the samples at $300 \mathrm{rpm}$ for 8 seconds, $4000 \mathrm{rpm}$ for 30 seconds and then pre baked (soft bake) at $95^{\circ} \mathrm{C}$ for 120 seconds.

14. Using a Mask Aligner, the samples were exposed to $320 \mathrm{~nm}$ UV light under a Cr mask for a $250 \mathrm{~mJ}$ power to transfer the mesa pattern on to the sample.

15. The samples were rinsed in AZ 400K developer for 105 seconds and DI water for 2 minutes

to get the patterns for mesa structures, the height of the photo-resist was measured using a profilometer and based on the photo-resist spinning conditions, the height should be around 4.6 microns in height, if not, the developing time should be increased accordingly.

16. The samples were hard baked in an oven at $120^{\circ} \mathrm{C}$ for 20 minutes before dry etching.

17. The ICP-RIE chamber is cleaned using oxygen plasma for 1800 seconds using $98 \mathrm{sccm} \mathrm{O}_{2}$ gas flow, $50 \mathrm{mT}$ chamber pressure, 500W ICP power, $80 \mathrm{~W}$ RIE power and $5 \mathrm{sccm}$ He gas flow (cooling the wafer).

18. The chamber was conditioned with GaN dry etch conditions, $10 \mathrm{mT}$ chamber pressure, $300 \mathrm{~W}$ ICP power, 100W RIE power, $20 \mathrm{sccm} \mathrm{Cl}_{2}, 10 \mathrm{sccm} \mathrm{BCl}_{3}$ and $5 \mathrm{sccm} \mathrm{He}$ gas flow for 1800 seconds.

19. Dry etching is done using the above mentioned conditions for $130-150$ seconds to get an etch depth of 450-600nm.

20. The samples were placed in an $\mathrm{AZ} 300 \mathrm{~T}$ stripper on a hot plate at $100^{\circ} \mathrm{C}$ to remove the residual photo resist for one hour and in acetone for 5 minutes.

21. The samples were baked in a conventional oven or hot plate at $120^{\circ} \mathrm{C}$ for 15 minutes to remove any moisture left on the surface.

22. AZ5214 EIR photo resist is spun over the samples at $4000 \mathrm{rpm}$ for 30 seconds and then pre baked (soft bake) at $95^{\circ} \mathrm{C}$ for 45 seconds.

23. Using a Mask Aligner, the samples were exposed to $320 \mathrm{~nm}$ UV light under a Cr mask for a $50 \mathrm{~mJ}$ power to transfer the p-contact pattern on to the sample.

24. An image reversal (post) bake at $120^{\circ} \mathrm{C}$ is done for 120 seconds to enhance the cross linking of polymer (photo resist).

25. Using a Flood Exposure system, the samples were exposed to $365 \mathrm{~nm} \mathrm{UV} \mathrm{light} \mathrm{for} \mathrm{a} 2000 \mathrm{~mJ}$ power.

26. The samples were rinsed in AZ 300MIF developer for 45 seconds and DI water for 2 minutes to get the patterns for p-contact deposition, the height of the photo-resist was measured using a 
profilometer and based on the photo-resist spinning conditions, the trenches should be around 1.6 microns in height, if not, the developing time should be increased accordingly.

27. Using e-beam evaporator, Ti (2nm)/ Al (100nm)/ Ti (30nm)/ Au (300nm), was deposited. The vacuum pressure is 1E-05 Torr and the power was varied depending upon the material that was being deposited.

28. The samples were placed in acetone for 10-15 minutes for lift-off process.

29. The samples were annealed in a RTA chamber at $430-480^{\circ} \mathrm{C}$ for $\mathrm{Ag}$ based metallization scheme and $600^{\circ} \mathrm{C}$ for $\mathrm{Ni} / \mathrm{Ag}$ contacts for 3 minutes in $\mathrm{O}_{2}$ ambient to form ohmic contacts.

\section{A2. Matlab code for $\mathrm{ZnO}$ Modeling}

The $\mathrm{ZnO}$ thickness is modeled using the Matlab code given below,

clc;

$\mathrm{Z}=[]$;

$\mathrm{k}=[]$;

$\mathrm{R} 1=[]$;

$\mathrm{R} 2=[]$;

$\mathrm{R} 3=[]$;

$\mathrm{Z}=[]$;

$\mathrm{r}=[]$;

ur= []; $\quad \%$ Relative permeability

er $=4 ; \quad \%$ Relative permitivity of $\mathrm{ZnO}$

er1=9.5;

$\mathrm{nz}=2.09 ; \quad \%$ Refractive index

$\mathrm{ng}=2.42$;

uo $=4 * p^{*} * 10$ e- $07 ; \quad \%$ Free space permeability

eo $=8.854 * 10 \mathrm{e}-12 ; \quad \%$ Free space permitivity

lambda=460;

lambdae $=($ lambda $/ \mathrm{nz}) ; \%$ wavelength

$\mathrm{b}=2 *$ pi/(lambdae);

b1 $=2 *$ pi/(lambda); 


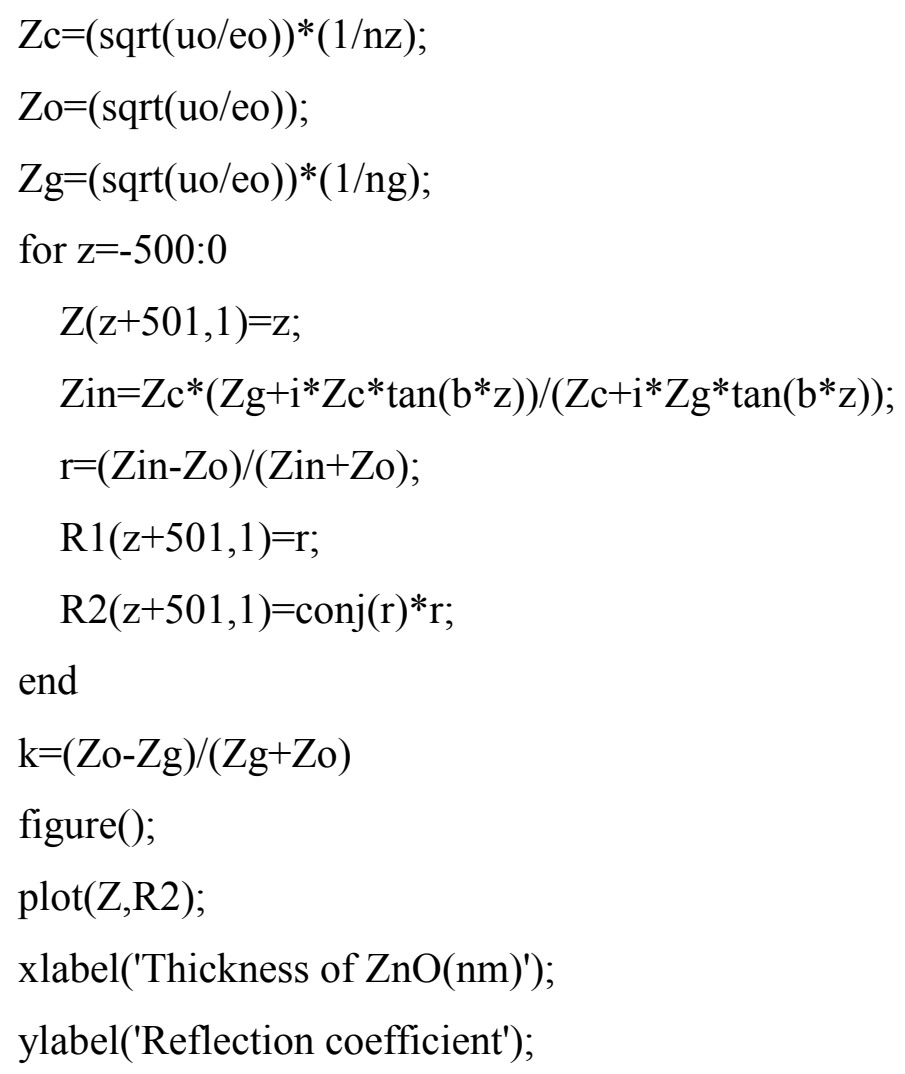

\section{A3. Matlab code for TLM and CTLM calculations}

The Matlab code used for calculating the specific contact resistances using TLM method is shown below,

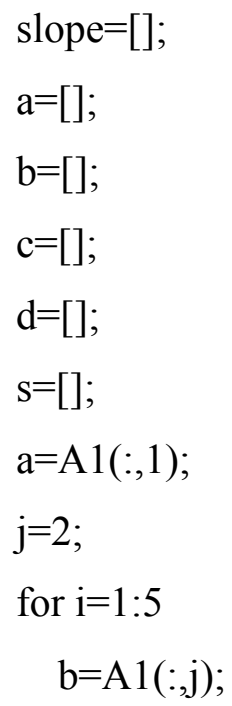




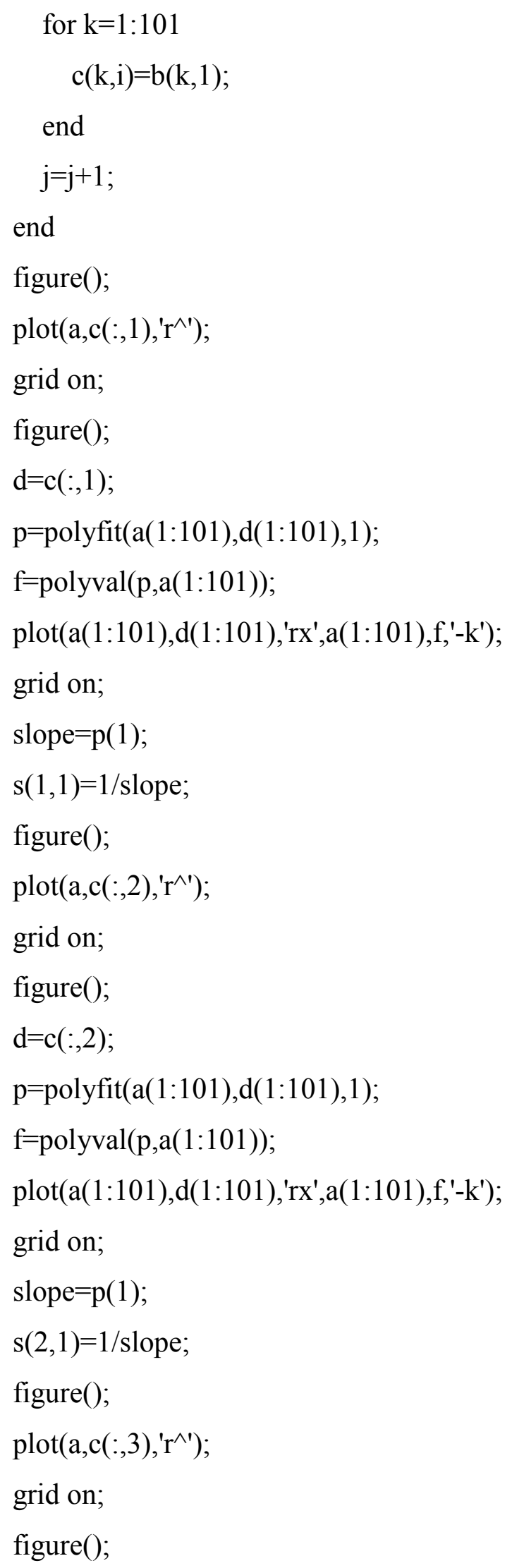


$\mathrm{d}=\mathrm{c}(:, 3)$;

$\mathrm{p}=\operatorname{polyfit}(\mathrm{a}(1: 101), \mathrm{d}(1: 101), 1)$;

$\mathrm{f}=\operatorname{polyval}(\mathrm{p}, \mathrm{a}(1: 101))$;

plot(a(1:101),d(1:101),'rx',a(1:101),f,'-k');

grid on;

slope $=\mathrm{p}(1)$;

$\mathrm{s}(3,1)=1 /$ slope;

figure();

$\operatorname{plot}\left(\mathrm{a}, \mathrm{c}(:, 4), \mathrm{r}^{\wedge}{ }^{\prime}\right)$;

grid on;

figure();

$\mathrm{d}=\mathrm{c}(:, 4)$;

$\mathrm{p}=\operatorname{polyfit}(\mathrm{a}(1: 101), \mathrm{d}(1: 101), 1)$;

$\mathrm{f}=\operatorname{polyval}(\mathrm{p}, \mathrm{a}(1: 101))$;

plot(a(1:101),d(1:101),'rx',a(1:101),f,'-k');

grid on;

slope $=\mathrm{p}(1)$;

$\mathrm{s}(4,1)=1 /$ slope;

figure();

$\operatorname{plot}\left(\mathrm{a}, \mathrm{c}(:, 5), \mathrm{r}^{\wedge}{ }^{\prime}\right)$;

grid on;

figure();

$\mathrm{d}=\mathrm{c}(:, 5)$;

$\mathrm{p}=\operatorname{polyfit}(\mathrm{a}(1: 101), \mathrm{d}(1: 101), 1)$;

$\mathrm{f}=\operatorname{polyval}(\mathrm{p}, \mathrm{a}(1: 101))$;

plot(a(1:101),d(1:101),'rx',a(1:101),f,'-k');

grid on;

slope $=\mathrm{p}(1)$;

$\mathrm{s}(5,1)=1 /$ slope;

$\mathrm{S}(1,1)=\mathrm{S}(1,1)$;

$\mathrm{S}(2,1)=\mathrm{s}(2,1)$; 


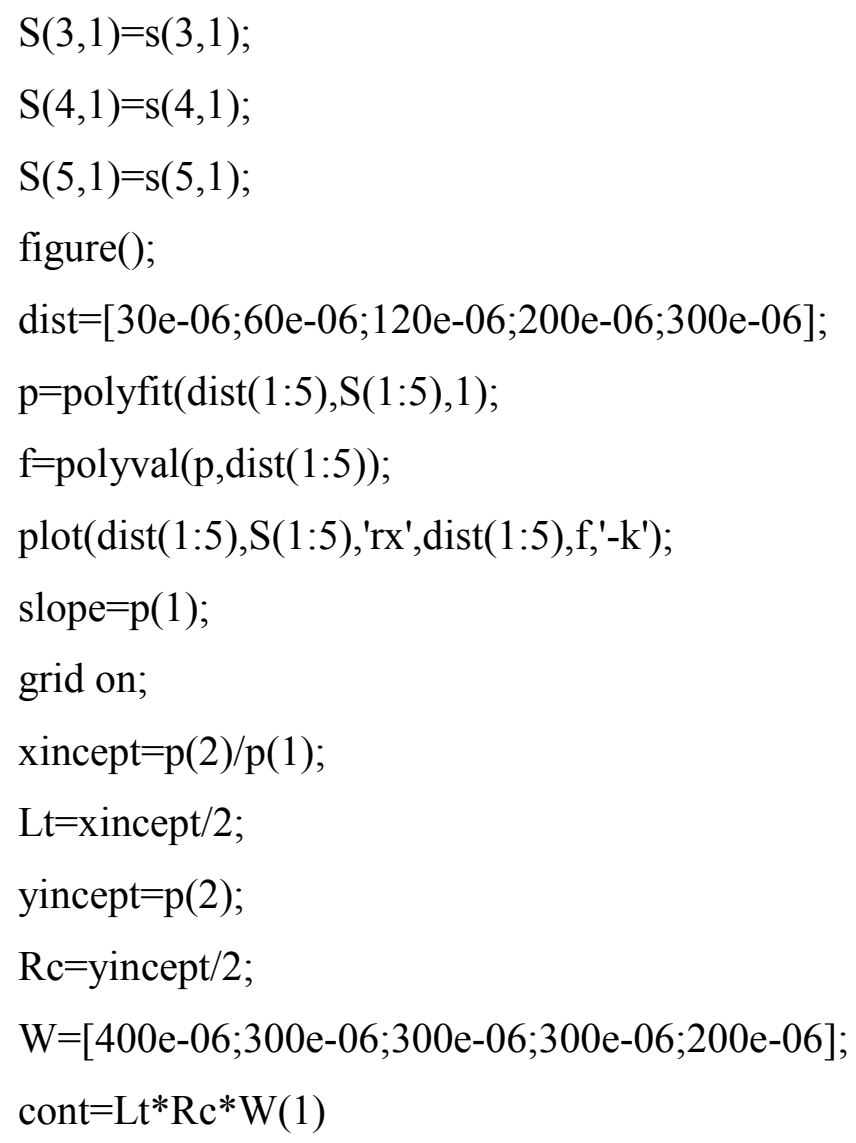

The Matlab code used to calculate specific contact resistances using CTLM method is shown below,

clc;

ra=input('Dot Radius:');

$\mathrm{x}=[]$;

$\mathrm{a} 1=\mathrm{A} 1(:, 2)$;

$\mathrm{b} 1=\mathrm{A} 1(:, 3)$;

p1=polyfit $(\mathrm{a} 1, \mathrm{~b} 1,2)$;

$\mathrm{fl}=\operatorname{polyval}(\mathrm{p} 1, \mathrm{a} 1)$;

figure();

plot(a1,b1,'*r',a1,f1,'-b');

grid on;

slope $=\mathrm{p} 1(1)$; 


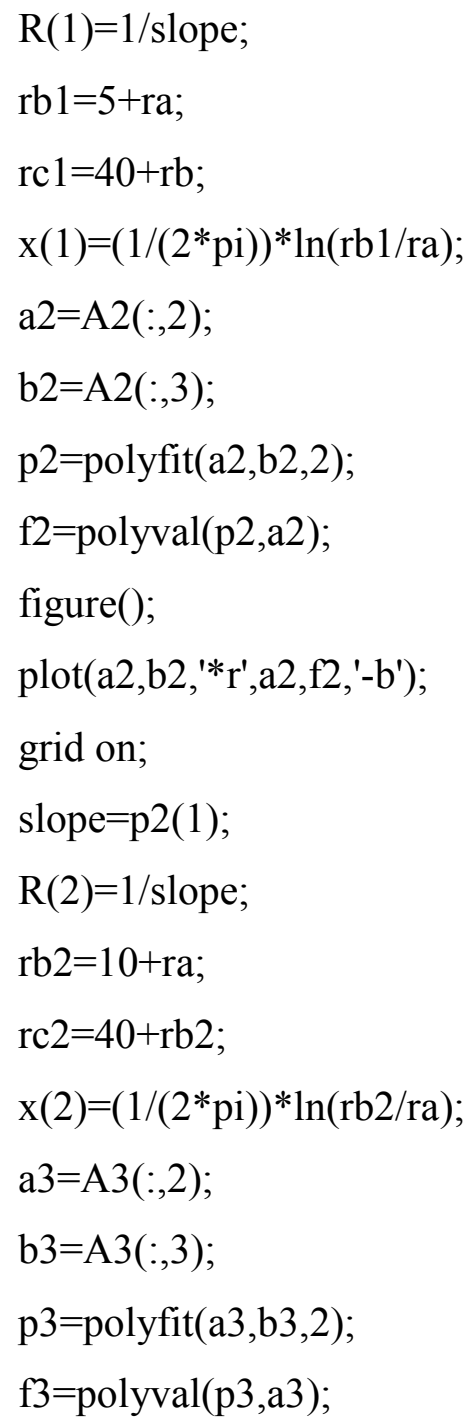


$\mathrm{f} 4=\operatorname{polyval}(\mathrm{p} 4, \mathrm{a} 4)$;

figure();

plot(a4,b4,'*r',a4,f4,'-b');

grid on;

slope $=\mathrm{p} 4(1)$;

$\mathrm{R}(4)=1 /$ slope;

rb4=20+ra;

rc4=40+rb4;

$\mathrm{x}(4)=(1 /(2 * \mathrm{pi})) * \ln (\mathrm{rb} 4 / \mathrm{ra})$;

a5 $=\mathrm{A} 5(:, 2)$;

$\mathrm{b} 5=\mathrm{A} 5(:, 3)$;

$\mathrm{p} 5=$ polyfit $(\mathrm{a} 5, \mathrm{~b} 5,2)$;

$\mathrm{f} 5=\operatorname{polyval}(\mathrm{p} 5, \mathrm{a} 5)$;

figure();

plot(a5,b5,'*'r',a5,f5,'-b');

grid on;

slope $=\mathrm{p} 5(1)$;

$\mathrm{R}(5)=1 /$ slope;

$\mathrm{rb} 5=25+\mathrm{ra}$;

rc5 $=40+\mathrm{rb} 5$;

$\mathrm{x}(5)=(1 /(2 * \mathrm{pi})) * \ln (\mathrm{rb} 5 / \mathrm{ra})$;

figure();

$\operatorname{plot}\left(\mathrm{x}, \mathrm{R},{ }^{\prime *} \mathrm{~g}^{\prime}\right)$;

grid on;

$\mathrm{p} 6=\operatorname{polyfit}(\mathrm{x}, \mathrm{R}, 2)$;

$\mathrm{f} 6=\operatorname{polyval}(\mathrm{p} 6, \mathrm{x})$;

$\mathrm{Rs}=1 / \mathrm{p} 6(1)$;

$\mathrm{Lt}=[((\mathrm{R}(1) * 2 * \mathrm{pi}) / \mathrm{Rs})-\log (\mathrm{ra} / \mathrm{rb} 1)] /[(1 / \mathrm{ra})+(1 / \mathrm{rb} 1)] * 100 ;$

$\mathrm{pc}=\mathrm{Lt} * \mathrm{Lt} * \mathrm{Rs}$; 